Florida International University

FIU Digital Commons

$10-3-2019$

\title{
A Quantitative Study of Expatriate Hotel Managers in Mainland China: An Exploration of Perceived Organizational Justice as a Mediator of Local Employee Job Satisfaction and Their Evaluation of Expatriate Manager Leadership Performance
}

Wei Ding

Florida International University, wding002@fiu.edu

Follow this and additional works at: https://digitalcommons.fiu.edu/etd

Part of the Leadership Studies Commons

\section{Recommended Citation}

Ding, Wei, "A Quantitative Study of Expatriate Hotel Managers in Mainland China: An Exploration of Perceived Organizational Justice as a Mediator of Local Employee Job Satisfaction and Their Evaluation of Expatriate Manager Leadership Performance" (2019). FIU Electronic Theses and Dissertations. 4361. https://digitalcommons.fiu.edu/etd/4361

This work is brought to you for free and open access by the University Graduate School at FIU Digital Commons. It has been accepted for inclusion in FIU Electronic Theses and Dissertations by an authorized administrator of FIU Digital Commons. For more information, please contact dcc@fiu.edu. 


\title{
FLORIDA INTERNATIONAL UNIVERSITY
}

Miami, Florida

\begin{abstract}
A QUANTITATIVE STUDY OF EXPATRIATE HOTEL MANAGERS IN MAINLAND CHINA: AN EXPLORATION OF PERCEIVED ORGANIZATIONAL JUSTICE AS A MEDIATOR OF LOCAL EMPLOYEE JOB SATISFACTION AND THEIR EVALUATION OF EXPATRIATE MANAGER LEADERSHIP PERFORMANCE
\end{abstract}

A dissertation submitted in partial fulfillment of the requirements for the degree of

DOCTOR OF EDUCATION

in

ADULT EDUCATION \&

HUMAN RESOURCE DEVELOPMENT

by

Wei Ding

2019 
To: Dean Michael R. Heithaus

College of Arts, Sciences and Education

This dissertation, written by Wei Ding, and entitled A Quantitative Study of Expatriate Hotel Managers in Mainland China: An Exploration of Perceived Organizational Justice as a Mediator of Local Employee Job Satisfaction and Their Evaluation of Expatriate Manager Leadership Performance, having been approved in respect to style and intellectual content, is referred to you for judgment.

We have read this dissertation and recommend that it be approved.

$\begin{array}{r}\hline \text { Jinlin Zhao } \\ \hline \text { Haiying Long } \\ \hline \text { Hyejin Bang } \\ \hline \text { Thomas Reio, Major Professor }\end{array}$

Date of Defense: October 3, 2019

The dissertation of Wei Ding is approved.

Dean Michael R. Heithaus College of Arts, Sciences \& Education

Andrés G. Gil Vice President for Research and Economic Development and Dean of the University Graduate School

Florida International University, 2019 


\author{
ABSTRACT OF THE DISSERTATION \\ A QUANTITATIVE STUDY OF EXPATRIATE HOTEL MANAGERS IN \\ MAINLAND CHINA: AN EXPLORATION OF PERCEIVED ORGANIZATIONAL \\ JUSTICE AS A MEDIATOR OF LOCAL EMPLOYEE JOB SATISFACTION AND \\ THEIR EVALUATION OF EXPATRIATE MANAGER LEADERSHIP \\ PERFORMANCE
}

by

Wei Ding

Florida International University, 2019

Miami, Florida

Professor Thomas Reio, Major Professor

This nonexperimental, quantitative study $(\mathrm{N}=283)$ is investigated the relationship between organizational justice, job satisfaction, and expatriate leadership performance. The study was undergirded by both social exchange (Blau, 1964) and transformational leadership theory (Bass \& Avolio, 1990). The target population of the study was local employees who work with expatriate managers in the hospitality industry in Mainland China. Sixty four percent $(n=182)$ of the sample was female and $36 \%(n=$ 101) of the sample was male. The research hypotheses were tested using correlational, regression analyses, and structural equation modeling.

The results show that there is a positive relationship between employee job satisfaction and employees' perceptions of the expatriate leader's job performance. Also, 
it shows there was a positive relationship between organizational justice and employee job satisfaction. Furthermore, it confirmed that relationship between job satisfaction and leadership performance was mediated by organizational justice.

The results of the study further understandings of social exchange theory and transformational leadership in a cross-cultural leadership context. It provides evidence of the direction and magnitude of relationships between organizational justice, job satisfaction and expatriate leadership performance. In addition, the results of the research help hospitality industry leaders face the reality of how local employees perceive their performance, and play a vital role to identify possible opportunities and shortcomings in HRD policies and procedures. Human resource development professionals can focus on creating developmental interventions that promote organizational justice, employee job satisfaction, and encourage a positive psychological climate. 


\section{TABLE OF CONTENTS}

CHAPTER

PAGE

CHAPTER I

INTRODUCTION 1

Background to the Problem 1

The Importance of Local Employee Perspectives $\quad 7$

Problem Statement $\quad 8$

Research Questions and Hypotheses $\quad 8$

Conceptual Framework 9

Research Variables $\quad 12$

Organizational Justice $\quad 12$

Employee Job Satisfaction 13

Transformational Leadership 14

Significance of the Study 15

$\begin{array}{ll}\text { Assumptions } & 18\end{array}$

$\begin{array}{ll}\text { Limitations } & 18\end{array}$

$\begin{array}{ll}\text { Delimitations } & 19\end{array}$

Definition of Terms 20

$\begin{array}{ll}\text { Summary } & 21\end{array}$

CHAPTER II $\quad 23$

LITERATURE REVIEW $\quad 23$

Important Stages of Hospitality and Human Resource Development in China 23

$\begin{array}{ll}\text { Organizational Justice } & 27\end{array}$

Guanxi and Organizational Justice $\quad 29$

Measuring Organizational Justice across Cultures $\quad 31$

Employee Job Satisfaction and Expatriate Managers 32

Measuring Job Satisfaction 36

$\begin{array}{ll}\text { Leadership } & 39\end{array}$

Transformational Leadership $\quad 41$

Transactional Leadership $\quad 45$

Laissez-faire Leadership $\quad 47$

Measuring Transformational Leadership $\quad 49$

Expected Relationship between Organizational Justice and Employee Job

Satisfaction $\quad 50$

Expected Relationship between Employee Job Satisfaction and Leadership $\quad 52$

Social Exchange Theory

Organizational Justice and Social Exchange Theory 55

Job Satisfaction within Social Exchange Theory 56

Cross-Cultural Management Issue in China’s Hospitality Industry 57

$\begin{array}{ll}\text { CHAPTER III } & 60\end{array}$ 
$\begin{array}{ll}\text { METHOD } & 60\end{array}$

Purpose of the Study $\quad 60$

Research Questions and Hypotheses $\quad 60$

Research Design and Data Collection $\quad 60$

$\begin{array}{ll}\text { Population and Sample } & 63\end{array}$

Variables and Research Instruments $\quad 63$

$\begin{array}{ll}\text { Organizational Justice } & 64\end{array}$

Transformational Leadership $\quad 66$

$\begin{array}{ll}\text { Data Collection } & 67\end{array}$

$\begin{array}{ll}\text { Internet-Based Surveys } & 68\end{array}$

Steps Taken to Reduce the Non-Response Rate 73

$\begin{array}{ll}\text { Summary } & 75\end{array}$

CHAPTER IV

RESULTS

Background of the Sample $\quad 76$

Gender and Years Worked in the Hospitality Industry 76

Position Level in Hotel 77

$\begin{array}{ll}\text { Examination of Hypotheses } & 78\end{array}$

$\begin{array}{ll}\text { Multicollinearity } & 78\end{array}$

$\begin{array}{ll}\text { Linearity } & 79\end{array}$

$\begin{array}{ll}\text { Measures } & 79\end{array}$

$\begin{array}{ll}\text { Variance Analysis } & 83\end{array}$

Correlational Analysis for Testing H1 87

Correlational Analysis for Testing $H 2 \quad 89$

Structural Equation Modeling (SEM) Analysis for Testing H3 91

Confirmatory Factor Analysis $\quad 91$

Summary 96

$\begin{array}{ll}\text { CHAPTER V } & 98\end{array}$

DISCUSSION $\quad 98$

Summary of the Study $\quad 98$

Discussion of the Results $\quad 100$

$\begin{array}{ll}\text { Hypothesis } 1 & 100\end{array}$

Hypothesis $2 \quad 102$

Hypothesis $3 \quad 104$

Implication for Research, Theory, and Practice 106

$\begin{array}{ll}\text { Implications for Research } & 107\end{array}$

$\begin{array}{ll}\text { Limitations of the Study } & 114\end{array}$

Recommendations for Future Research 116

$\begin{array}{ll}\text { Conclusions } & 118\end{array}$

$\begin{array}{ll}\text { Appendix } & 151\end{array}$

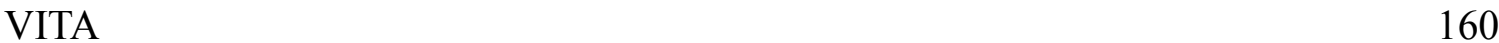




\section{LIST OF TABLES}

TABLE

PAGE

1. Erkutlu (2008) Hierarchical Regression Analyses for Transformational..............48 Leadership and Employee Satisfaction with Work

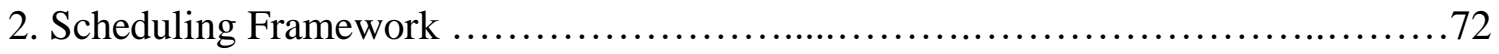

3. Frequency Table of Demographic Variables.................................77

4. Scale Reliability Scores and Means/Standard Deviations of Questionnaire Items......80

5. Gender and Organizational Justice, Employee Satisfaction and Leadership ..........83 Performance

6. One-Way ANOVA of Group Years of Experience by Research Variable ............84

7. One-Way ANOVA of Position Level by Research Variable ........................85

8. Pearson Correlations among Research Variables $\ldots \ldots \ldots \ldots \ldots \ldots \ldots \ldots \ldots \ldots \ldots \ldots . \ldots . \ldots \ldots$

9. Zero-Order Correlation Coefficients for Employee Job Satisfaction and .............88 Leadership Performance

10. Zero-Order Correlation Coefficients for Employee Job Satisfaction and ............90 Organizational Justice

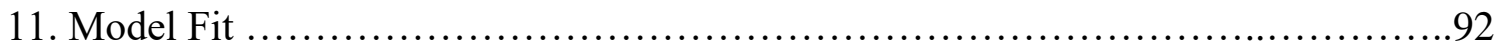

12. Confirmatory Factor Analysis .......................................... 93

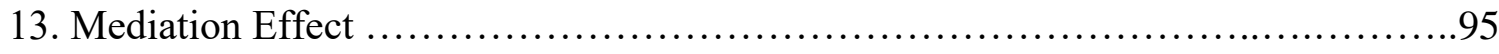

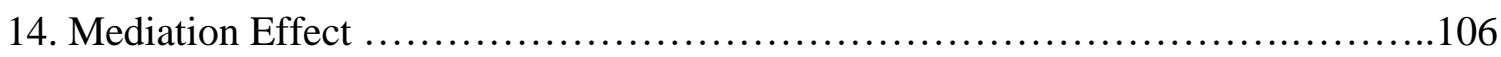




\section{LIST OF FIGURES}

FIGURE

PAGE

1. Hypothesized model of the relationships between organizational justice, job.........15 satisfaction, job satisfaction

2. Full Range of Leadership Model............................................41

3. Transformational Leadership Model.........................................43

4. Confirmatory Factor Analysis Model........................................94

5. Structural Equation Modelling ............................................ 96 


\section{CHAPTER I}

\section{INTRODUCTION}

This chapter begins by introducing the background to the problem, and then goes into the problem statement, the research questions, theoretical framework, and significance to the field. The chapter then concludes with the assumptions, limitations, definition of key terms, and a short summary.

\section{Background to the Problem}

Global trade has grown exponentially since 1970 and continues to accelerate despite a temporary slowdown during the global economic crisis which began in 2008 (United Nations Conference on Trade and Development, 2012). Annual foreign direct investment has grown from \$207 billion in 1990 to $\$ 1.65$ trillion in 2012 (United Nations Conference on Trade and Development, 2013), and as a result of growing annual foreign direct investment, organizations have grown and continue to grow internationally. Multinational corporations often rely on global human resource management to help transfer skills and knowledge across borders (Pine, 2000; Shim \& Paprock, 2002). International assignments are considered a key aspect of human resource development (HRD) in large multinational corporations (Collings \& Scullion, 2009).

China has received a significant amount of foreign direct investment as well as attention as a tourist destination (Kearny, 2013). A World Travel \& Tourism Council report stated that travel and tourism in China in 2013 generated 1.49 trillion Renminbi (RMB; approximately US \$240 billion) directly to the GDP, and \$5.23 trillion RMB (approximately US $\$ 840$ billion) directly and indirectly to the GDP (World Travel \& 
Tourism Council, 2014) $)^{1}$. Many hotel chains are focusing much of their overall growth strategy in China because of seemingly endless opportunities for hotel development, management and franchising in this emerging market (InterContinental Hotels Group, 2013; Yu, 2010).

China's hospitality industry is growing quickly, and is expected to continue unabated over the next decade (Kearny, 2013). The success of international hotel chains depends on technically competent and culturally adaptable expatriate managers (Causin, Ayoun, \& Moreo, 2011). Expatriate workers are citizens from one country who live and work in a different country, primarily because of their specialized operational abilities or because of their knowledge of the employing organization (Pine, 2000; Shim \& Paprock, 2002). The benefits of utilizing expatriate managers are numerous, including more familiarity with corporate culture than Chinese managers (Guzzo, Noonan, \& Elron, 1994). Expatriates are typically effective communicators and coordinators with their main office or headquarters (Barber \& Pittaway, 2000). Therefore, demand in the hospitality industry for expatriate professionals is expected to continue to increase substantially. However, a lack of qualified managerial staff and high turnover rates are key issues for industry executives (Zhang \& Wu, 2004), especially because demand for qualified managers continues to flourish and outstrip supply (Quelch \& Bloom, 1999).

\footnotetext{
${ }^{1}$ According to the World Travel \& Tourism Council, the direct contribution of travel and tourism to GDP "reflects the 'internal' spending on Travel \& Tourism (total spending within a particular country on Travel and Tourism by residents and non-residents for business and leisure purposes) as well as government 'individual' spending - spending by government on Travel \& Tourism services directly linked to visitors." The total contribution of travel and tourism to GDP "includes 'wider impacts' (i.e., the indirect and induced impacts) on the economy [which includes] tourism marketing and promotion, aviation, administration, security services [...] purchases of food and cleaning services by hotels, of fuel and catering services by airlines, and IT services by travel agents."
} 
With the explosive growth in China in recent years, finding, developing and retaining talent have been important issues for companies seeking to grow their presence in the country (Kaye \& Taylor, 1997).

Expatriate assignments are typically planned to last two to three years, particularly for managers (Guzzo, Noonan, \& Elron, 1994). As globalization increases, more and more firms are sending larger numbers of managers on overseas assignments (Kobrin, 1988; Scullion, 1991). The present research focuses on the study of expatriate managers' leadership performance who work in the hospitality industry in China. The research is being conducted in the Chinese context because the majority of executive positions are taken by expatriates in joint-venture hotels because of their expertise in hotel management (Feng \& Pearson, 1999). For the purposes of the current research, expatriate success is achieved when expatriate managers meet the objectives set by their employing/sponsoring firm for the duration of their assignment (Magnini \& Honeycutt, 2003). Effective leadership practices can enhance the success of expatriates during their assignment period.

Prior research has shown that a significant number of expatriate managers return prematurely from their overseas assignments and/or perform below expectations (Black \& Gregersen, 1999; Dunbar \& Ehrlich, 1986; Kaye et al., 1997; Osman-Gani \& Rockstuhl, 2009). Some studies have suggested that the failure rate is approximately $25 \%$ to $40 \%$ for an expatriate in a developed country, and as high as $70 \%$ for an expatriate in a developing country (Li-Yueh, Veasna, \& Wu, 2013, Shay \& Tracey, 1997). Failure rates are costly to organizations and employees, costing employers between two to four times their employee's annual salary (Lewis, 2006), in addition to potentially negatively 
impacting the careers of failed expatriates (Varner \& Palmer, 2003). Overall, expatriate failures cost multinational corporations billions of dollars, damage corporate image and disrupt relationships with local nationals, in addition to potentially damaging the expatriate's psychological well-being (Fisher \& Hartel, 2003).

Since China announced its "Open Door" policy in 1978, the number of expatriate workers and corporations conducting business in China has increased substantially (Kaye et al., 1997). In a report released November 2013 by the Hong Kong Shanghai Banking Corporation (HSBC), China was ranked as the Number 1 destination for expatriates among 37 countries (HSBC, 2013). Out of 37 countries, China is ranked Number 2 in terms of expatriate economics, which measures expatriate income levels, spending, and saving and investment ability (HSBC, 2013). In addition, China ranked Number 3 in terms of general quality of life, which includes access to healthcare, entertainment, work environment, and local culture, among other factors (HSBC, 2013). Despite an abundant labor pool, China has had to overcome a relative scarcity of skilled workers and managers versed in modern business practices (Kaye et al., 1997; Magnini \& Honeycutt, 2003). Therefore, companies have increasingly relied on workers from abroad to fill management-level positions in their organizations (Hon, Lu \& Chan, 2015).

Expatriate managers occupy an important aspect of organizational culture and employee engagement (Shiang-Lih, Tsai, \& Bellino, 2010). Expatriate managers drive organizational culture and employee engagement because of their power to hire, fire, determine compensation, and set other policies and procedures that impact employee dayto-day activities and experiences (Rothfelder et al., 2012). Employee attitudes and behaviors in response to the culture set by their managers and organization play a central 
role in the quality of service and business success of hospitality organizations (Lee, 2000).

Organizational justice has a direct impact on employee attitudes and behaviors, and consequently customer service especially in hospitality organizations (You-De et al., 2013). Organizational justice is defined as employees' perceptions of the fairness of treatment received from organizations (Cropanzano \& Greenberg, 1997). The idea of organizational justice has increasingly been explained at as a variable of organizational effectiveness - with an increasing number of studies and papers focusing on the role of fairness in a work environment (Colquitt et al., 2001; Greenberg, 1990). Organizational effectiveness is defined as how effective an organization is in achieving the outcomes that the organization intends to produce (Taylor, Cornelius, \& Colvin, 2014). Overall, organizational justice has been shown to be positively associated with job satisfaction (López-Cabarcos, Machado-Lopes-Sampaio-de Pinho, \& Vázquez-Rodríguez, 2015; Shiang-Lih et al., 2010).

Organizational justice involves perceptions of fairness, and can be conceived differently depending on the individual and cultural contexts of the perceiver (Cropanzano \& Greenberg, 1997; Greenberg, 1990; You-De et al., 2013). Organizational justice can have an impact on how local employees evaluate expatriate managers (Alice, Hon, \& Lu, 2013). For example, "fair wages" for an expatriate manager from a country like the United States can seem exorbitant to local employees in a developing country like China. The discrepancy is often compounded because the expatriate manager not only has a higher relative base salary than the local employee, but the expatriate manager also occupies a senior level position, and thus is likely to have a higher level of 
compensation than local employees receive (Leung, Wang \& Hon, 2011; Leung, Zhu \& Ge, 2009). The discrepancy has been confirmed in mainland China (Leung et al., 2011). The large compensation gap between expatriate and local employees can be a source of perceived injustice for the latter, which can negatively influence local employee evaluations of their expatriate managers and their firms (Choi \& Chen, 2007). Thus, different expectations and perceptions of organizational justice is likely to serve as a mediator between employee job satisfaction and how they perceive expatriate leadership performance.

Employee job satisfaction is important because of the outcomes job satisfaction correlates with, including increased employee loyalty and effort on the job, both of which are linked to improving operational performance. In service-oriented industries, employee job satisfaction has been directly and positively correlated with customer satisfaction (Rothfelder et al., 2012). For these reasons, organizational leaders may want to focus on facilitating and enhancing employee happiness and satisfaction (Rothfelder et al., 2012).

Leadership is the capability of an individual to influence a group toward the achievement of a vision and is a significant factor in terms of organizational performance and success (Northouse, 2010). Impactful leadership, especially transformative leadership, involves more than transactional behaviors and processes such as managing systems of rewards or punishments (Salem, 2015). Transformational leadership is defined as a process that changes and transforms individuals (Northouse, 2004). Transformational leaders speak directly to their reports' values and goals, and use this understanding to increase commitment toward organizational goals (Thamrin, 2012). 
The Importance of Local Employee Perspectives

McNulty (2015) showed that the five most common purposes for international assignments are "(a) filling a skills gap, (b) building management expertise, (c) launching new endeavors, (d) transferring technology, and (e) transferring corporate culture" (p. 1). Almost all of these assignments carry a primary or secondary objective of transferring knowledge and skills to local employees and utilizing local talent to build local managerial capacity and enhancing organizational performance (Adeniyi, 2015). How well skills and knowledge are transferred is a significant indicator of expatriate success (Naumann, 1992). Therefore, expatriate leadership performance is strongly associated with how much local employees have learned and benefited from expatriates' presence (Yu \& Huat, 1995). Allowing local employees to evaluate expatriate manager job performance seems aligned with the purposes of an international assignment. In addition, local employees work with expatriate managers, side-by-side, on a daily basis and are in a unique situation to evaluate expatriate performance.

A common point of tension between local employees and expatriate managers is organizational justice (Leung, Wang, \& Smith, 2010). Expatriate managers often occupy senior positions in foreign-owned or international joint venture hotel properties and enjoy compensation that tends to be many times more than what local employees earn (Leung et al., 2010). In a number of cases, local employees do not think that expatriate managers deserve the level of compensation that expatriate managers earn compared to local wages (Leung et al., 2010). Furthermore, difficulty of communication, and lack of knowledge about the local market and national culture add to the difficulties experienced between local employees and expatriate managers (Podsakoff \& MacKenzie, 2000). Lack of 
communication can contribute to the high failure rates of expatriate managers (Feng \& Pearson, 1999).

\section{Problem Statement}

Much of the existing literature on expatriate hotel professionals in China, or expatriate professionals in general, focuses on issues of expatriate manager dissatisfaction and causes of failure (Dunbar \& Ehrlich, 1986; Feng \& Pearson, 1999). In particular, researchers have looked into cross-cultural concerns (Kaye et al., 1997), training programs (Zhang \& Wu, 2004), lack of managerial support (Yu et al., 1995), personality factors, and expatriate adjustment (Feng \& Pearson, 1999; Magnini \& Honeycutt, 2003). However, there is a notable research gap in examining expatriate manager leader performance from a local staff perspective. There also is a lack of empirical evidence in the existing expatriate literature that simultaneously examines expatriate leader performance, with employee job satisfaction as a predictor, and organizational justice as a mediator in a cross-cultural environment in China.

\section{Purpose of the Study}

The purpose of the nonexperimental, quantitative study is to investigate the relationship between organizational justice, job satisfaction, and expatriate leadership performance.

\section{Research Questions and Hypotheses}

The present study focuses on three research questions: (a) What is the relationship between organizational justice and employee job satisfaction? (b) What is the relationship between employee job satisfaction and expatriate leadership performance? and (c) Does organizational justice mediate the job satisfaction-leadership performance relationship? 
To explore these three research questions, three hypotheses were tested:

H1: There is a positive relationship between organizational justice and employee job satisfaction.

$\mathrm{H} 2$ : There is a positive relationship between employee job satisfaction and employees' perceptions of the expatriate leader's job performance.

H3: The relationship between job satisfaction and leadership performance will be mediated by organizational justice.

\section{Conceptual Framework}

The conceptual framework includes concepts, assumptions, expectations, beliefs and theories that supports and informs research, and is a key part of a successful research design (Miles \& Huberman, 1994). The conceptual framework determines what will be measured and what statistical relationship(s) will be determined (Miles et al., 1994). The present study, undergirded by both social exchange (Blau, 1964) and transformational leadership theory (Bass \& Avolio, 1990), seeks to explore the association among organizational justice, employee job satisfaction, and employees' perceptions of the expatriate leader's performance. A key expectation underlying the research is the idea that evaluating expatriate leadership performance from a local employee perspective is unique and could be valuable to HRD researchers and practitioners working in the hospitality industry, and also beneficial to expatriate hotel leaders in China.

Social Exchange Theory

Social Exchange Theory (SET) serves as a model for understanding workplace behavior (Blau, 1964); this theory is one of this study's two theoretical foundations for 
understanding the degree organizational justice, employee job satisfaction, and expatriates' leadership performance are associated.

The SET theory attempts to explain and understand human interactive behaviors (Blau, 1964). Put simply, the theory indicates that relationships are built off interactions that generate other interactions or obligations (Blau, 1964). In SET, one individual initiates an action and another individual responds to it, according to reciprocal interaction. Underlying the entire interaction is the concept of reciprocity, where in a social exchange relationship is the case when employees can develop more commitment to each other on the basis of the benefits they receive and expect to receive in the future (Blau, 1964). For example, employees satisfied with their leader-follower exchange would be more likely to evaluate their leader's performance positively.

Transformational Leadership Theory

Transformational leadership theory will be used to examine expatriate leadership performance. Transformational leadership is defined as a process that changes and transforms individuals (Northouse, 2004). Transformational leadership theory was the first theory to provide both a moral and ethical dimension to leadership and focus on ways to transform employees (Gasper, 1992).

In the past 30 years, one of the leading approaches to analyzing leadership focused on the transformational and transactional paradigm conceptualized by Bass (Bass \& Avolio, 1990). The first transformational and transactional leadership theory, however, was proposed by Burns in 1978. Transformational leadership theory has been supported at a variety of jobs and occupations, such as school principals, teachers, ministers, officers, privately owned businesses, education, and government (Bass \& Avolio, 1997). 
Transformational leadership was selected as a focus area in the present study because transformational leadership has been shown in multiple studies to be associated with increased employee motivation and performance (Arendt, Brown \& Eric, 2011; Salem, 2015). For example, strong transformational leaders can increase employee commitment to the organization, as well as lead to greater employee trust in management and other positive behaviors, such as altruism and conscientiousness, that are not as easily rewarded or encouraged in formal processes or in normal compensation (Patiar \& Mia, 2009; Salem, 2015). Transformational leadership theory predicts that, transformational leaders are able to develop relationships and act in ways with their followers that moves the followers to act at a higher level (Salem, 2015).

In the hospitality industry, given the labor-intensive nature of the industry and the turbulent conditions it now faces, transformational leadership can unlock significant value and long-term success for organizations (Tracey \& Hinkin, 1994). For example, transformational leadership has been shown to be linked to improved employee satisfaction, performance, and have a positive link to producing supportive, productive and innovative working environments (Patiar \& Mia, 2009). Transformational leaders develop a strong vision to communicate to employees and create a working environment that raises motivation, commitment and constant development (Tracey \& Hinkin, 1994). By understanding ways to identify, encourage and support transformational leaders, organizations can benefit from tools and tactics that are not limited to normal transactions, where rewards or punishments are used to beget performance (Salem, 2015). 


\section{Research Variables}

The following section discusses the three variables that will be explored in this study. First, organizational justice will be discussed, then employee job satisfaction, and finally transformational leadership.

\section{Organizational Justice}

Organizational justice is defined as employees' perceptions of the fairness of treatment received from organizations (Cropanzano \& Greenberg, 1997; Greenberg, 1990; You-De, You-Yu, Kuan-Yang \& Hui-Chun, 2013). Organizational justice is a significant fundamental requirement for the effective functioning of organizations (Greenberg, 1990), and has an impact on employee attitudes and behaviors at work, which have been shown to be correlated with employee perceptions of organizational justice (Usmani \& Jamal, 2013). The knowledge gained from this research may enhance the understanding of the degree to which organizational justice is linked to employee job satisfaction in the unique context of China (You-De et al., 2013).

In the present study, organizational justice serves as a mediator between employee job satisfaction and how employees perceive expatriate leadership performance. The current study focus on three main types of organizational justice: distributive justice, procedural justice and interactional justice. Distributive justice is related to personal outcomes and is derived from the idea of equity (Adam, 1965). Specifically, the idea behind distributive justice is that individuals care about the perceived fairness of what they get from their work (e.g., promotions, pay, recognition) relative to their input (e.g., hard work, skills, and commitment) (Elamin, 2012). Procedural justice is related to organizational outcomes, and specifically is about the fairness of procedures used to 
produce various outcomes (Shiang-Lih, Tsai, \& Bellino, 2010). Through a procedural justice lens, the process of reaching an outcome can be just as significant as the outcome itself, and variables such as employee trust, satisfaction, and compliance can be impacted by perceived procedural justice (Elamin, 2012). Interactional justice, on the other hand, involves leaders' treatment of the employee and their feelings and perspectives (Niehoff \& Moorman, 1993). Examples of interactional justice involve leaders being respectful, truthful, sensitive, and highly communicative (Roch \& Shanock, 2006).

\section{Employee Job Satisfaction}

As a service industry, the hospitality industry depends on the abilities and motivations of its employees (Erkutlu, 2008). Job satisfaction is strongly affected by different leadership behaviors and has been shown to be positively associated with an employee's perception of leader performance (Khalilzadeh, Giacomo, Jafari, \& Hamid, 2013).

Job satisfaction is an attitude (Fisher, 2000). Attitudes are comprised of two important components, an affective component and a cognitive component. An affective component is described as a mood, emotion and feeling; the cognitive component is described as judgment, belief, and comparison (Fisher, 2000). Both components contribute uniquely and variably to the overall attitude, and may be linked and related to behavior (Weiss, 2002).

Job satisfaction indicates an employee gives a generally affective evaluation of his or her job (Nedeljkovic, Hadzic \& Cerovic, 2012), and reflects the degree of happiness measured by the difference between someone's actual returns and expected returns (Lawler, 1968). Job satisfaction is a significant variable of organizational studies, 
and is a common topic in hospitality management studies (Khalilzadeh et al., 2013). In the present study, job satisfaction is used not only as a dependent variable that may be linked with organizational justice, but also as a predictor of employee perception of expatriate leadership performance.

Job satisfaction is influenced by both intrinsic and extrinsic factors (Ge et al., 2011). Intrinsic job satisfaction is associated with a work-related goal that is essential, but not dependent on external processes (Mardanov, Sterrett \& Baker, 2007), which includes achievement, work itself, recognition, responsibility, advancement (Wernimont, 1966). Extrinsic job satisfaction, on the other hand, refers to how company policies are handled, relations with the supervisor, the quality of working conditions, and so forth (Ge et al., 2011), which includes job security, salary, working conditions, company policies, technical competence, interpersonal relations (Wernimont, 1966).

\section{Transformational Leadership}

Leadership is one of the most frequently researched topics worldwide and provides a broad theoretical base for the present research (Kirkbride, 2006). Leadership is defined as the capability of an individual to have influence and control over other people to achieve goals or a vision (Li-Yueh, Veasna \& Wu, 2013; Thamrin, 2012). Leadership influences employees' ability to understand and agree about what needs to be done and how to achieve shared goals (Onorato, 2013).

An effective relationship between leaders and followers depends on the degree of understanding between leaders and followers (Chathoth \& Olsen, 2002; Kirkbride, 2006). Organizational scholars have developed several approaches to analyzing leadership, including investigating trait, behavioral, situational, and charismatic approaches 
(Northouse, 2010). Transformational leadership, a focus of the present study, is divided into four dimensions: idealized influence, intellectual stimulation, individualized consideration, inspirational motivation (Bass, 1985).

Many studies have demonstrated that there is a positive relationship between a transformational leadership style and employee job satisfaction (Barling, Weberand, \& Kelloway, 1996; Dubinsky, Yammarino, Jolson, \& Spangler, 1995; Kirkman et al., 2009; Kim, Magnusen, Andrew \& Stoll, 2012; Rothfelder et al, 2012). Thus, in the following hypothesized model, organizational justice has a positive relation with employee job satisfaction, and employee job satisfaction has a positive relation with employees' perceptions of the expatriate leaders' performance (see Figure 1).

\section{Figure 1.}

Hypothesized model of the relationships between organizational justice, job satisfaction, job satisfaction

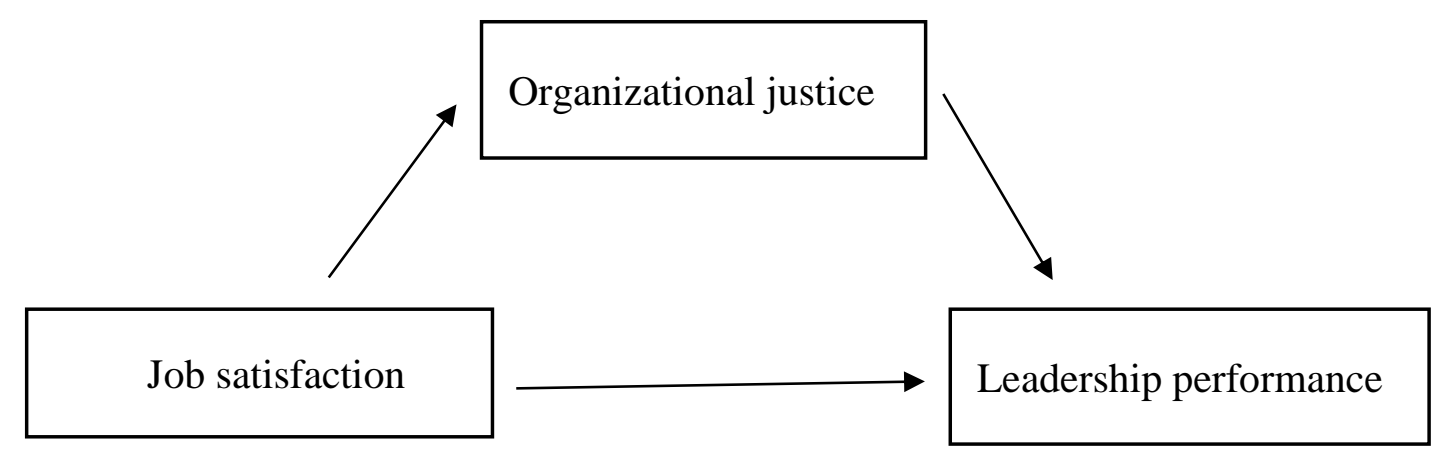

Significance of the Study

The current study makes contributions to both academic and industrial implications in the hospitality management field. First, the study seeks to enrich what we already know about social exchange theory and transformational leadership theory. Both theories have been widely accepted, tested, and applied to investigating leadership 
productivity in English speaking counties (Graves, Sarkis, \& Zhu, 2013). How cultural factors might influence the validity of the precepts, especially in eastern cultures and in the hospitality industry, however, has not been tested (Qin, Wen, Ling, Zhou, \& Tong, 2014). The results of the present study may enhance our understandings of social exchange theory and transformational leadership in a cross-cultural leadership context.

The current research is designed to fill a gap in knowledge about leadership performance in the hospitality industry. The results of the study will provide evidence of the direction and magnitude of relationships between organizational justice, job satisfaction and expatriate leadership performance.

Moreover, there is a noteworthy research gap in terms of examining expatriate leadership performance from a local employee's perspective. There has been little research on leadership from follower and subordinate perspectives. Previous studies have focused more on how leaders/managers perceive their own performance, with little concern for the view for the bottom-up perspective (Wong, 2008).

Existing research methods often have asked expatriate leaders to evaluate themselves in terms of their own performance, which may lead to a predilection towards self-serving bias (Arkin, Appelman, \& Burger, 1980). It is human nature to take credit for being successful, enlarging their own contribution to success, and denying any responsibility for failure (Arkin et al., 1980). Through the new angle of expatriate evaluated by local employee, the current study may help inform and evaluate HRD practices in international corporations, particularly those that do business in China. The importance of people for the delivery of high quality tourism experiences and services 
requires managers and leaders to commit to strategic processes that identify future changes, likely human resource implications, and human resource development.

Third, the results of the present research may help hospitality industry leaders face the reality of how local employees perceive their performance, and play a vital role to identify possible opportunities and shortcomings in HRD policies and procedures. Human resource development professionals could focus on creating developmental interventions that promote organizational justice, employee job satisfaction, and encourage a positive psychological climate. In addition, the information gained from the current study may help multinational hotel companies better understand China's organizational justice, job satisfaction and the type of leadership that best relates with that workforce. Leadership plays a significant role in terms of hospitality industry development and organizational success (Rothfelder, Ottenbacher, \& Harrington, 2012; Tracey \& Hinkin, 1994). To be successful in international business requires leaders to be aware of the cultural differences and local dynamics of their local workforce, which may influence business practices in a foreign country (CB Richard Ellis Hotels, 2009). Those leaders in an international business setting need to have a comprehensive understanding of what is expected of leaders.

Expatriate failures may damage firm reputation, disrupt local relationships (Bhaskar-Shrinivas et al., 2005), are costly (Pires et al., 2006), and often exact a cost on the failing expatriates' own psychological well-being (Solomon, 1996). Therefore, reducing the failure rate of expatriation and making it more successful should be a high priority for global business operations (Qin and Baruch, 2010). 
In addition, the current study may help leaders in multinational organizations, and organizations that might want to extend business in China, by potentially assisting organizations develop diversity training to help their leaders effectively fit into the local leadership perspective (Dunbar \& Ehrlich, 1986). Because expatriate managers experience high failure rates (Feng \& Pearson, 1999), the current study has multiple practical objectives by exploring their perspective including helping organizations better recruit, support and/or retain good managers, thereby avoiding the high costs associated with expatriate manager failure.

\section{Assumptions}

Although local employees are a diverse group, it is assumed that using a specific sample of local employees to evaluate expatriates in a particular industry in China will increase the possibility that meaningful patterns or interesting themes could be found. It is further assumed that participants to the study gave truthful and honest responses that were free from bias and unintended to negatively influence the study (Schwarz, 1999).

\section{Limitations}

Like any study, the present study has limitations. First, by utilizing a purposive sampling of subjects to give surveys to, the study decreases the potential generalizability of its findings (DeFeo, 2013). Second, social desirability bias may impact responses as participants were asked to report sensitive information about their manager (Nederhof, 1985). Social desirability reflects the tendency on behalf of the subjects to deny socially undesirable traits and claim instead socially desirable ones (Hebert, Clemow, Pbert, Ockene, \& Ockene, 1995). A few ways one can reduce social desirability bias includes: assuring participant anonymity, forced-choice items, and neutral questions, randomized 
response technique, self-reported questionnaires, and selecting interviewers. From among all those methods, self-reported measures will be used to cope with possible social desirability bias because research has demonstrated that self-reported method reduces the salience of social cues through isolating the subject, thereby reducing the likelihood of giving socially desirable responses (Durant, Carey, \& Schroder, 2002; Nederhof, 1985).

Third, self-report measures offer benefits to the researcher, such as inexpensive use and ease of distribution (McCabe, 2004); however, using these measures raises the possibility of introducing common method variance bias (CMV) into the study. In the current survey research, CMV may threaten the validity of the findings because participants respond to the survey as a single source of data (mono-method), rather than a multitude of data sources (Podsakoff, MacKenzie, Lee, \& Podsakoff, 2003; Reio, 2010). Survey results may produce inflated or deflated correlations among the variables of interest (Podsakoff et al., 2003). Reio (2010) suggested a few ways to reduce the likelihood of CMV bias. First, ensure participant anonymity and confidentiality. Second, let participants be aware that is no correct or preferred answer, focusing instead on an honest response. Third, offer clear instructions for the survey and eliminate confusion. For example, surveys can be reviewed by knowledgeable experts and conducting a pilot study to reduces the chance of nonresponse error, sampling error, measurement during the collection process.

\section{Delimitations}

Delimitations of a study are the characteristics that narrow the focus of inquiry by identifying aspects the researcher can control (Creswell, 2002). The study is primarily concerned with factors related to expatriate managerial success, and in particular, a 
decision was made to purposefully limit the focus of the study to hospitality expatriate managers in China. The focus on expatriate managers in China was derived from research considerations and prior research on work culture, leadership styles and corporate operations in China.

\section{Definition of Terms}

This section includes a review of the terms that are commonly used or referenced in this study and are included to clarify meaning and provide context.

Adaptation: Merriam-Webster defines adaptation as the process of adjusting to fit some purpose or situation (Merriam-Webster, 2014). In the context of this study, we refer to the ability of expatriate managers to adjust to new cultures and environments compared to their home country. Studies have shown that the ability of managers to adapt and adjust correlates with job satisfaction and job performance (Abbott \& Stening, 2006).

Culture: For the purpose of this study, culture is defined as the "learned and shared human patterns or models for living [...] these patterns and models pervade all aspects of human social interaction.” (Damen, 1987)

Expatriate: Expatriates are citizens from one country who live and work in a country different from their home country, primarily because of their specialized operational abilities or due to their knowledge of the employing organization (Pine, 2000; Shim \& Paprock, 2002). In this study, the term is primarily used to describe expatriate managers in the hospitality industry working in China.

Expatriate failure: For the purposes of this study, expatriate failure is established when expatriate managers return prematurely from their overseas assignments and/or 
perform below the institutional standards established by their employing/sponsoring organization (Harrison, 1994; Black \& Mendenhall, 1989). Some studies have suggested that the expatriate failure rate is approximately $25 \%$ to $70 \%$ (Shay \& Tracey, 1997).

Expatriate success: Expatriate success is considered when expatriate managers meet the objectives set by their employing/sponsoring firm for the duration of their assignment (Magnini \& Honeycutt, 2003).

Hospitality industry: The hospitality industry encompasses a broad category of fields within the service industry that generally is comprised of lodging, food service transportation and commercial recreation (FAU, 2014). For the purposes of this study, researcher focus on the lodging industry in China.

Job satisfaction: A general attitude toward one's job (Fisher, 2000).

Local employees: The local employees in this research are the native employees in the hotel with Chinese nationality.

Organizational justice: Employees' perceptions of the fairness of treatment received from organizations (Cropanzano \& Greenberg, 1997).

Social Exchange Theory: it is a theory that attempts to explain and understand human interactive behaviors (Blau, 1964).

Transformational leadership: it is defined as a process that changes and transforms individuals (Northouse, 2004).

\section{Summary}

As the world economy continues to globalize, one of the key challenges facing leaders of multinational organizations as they grow their operations and do business in new countries is the high failure rate of expatriate managers. In particular, China is often 
cited as a leading destination for investment and growth, particularly in the hospitality industry (CB Richard Ellis Hotels, 2009; HSBC, 2013). Although there is extensive research on expatriates in China, this study discussed the lack of research studying expatriate managers' leadership performance from the local employees' perspective. Chapter 2 includes a review of the literature that supported the study. 


\section{CHAPTER II}

\section{LITERATURE REVIEW}

This chapter begins with an introduction to the hospitality industry and human resource development in China. Then, relevant literature around the three research variables (organizational justice, employee job satisfaction and leadership) is explored along with empirically validated measurements for each variable. Third, social exchange theory is presented and explored as an influential theory for the current research. The chapter concludes with a discussion of cross-cultural management issues in China's hospitality industry.

Important Stages of Hospitality and Human Resource Development in China China's modern hospitality industry has developed remarkably quickly, especially when considering that the country's most recent economic transformation only began in the late 1970s (Kong \& Cheung, 2009). Prior to 1978, only a few hotel facilities met international standards for the hospitality industry (Kong et al., 2009), particularly in areas around property construction and design, operations, and human resource development. But since China's “Open Door" policy starting in 1978, its hospitality industry and its service industry has developed rapidly to the point where China's service industry is rapidly growing to comprise a relatively high percentage of its Gross Domestic Product (GDP), similar to most developed countries (CIA, 2009; Tsai, Cheng, \& Chang, 2010). To staff the growth of new properties, as well as increase service quality to meet international standards, hospitality companies operating in China have had to recruit and utilize management and leaders sourced internationally. These expatriate managers are citizens from one country who live and work in a country different from 
their home country, primarily because of their specialized operational abilities or because of their knowledge of the employing organization (Pine, 2000; Shim \& Paprock, 2002).

In the early 1980s, the Chinese government offered incentives to expand and modernize the hospitality industry because of hotel room shortages. The more started the importation of advanced hospitality management skills, overseas investments and partnerships, and the adoption of international industry standards (Hines, 1984; Kong et al., 2009). The first joint-venture hotel in China, the Jianguo Hotel, began in 1982 (Pine, Zhang \& Qi, 2000). Since then, the number of expatriate workers and corporations conducting business in China has increased substantially (Kaye et al., 1997), and the quality and standards brought in by major international hotel chains such as Holiday Inn, Hilton, and Sheraton challenged the domestic hotel industry to improve to match the competition (Alexander \& King, 1995). To measure the modernization national hotel standards, the China National Tourism Administration (CNTA) created a hotel star rating system in 1990 (Alexander et al., 1995).

In the 1990s, in a pattern that would play out in other industries, multinational hotel chains not only felt the need to bring the best and most up-to-date talent, processes, and management practices to China, but also that corporate processes and properties had to mesh with Chinese characteristics through cross-cultural management (Wong, 2008). Cross-cultural management has since become the main operating model for international hotel chains seeking to reduce cultural conflict among the multitude of important stakeholders in China (Wong, 2008).

Expatriate managers are an important tool for bridging the gap between modern, international business practices and local norms and customs. Expatriate managers bring 
technical competence, managerial experience and corporate best practices from abroad to help Chinese operations achieve success (Adeniyi, 2015). As companies continue to grow internationally, the benefits of utilizing expatriate managers become more pronounced. Not only does using expatriate managers mean opening up important positions to a global talent pool, but the use of expatriates also provides managerial talent in developing countries where there maybe limited local talent. Expatriate managers can enhance the global mind-set of the organization (Abbott \& Stening, 2009).

Expatriates can also be a better option during high growth periods than domestic managers in successfully growing a business in the target country because of their training and experience (Causin, Ayoun, \& Moreo, 2011). China has been operating in such a high growth environment since the country ascended to the World Trade Organization (WTO) in 2001 - requiring China to update and iterate from its "Open Door" policy first developed in 1978 (Lee, 2002), which has also brought on more international trade and travelers. In about twenty years, China's hospitality industry grew from 137 hotels with 15,539 rooms in 1978 to 10,481 hotels and almost 1 million rooms in 2000 (Wong \& $\mathrm{Li}, 2015$ ).

Today, some of the largest hotel chains in the world consider China as one of their primary markets. One of the largest hotel operators in the world is InterContinental Hotel Group (IHG). China is InterContinental Hotels Group's second largest market globally. The IHG now has 271 hotels in over 100 cities and 222 in the development pipeline in China (IHG, 2016). Despite statistics indicating rapid advancement in the hospitality industry in China - there are also variables that have negatively impacted growth, such as a shortage of qualified personnel, shortage of qualified managers, high turnover, lack of 
prestige as an occupation among college graduates, and an education gap between what is taught in schools and the skills needed on the ground (Tsang, Lee, \& Qu, 2015; Wong \& $\mathrm{Li}, 2015)$.

The Importance of Human Resource Development in the Chinese Hospitality Industry The hospitality industry is a labor-intensive industry in which business success can be determined by the quality of labor in providing products and services to the consumer (Heskett \& Schlesinger, 1994). Studies have shown that new customer acquisition is up to five times more expensive to attract than retaining existing customers (Pizam, Shapoval, \& Ellis, 2016). Service levels that employee hosts give to guests is directly related to customer retention (Pizam, Shapoval, \& Ellis, 2016). How organizations manage their employees and ensure service quality are therefore key components of long-term business success.

Key means of ensuring high quality service has been shown to rest on a fair and just working environment (i.e., organizational justice) and employee satisfaction (Salem, 2015). Human resource development plays an important role in setting the backdrop for high quality service, and promotes positive outcomes through trainings and systems that promote skill-set growth, utilizes employee abilities effectively, and increases organizational and employee knowledge in technical, inter-personal and social areas. These systems and trainings are a result of an increased focus on learning as an impactful component of developing healthy organizational culture (Egan, Yang \& Bartlett, 2004).

Another important factor is sufficiently competent hotel leadership and management who can act as positive representatives of the brand, promote and maintain strong employee morale, and enforce codes of conduct (Salem, 2015). In the context of 
the Chinese hospitality industry, many of these factors are directly influenced by the managerial behaviors and leadership of expatriate managers. Furthermore, expatriate managers charged with running foreign operations are more in tune with their organization's corporate culture and control systems than host-country managers, which helps bring more effective communication and coordination with headquarters (Barber \& Pittaway, 2000). The following sections explore the three research variables linked to high quality service; that is, organizational justice, employee satisfaction and leadership.

\section{Organizational Justice}

Organizational justice involves employee perceptions of fairness in organizations (Cropanzano \& Greenberg, 1997; Greenberg, 1990; You-De et al., 2013). Fairness has become more and more popular as a research topic in the field of HRD in the last few decades, and initially focused on distributive justice (Colquitt, 2001). In 1965, Adams theorized that people judge justice by comparing outcomes they receive with outcomes they see others receive. While his theory led to the development of the idea of distributive justice, it did not dive deeply into employee perceptions of other types of justice in the workplace (Colquitt, 2001). Distributive justice is a measure of whether employees perceive inputs and outputs to be fair or unbiased in the workplace (Adams, 1965; Roch \& Shanock, 2006). High levels of distributive justice would mean employees perceive that for the amount and quality of work performed (inputs), compensation and rewards (outputs) like pay, bonuses, workload, and promotion are fair and evenhanded. Low distributive justice, on the other hand, would be associated with perceptions of being treated unfairly relative to the outputs received and the amount and quality of work performed. Human resource development processes and decisions play a huge role in 
shaping employee perceptions of fairness, and is often an evolving process to optimize (Wooten \& Cobb, 1999).

Empirical research has also focused on the justice of the process that leads to decision outcomes; that is, procedural justice. Procedural justice refers to the process of making decisions and whether the procedures employed during the decision process are fair and equitable (Leventhal, 1980). Those procedures including performance ratings, promotions, terminations, and anything else of value that the organization offers (Leventhal, 1980; Imberman, 2009). Favorable perceptions of procedural justice are cultivated when the process of administering decisions are seen as consistent, impartial, made on the basis of accurate information, and employee input (Chan \& Jepsen, 2011). In summary, distributive justice is related to personal outcomes and procedural justice is related to organizational reference outcomes (Shiang-Lih et al., 2010).

A third form of justice is interactional justice. Interactional justice involves leaders' treatment of the employee and their feelings and perspectives (Colquitt, 2001). Examples of interactional justice involve leaders being respectful, truthful, sensitive, and highly communicative (Colquitt, Conlon, Wesson, Porter, \& Ng, 2001). Interactional justice can be divided into interpersonal and informational justice (Roch \& Shanock, 2006). Interpersonal justice concerns how people are treated, and is typically reflected by terms such as respect, dignity and politeness by authority figures in the organization that are responsible for executing procedures or determining outcomes. Informational justice involves sharing information and context about why procedures are the way they are or why outcomes are distributed the way they are (Raja \& Krishnan, 2014). 
The idea of organizational justice has increasingly been examined as a variable of organizational effectiveness - with an increasing number of studies and papers focusing on the role of fairness in a work environment (Colquitt et al., 2001; Greenberg, 1990). Many studies indicate that organizational justice is directly associated with employee job satisfaction, ethical behavior, commitment, turnover rate and loyalty (e.g., Chan \& Jepsen, 2011; Lopez-Cabarcos, Machado-Lopes-Sampaio-de Pinho, \& VazquezRodriguez, 2015). Employees who perceive that their treatment and corporate procedures are fair tend to have higher scores on employee job satisfaction, organizational commitment, work retention and task effectiveness (Huong, Zheng, \& Fujimoto, 2016).

\section{Guanxi and Organizational Justice}

The term "guanxi" is widely used to describe interpersonal relationships in Chinese culture (Chou, Han, \& Zhang, 2014). In organizational studies, "guanxi” has been defined as the relationship between leader/supervisor and employee, and this relationship involves special social connections built on mutual interest and benefit (Han \& Altman, 2009). Unethical "guanxi" practices have a negative impact on employee trust in management and include actions such as unfair task allocations, salary, bonuses, and unwarranted influence on employee's promotion (Chen, Chen, \& Xin, 2004). Negative facets of "guanxi" include distributive injustice, procedural injustice, and interactional injustice (Han \& Altman, 2009).

Han and Altman (2009) conducted a study on leader-subordinate "guanxi" in the field of organization and management in China. The sample size was drawn from employees from six firms in China, which represented a diversity of ownership styles (state-owned organizations, joint ventures, and privately-owned companies), as well as 
included a variety of industries (service, construction, manufacturing, finance, medicine and technology). The study identified some of the major causes (by percentage of participants indicating whether each was a factor in organizational injustice) of organizational injustice caused by unethical "guanxi": distributive injustice (3\%), procedural injustice (11\%), interpersonal injustice (5\%), ingratiation (6\%), exemplification (2\%) and false pretense for authority (2\%), which drove approximately $29 \%$ of employee perception of organizational unfairness (Han \& Altman, 2009).

In another study investigating the relationship between "guanxi" and organizational justice, Chen et al. (2001) suggested that manager interpersonal "guanxi" was positively linked to employee perception of fairness, whereas group-level "guanxi" was negatively linked. In a separate study, Han et al. (2012) found that subordinatesupervisor "guanxi" was a significant indicator of supervisory trust. Human resource development in this context plays an important role for multinational organizations to balance cross-cultural corporate goals applied to a local context. For example, human resource development involves the onboarding, training, and expectation setting for newly onboarded employees, which plays a role in helping to establish corporate culture. Strong human resource development can also clarify the manager-employee relationship as well as set expectations for how a manager will contribute to employee success (Bass \& Avolio 1993). Applied to a Chinese context, a multinational human resource development plan can take into account the importance and utility of "guanxi" as a potential motivation, communication, and/or collaborative tool, and adjust global strategies and tactics as necessary to take "guanxi" into account, for example in making decisions on or communication promotions, salary increases, or bonuses. 
Misunderstandings or misutilization of "guanxi" can result in negative employee procedural justice perceptions (Gibb \& Zhang, 2017).

\section{Measuring Organizational Justice across Cultures}

Evaluating organizational justice across cultures has gained cross-cultural theorist attention as organizational justice has had a proven influence toward employee job satisfaction in Western cultures (Wang, Liao, Xia, \& Chang, 2010). Accurately measuring organizational justice is important in that organizational justice scores can predict other indicators of organizational health (Xiaoyi \& Chunben, 2008).

Organizational justice constructs that work in Western countries may not apply or work as well in other countries where social norms and behavior are different from many Western societies (Guo, 2009), particularly in the Far East. Thus, there is a research need to first understand the local context of how theoretical constructs may apply. Without considering how native populations act and interact, cross-cultural validity cannot be assumed. A common criticism of cross-cultural organizational justice studies are that they make cross-cultural comparisons without taking into account culture-specific details (Fodchuk, 2009; Guo, 2009). For example, psychological constructs can be different from cultural context to cultural context because of cultural biases, false equivalence, and other culture-specific dimensions.

Moorman's (1993) and Colquitt's (2001) justice scales are two well-known and frequently used measures of organizational justice in Western countries. Moorman's justice scales provide separate scales for distributive, procedural and interactional justice to measure organizational justice (Moorman, 1993). Colquitt's justice scales measure distributive, procedural, interpersonal and informational justice (Colquitt, 2001). Both 
justice scales indicate high alphas of 0.84 or higher for all items measured on both justice scales (Miller, Konopaske, \& Byrne, 2012). Specifically, alpha reliability scores on Moorman's justice scales were $0.92,0.86$, and 0.94 for distributive justice, interactional justice, and procedural justice, respectively (Miller et al., 2012), and 0.89, 0.92, 0.84, and 0.93 for informational justice, interpersonal justice, procedural justice and interpersonal justice on Colquitt's justice scales, respectively (Miller et al., 2012).

To address culture gaps, Fodchuk (2009) examined organizational justice perceptions in China and developed a Chinese Organizational Justice Scale (COJS). The COJS is a five-factor model, which includes distributive justice east (guanxi), distributive justice, procedural justice, informational justice and interpersonal justice. Distributive justice and procedural justice are identified for Chinese organizational justice criteria (Fodchuk, 2009). The study indicated that both east and west forms of distributive justice related to pay satisfaction pretty consistently (Fodchuk, 2009), and indicated that role ambiguity negatively impacted informational justice, while lack of organizational support negatively impacted interpersonal justice (Fodchuk, 2009). In another report, Silva et al. (2016) indicated that organizations should recognize that there are sociocultural influences on perceptions of justice across cultures, and that positive perceptions of organizational justice are indicative or related to positive performance outcomes (Silva \& Caetano, 2016).

Employee Job Satisfaction and Expatriate Managers

Employee job satisfaction has become a popular and significant variable of organizational studies because of the high cost of employee turnover rate and significant impact employee happiness can have on job performance and operational performance 
(Khalilzadeh, Giacomo, Jafari \& Hamid, 2013). Job satisfaction refers to an employee's level of evaluative affection towards his or her job (Nedeljkovic et al., 2012). Human resource development plays a huge role in setting up an employee or manager for a successful experience during day-to-day activities through expectation setting, training, and establishing organizational culture. Job satisfaction has an impact on whether or not workers are happy, productive, and successful (Tsai et al., 2010). Job satisfaction reflects the degree of happiness measured by the difference between someone's actual returns and expected returns (Lawler, 1968). Many factors are linked to job satisfaction, including: organizational justice, past experience, personal competency, comparisons with others, etc. (Ning-Kuang Chuang, Yin, \& Dellmann-Jenkins, 2009).

In 1959, Herzberg developed the Two-Factor Theory of Motivation, which is a qualitative analysis of factors-attitudes-effects that explores how employee attitudes regarding their work can be specified, what leads to those attitudes, and the impact of those attitudes (Herzberg, Mausner \& Snyderman, 1959). The motivator-hygiene theory identifies factors that lead to job satisfaction or dissatisfaction (Ning-Kuang Chuang, et al., 2009). To observe employee attitude, Herzberg developed two lists of factors called motivators and hygiene factors (Herzberg et al., 1959). Motivation factors, also defined as intrinsic factors, are essentially related to self-fulfillment. These factors impact work attitudes and job satisfaction, and indicates satisfaction of psychological needs, including the nature of the work itself, recognition, growth, personal interest, achievement, advancement, and responsibility (Herzberg et al.; McPhail, Patiar, Herington, Creed \& Davidson, 2015). Hygiene factors, also defined as extrinsic factors, include salary, policy 
and administration, interpersonal relations, job security, working conditions and work environment (Gaertner, 1999; Wang, Yang, \& Wang, 2012; Wesley, 2012).

A service industry, profit chain model, introduced by Heskett in 1994, establishes relationships between employee satisfaction, productivity, customer loyalty, and profitability (Heskett \& Schlesinger, 1994). Profit growth occurs as customers build loyalty. Loyalty is a result of customer satisfaction (Heskett \& Schlesinger). Customer satisfaction can largely be linked to the quality of service received (Heskett \& Schlesinger). Employee job satisfaction will be strongly linked to the value of the service delivered to the customer (Tsai, Cheng, \& Chang, 2010). Therefore, employee satisfaction significantly drives customer loyalty, company profitability and success (Heskett \& Schlesinger). Leaders who understand the service-profit chain develop and maintain a corporate culture centered on improving employee job satisfaction (Heskett \& Schlesinger).

Human resource development plays a crucial role in helping corporations form the organizational culture they need to be successful in today's global economy and ever changing and evolving business environments. Knowledge and a balance of standardization and localization/customization are growing in importance in determining competitive success (Egan, Yang, \& Bartlett, 2004). Human resource development involves developing the employees and the team to perform at high expectations but is not a cure-all to ensuring top performance. Human resource development is inherently dependent on multiple factors that can apply differently in unique contexts, such as local culture, corporate culture, corporate key objectives, personnel, etc. How corporations 
apply human resource development can have a huge impact on factors such as job satisfaction, employee motivation, and workplace performance (Egan et al., 2004).

The task of improving employee job satisfaction is a critical issue in the hospitality industry. Front-line employees should be empowered to respond to guests' special requests because they are the direct point of contact for customers and as such need the autonomy to deal effectively with customers' concerns (Sparrowe, 1994). Transformational leadership emphasizes the empowerment of employees, as opposed to transactional leadership that emphasizes follow instruction (Sparrowe, 1994). In the highly interactive hospitality industry, employee satisfaction has a meaningful and empirical positive relationship with service quality and customer satisfaction (Wong \& $\mathrm{Li}, 2015)$.

Studies show that employee retention is supported by their job satisfaction (Arnett, Laverie, \& McLane, 2002). Satisfied employees are less likely to turnover. Low turnover is an important goal for hotel organizations and the hospitality industry, an industry characterized by a high level of fluctuation among staff (Kara, Uysal, \& Magnini, 2012). Retaining employees is critical to organizational success because of economic and non-economic costs. Economic costs born the organization for high turnover include lost productivity and output during the period before a new hire is successfully onboarded, training costs, and recruiter costs. Non-economic costs borne by the organization for high employee turnover can include negative impacts to employee culture, time lost caused by hiring and retraining, and reduced team morale. According to Nedelijkovic, economic costs to organizations can equate to $150 \%$ or more of an employee's annual salary (Nedeljkovic et al., 2012). 
Expatriate managers often occupy an important role in maintaining employee job satisfaction, maintaining team morale and collaboration, as well as enforcing organizational standards and expectations (Selmer, 2004). Highly trained expatriate managers can navigate cross-cultural norms and expectations to better align domestic employee performance with global organizational goals (Adeniyi, 2015). Furthermore, strong expatriate managers will have a long-lasting impact on their organization's development, particularly in a fast-growing country and industry like the Chinese hospitality industry (Adeniyi, 2015). Early reports to strong expatriate managers may become future leaders for the organization long-term (Barber \& Pittaway, 2000).

High job satisfaction in the hospitality industry can lead to positive employee behavior, such as: committing to go "above and beyond" with great customer service, having team spirit and a positive work culture, and increased loyalty to the corporation (Khalilzadeh, et al., 2013). These activities and beliefs contribute to the hotels' ability to deliver a high level of service that can improve customer loyalty. An increase in employee satisfaction may motivate workers to be more engaged and, as a result, to take actions that result in increased guest satisfaction and profitability, which is important for sustainability and success in the hospitality industry.

\section{Measuring Job Satisfaction}

Accurately measuring job satisfaction has been challenging to researchers. One of the problems is the development of an instrument to accurately, reliably, adequately measure the construct (Carruthers, 1988). In most methodologies, there has always been a gap between true job satisfaction and what was measured. An unbiased method to measure job satisfaction is crucial to the current study because of its dominating 
importance in the field of labor relations. There are numerus instruments to measure employee job satisfaction, including the Job Descriptive Index (JDI; Smith et al., 1969); Minnesota Satisfaction Questionnaire (MSQ; Weiss \& Dawis, 1967); a weighted JDI evaluation model (Quinn \& Mangione, 1973) and the Six Item Global Satisfaction Index (Agho \& Price, 1992).

The Job Descriptive Index (JDI). The JDI is the most commonly used measure of job satisfaction (Castanheira, 2014). The JDI measures job satisfaction, defined as "the feelings a worker has about his job" (Smith, Kendall, \& Hulin, 1969, p. 100). The JDI has been revised multiple times in 1985, 1997, and most recently in 2009 (Lopes, Chambel, Castanheira, \& Oliveira-Cruz, 2015). The intent is designed to measure five subscales of job satisfaction, including: 1) work itself - the idea that the job is interesting, and gives opportunities for personal learning and growth, 2) pay -fair pay compared with similar positions within or outside the company, 3) promotion opportunities - the chance for promotion and advancement in the company, 4) satisfaction with supervision - the quality of supervisors who provide emotional, social, technical support and help, and 5) relationship with coworkers - workers feel respected, supported and collaborative with colleagues to maintain a harmonious working environment (Lopes et al., 2015). Each subscale contains 9-18 questions, culminating in 72 questions in total for the whole JDI measure (Yeager, 1981). Respondents are asked to fill the blanks beside each item as follows: yes, no, or I don't know (Carruthers, 1988).

The JDI has been tested, validated and shown to have reliability in numerous studies in different fields (Kinicki, Mckee-Ryan, Schriesheim, \& Carson, 2002). In 2002, a review and meta-analysis of 152 studies assessing the construct validity of the JDI 
indicated that the JDI measure presented adequate internal consistency, validity and reliability (Kinicki, 2002). In 2005, Wang and Russel tested the relevancy of the Job Descriptive Index among American and Chinese workers, and found that all five aspects of the Job Descriptive Index were equally impactful across American and Chinese workers.

Minnesota Satisfaction Questionnaire. The MSQ was first adopted in 1967 by Weiss, Dawis, England, and Lofquist, and developed in 1985 to a shorter form (Podsakoff et al., 1990). The MSQ measures satisfaction in terms of working conditions, chances for advancement, feelings of accomplishment, freedom of judgment and so on. It contains 20 questions to measure two variables: intrinsic job satisfaction and extrinsic job satisfaction (Ge et al., 2011). Intrinsic job satisfaction incudes 12 questions that reflect subject matter dealing with achievement, ability utilization, activity, doing things for others on the job, type of work and so forth, (Ge, Fu, Chang, \& Wang, 2011). Intrinsic measures belong to a work-related goal that is essential, but not dependent on external processes (Mardanov, Sterrett \& Baker, 2007). Extrinsic job satisfaction incudes 6 questions that refer to how company policies are handled, relations with the supervisor, the quality of working conditions, and so forth (Ge et al., 2011). The questionnaire is one of the valid and reliable scales used by researchers worldwide to gather information associated with job satisfaction (Van Saane et al., 2003). The 20-item form MSQ used a 5-point Likert scale from 1 (very dissatisfied) to 5 (very satisfied). Previous research on the MSQ has verified the scale's psychometric properties are quite acceptable (Gillet \& Schwab, 1975). The MSQ has a typical 0.8 to 0.9 reliability coefficients and the considerable evidence supporting its validity (Weiss et al., 1967). In 2006, Tu utilized 
MSQ to measure job satisfaction among Taiwanese and Filipino caregivers and found high reliability and alpha scores.

\section{Leadership}

Leadership has been studied for many decades, and there is extensive research in the field of leadership in different notions of leadership, including trait-based leadership, laissez-faire leadership, transactional leadership and transformational leadership, among others (Thamrin, 2012). Given a leader's ability to make decisions and manage teams, it is not surprising that leadership is essential for organizational success (Kumar \& Kaptan, 2007; Yahaya \& Ebrahim, 2016). Burns defined leadership as "a stream of evolving inter-relationships in which leaders are continuously evoking motivational response from followers and modifying their behavior as they meet responsiveness or resistance in a ceaseless flow and counterblow" (Burns, 1978, p. 440).

A specific leadership style described as transformational leadership has been one of the most influential leadership theories of the past forty years (You-De et al., 2013). The idea of transformational leadership has been used in hospitality industry and is one of the most cited ideas for evaluating leadership impact (Podsakoff \& MacKenzie, 2000). Transformational leadership is defined as a process of changing and transforming individuals (Northouse, 2004), and is often contrasted against transactional leadership, the idea of influencing action through negotiation, exchange, or agreement. Leaders who are considered transformational can help their followers increase their motivation and engage those followers to accomplish a shared vision (Burns, 1978). On the other end of the spectrum, transactional leaders influence their followers through the exchange of value (Burns, 1978). Transformational and transactional leadership models are useful so 
that managers, and expatriate managers, can leverage their leadership style's strengths and be mindful of potential shortcomings.

In 1985, Bass introduced the Full Range Leadership Model, which outlined characteristics of transactional leadership, transformational leadership, and laissez-faire leadership styles. Laissez-faire leaders are hands-off and allow their reports or followers wide latitude to make decisions. Bass's original theory composed of two components of transactional behavior (contingent reward and passive management by exception), and three components of transformational behavior (idealized influence, intellectual stimulation, and individualized consideration). A revised version of the theory has added one more transactional behavior called active management by exception and another transformational behavior called inspirational motivation. The conceptualization of the Full Range Leadership model (see Figure 2) has seven factors which includes, idealized influence, inspirational motivation, intellectual stimulation, individualized consideration, contingent reward, management by exception, and laissez-faire. 


\section{Figure 2.}

Full Range of Leadership Model (Bass, 1985)

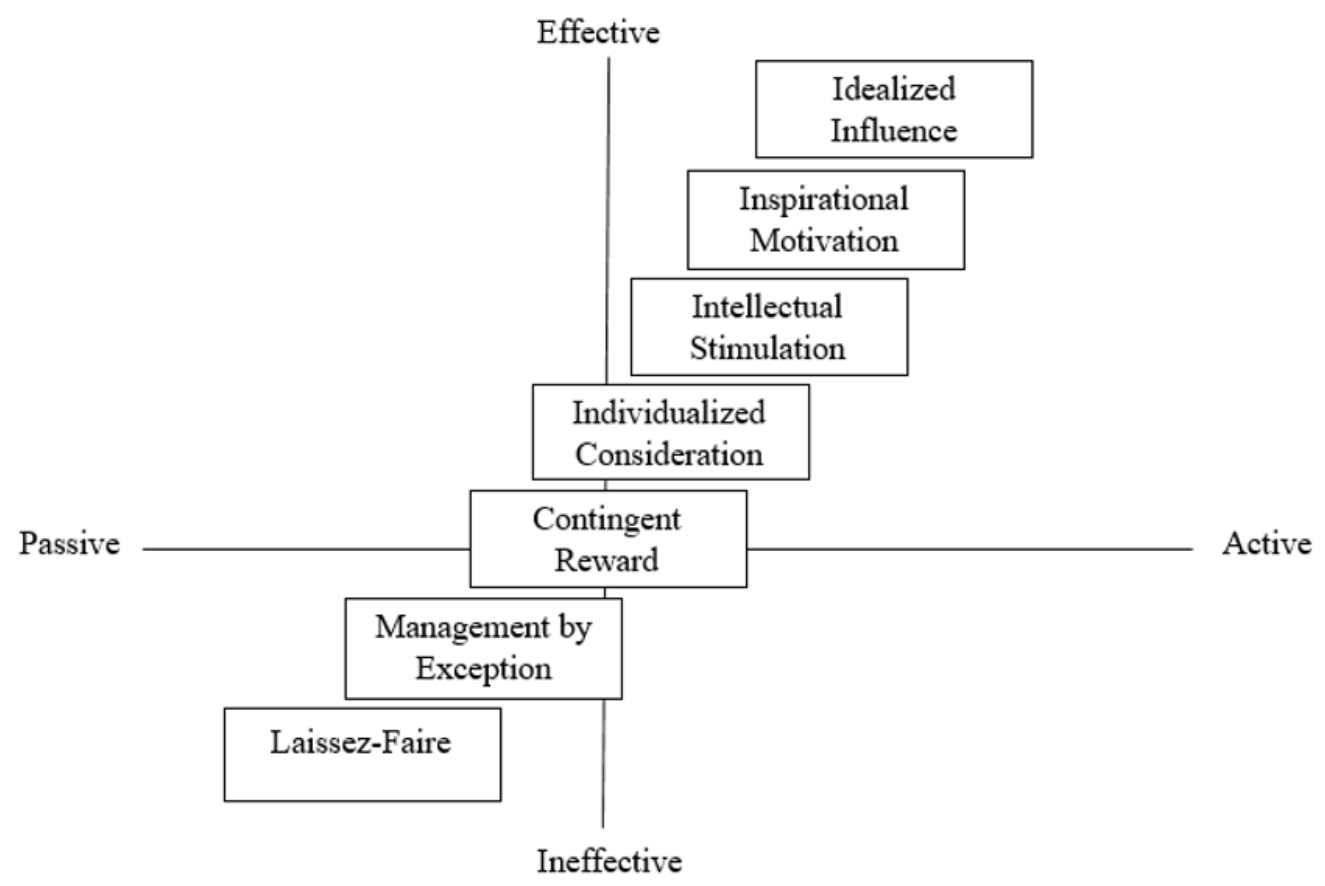

Transformational Leadership

Transformational leadership is defined as a process that changes and transforms individuals (Northouse, 2004, p. 169). Transformational leaders empower employees to achieve deep and essential change, and provide profound levels of relations and contact. Employees have much higher levels of performance, commitment, and morality to the leader and organization under transformational leadership as opposed to transactional leadership (Burns, 1978), because the idea of transformational leadership is that you push employees to perform beyond what they should achieve merely to finish a transaction, but to serve a greater cause (Braun, Peus, Weisweiler, \& Frey, 2013). The basis of many transformational leadership traits can be found in a leader's intention and ability to 
transform the hearts and minds of employees to achieve higher levels of motivation and performance (Park, 2015).

In 1985, Bass applied his transformational leadership theory to business settings in his research of industrial executives. Bass incorporated political science and organizational psychology to the concept of transformational leadership. In contrast to Burns' point of view, which was that leaders display either transactional or transformational behavior, Bass believed leaders demonstrate both transactional and transformational leadership behaviors, but in different amounts (Yahaya et al., 2016). Bass stated that leaders perform differently based on different situations. Transactional leadership behavior is more practical in day-to-day relationships with employees, and transformational leadership behavior is preferred when a leader needs to get an extraordinary level of commitment from employees (Snodgrass \& Shachar, 2008).

The transformational leadership model is divided into four dimensions: idealized influence, intellectual stimulation, individualized consideration, inspirational motivation (see figure 4). These four dimensions can help expatriate managers inspire local employees to perform better, to adopt unfamiliar and international best practices, and increase local employee motivation and morale. 


\section{Figure 3.}

Transformational Leadership Model

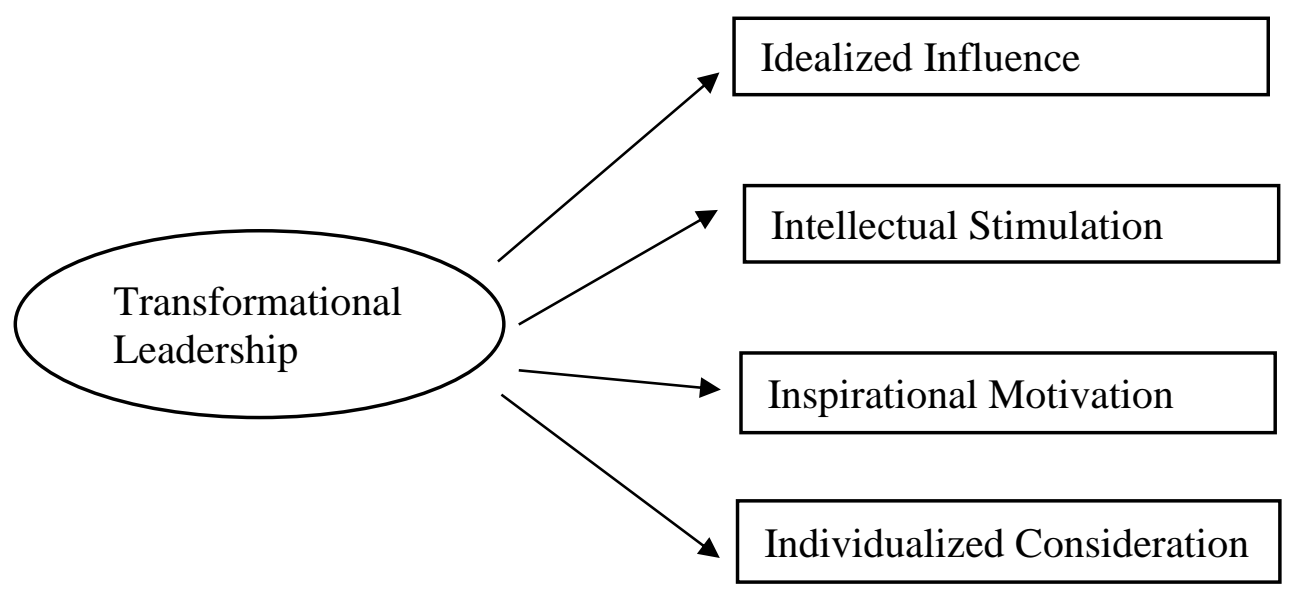

Idealized influence is associated with charisma, and a leader who can inculcate

faith, pride, and respect in followers and who gives a vision and a shared mission to a team through excellent communication (Hoffman \& Frost, 2006). Idealized influence leaders have the ability to communicate a clear vison and sense of purpose and arouse emotion that attracts followers with a high standard of ethical and moral conduct. Leaders with charisma consider followers' demands more than the leader's own demands (Bass, Avolio, Jung, \& Benson, 2003). A transformational leader is one who is purpose driven, leads by example and sets the expectations for followers to emulate. Through demonstrating the right behaviors, leaders gain the respect and trust from followers. The idealized influence type of transformational leader serves as a role model who have great self-confidence and self-esteem, which helps the leader gain full commitment from followers (Salem, 2015).

Intellectual stimulation characterizes a leader who advocates intelligence, rationality, and smart problem solving, and encourages followers to find innovative 
solutions to problems. These leaders encourage and facilitate learning for everyone in the team so that each teammate can be benefit from continuous improvement. Intellectual stimulation "arouses subordinates to challenge their own thinking and believes and to be creative in problem solving" - which leads to leaders pushing their teams to take extra steps in being innovative and creative in solving problems while participating in the decision-making process (Bass et al., 2003, p. 8). A key component for an intellectual stimulation type of transformational leadership style is the involvement and empowerment of followers in making decisions and working actively to solve problems.

Inspirational motivation is aimed at inspiring followers to go above and beyond and aim higher in surmounting challenges, solving problems, and working towards business objectives. These leaders do not tell or punish followers to do things, but inspire people. These leaders tend to communicate in a way that is easy to understand and can provide meaning to their followers (Salem, 2015). Inspirational motivation leaders articulate a vision in a way that motivates employees and establishes loyalty and commitment to the organization. Team spirit and inspiring members to go above-andbeyond are positive outcomes of the inspirational motivation type of transformational leader (Salem, 2015).

Individualized consideration refers to leaders who are people driven and typically act as mentors as part of their leadership style, which includes facilitating learning, improvement and empowerment. These leaders provide more personal attention to employees, treat each employee individually, and work to develop the employee's longterm interests (Hoffman et al., 2006). The individualized consideration type of 
transformational leader assists employees achieve higher-level of potential successfully (Park, 2015).

Strong leadership can improve employee satisfaction in the workplace by motivating employees to overcome challenges and obstacles and focus on achieving results (Northouse, 2007). In particular, transformational leadership is one of the most important factors influencing employee job performance (Kirkman, Chen, Farh, \& Lowe, 2009). Transformational leadership motivates employees to go beyond their own selfinterest to achieve high levels of performance (George \& Jones, 2012; Uhl-Blen, 2010), for example working extra hours, going the extra mile to accomplish work goals, and helping other team members.

Because transformational leadership has been shown to be positively related with subordinates' commitment and satisfaction, managers could use transformational leadership traits to increase their organization's performance (Park, 2016). For example, by helping employees understand the underlying goals of an organization, transformational managers can push employees to think more creatively or be more involved in voluntary tasks that help push the organization forward. Transformational leaders can help employees better prepare to deal with short-term setbacks and keep team morale high. In addition, if transformational leadership can be taught to individuals at all levels within an organization, it can positively affect a firm's performance (Bass, 1990).

\section{Transactional Leadership}

Transactional leadership involves the exchange of value between leaders and followers (Burns, 1978). The exchanged value can be economic, political or psychological, but is built on the agreement and understanding between the leader and 
employee on what the requirements, rewards, and potential punishment are (Burns, 1978). Both parties have related purposes, but the relationship does not go beyond the exchange of valued benefits - to put simply, the leader and follower are not necessarily friends and do not necessarily inspire each other to go above-and-beyond what is required (Washington, 2007). Transactional leadership style is typically dependent on hierarchical authority, rewards and punishment - followers are typically motivated by the exchange or rewards of the job and not through being inspired, exceptionally dedicated or committed (Avolio \& Bass 2002).

Two factors of transactional leadership are (a) contingent reward and (b) management-by-exception (Bass, 1990). Contingent rewards are rewards that are dependent on meeting pre-determined or assumed requirements, and are incentives used to impact a follower's motivations. These contingent rewards can be salary, bonuses, promotions or any other item of value that can be exchanged. Leaders distribute these rewards when followers meet their expectations. Leaders and followers typically begin with a negotiated agreement regarding the expectations of performance and appropriate motivating rewards. Transactional leaders use contingent rewards to get followers to accomplish work goals (Avolio et al., 2002).

Management-by-exception can be broken up in two different styles; that is, active and passive. Active management-by-exception involves the leader actively monitoring their followers' job performance, looking for errors and correcting those errors. These active managers take the initiative to observe followers' behavior to correct them. Passive management-by-exception involves a leader waiting for problems to come up 
before attempting to solve them - these leaders step in when their reports or followers make mistakes on the job.

\section{Laissez-faire Leadership}

Laissez-faire leadership is also known as delegative leadership, in which the leader avoids decision making, disregards problems, and provides no follow-up. Typical laissez-faire leaders will offer basic assistance to their followers and then allow them full responsibility to fulfill the obligations. The laissez-faire leader believes in maximizing employees' ability to make choices; however, there is no initiative to give directions or interact with employees. However, the laissez-fair leadership style is not necessarily ideal where team member either lack knowledge or experience to make decisions and complete tasks. Furthermore, because laissez-faire leaders are typically passive and do not actively seek to rally or direct their team, laissez-faire leadership style can lead to withdrawn, uninvolved or unmotivated team members (Skogstad, Einarsen, Torsheim, Aasland, \& Hetland, 2007). The feedback and leader involvement are missing during the leadership process (Yahaya et al., 2016).

Of the three leadership types, transformational leadership factors appear most positively correlated with employee job satisfaction. For example, Erkutlu (2008) examined the impact of three different leadership behaviors (transformational, transactional, and laissez-faire) on the job satisfaction of 662 employees from 60 boutique hotels. Study indicated that all the transformational leadership factors (idealized influence, inspirational motivation, intellectual stimulation and individualized consideration) were positively correlated with employee job satisfaction, as was contingent reward transactional leadership. However, laissez-faire leadership $\left(R^{2}=-.02\right)$ 
and transactional leadership-management by exception (passive) $\left(R^{2}=-.07\right)$ were negatively linked to employee job satisfaction. See Table 1 for specific regression coefficients.

Table 1

Erkutlu (2008) Hierarchical Regression Analyses for Transformational Leadership and Employee Satisfaction with Work

Variables $R^{2}$ value

Transformational leadership - Idealized influence (attributed) $.02 * *$

Transformational leadership - Idealized influence (behavior) $.05 * * *$

Transformational leadership - Inspirational motivation $.02 *$

Transformational leadership - Intellectual stimulation $.02 * * *$

Transformational leadership - Individualized consideration $.04 * * *$

Transactional leadership - Contingent reward $.04 *$

Transactional leadership - Management by exception (active) .00

Transactional leadership - Management by exception (passive) $-.07 * * *$ Laissez-faire leadership $-.02 * *$ Note. $* p<.05 ; * * p<.01 ; * * * p<.001$

The Erkutlu (2008) study provides evidence that transformational leadership in management is positively correlated with positive outcomes in the hospitality industry. Leaders use various leadership styles to lead and manage employees to get things done in an organization. In another study, Hoffman et al. (2006) examined the influence of leadership behaviors on both organizational and leader effectiveness at boutique hotels. Both Erkutlu (2008) and Hoffman et al.'s (2006) studies demonstrated that leaders should 
strive to inspire and motivate employees, as well as pay attention to each employee's personal growth and individual needs. Creating a supportive organizational climate, recognizing individual differences in terms of needs and desires, and encouraging twoway opinions are examples of transformational leadership behaviors that are relationshiporiented (Erkutlu, 2008).

Given the labor-intensive nature of the hospitality industry and the turbulent conditions it now faces, transformational leadership may be significant for long-term organizational success (Thamrin, 2012; Tracey \& Hinkin, 1994). Hospitality leaders must develop a strong sense of vision to communicate organizational goals with employees and create a working environment that raises motivation, commitment and constant development (Tracey et al., 1994).

\section{Measuring Transformational Leadership}

The Multifactor Leadership Questionnaire Form (MLQ), developed by Bass and Avolio (1989), is a standard and validated instrument for assessing transformational leadership scales (Bass \& Avolio, 2004). Transformational leadership is measured by four variables: idealized influence, inspirational motivation, intellectual stimulation, and individualized consideration (Bass \& Avolio, 1989). In 2009, Munyanyiwa specifically studied best leadership practices conducted by the top international hotel firms, utilizing MLQ to measure the performance of expatriate managers. The average scores for leaders in top international hotel firms scored from 3.25 to 3.36 with a standard deviation from .48 to .60 .

In 1990, Podsakoff et al. introduced another tool to measure transformational leadership. The tool is a 23 -item instrument designed to measure six dimensions of 
transformational leadership: 1) identifying and articulating a vision, 2) being or providing a role model 3) fostering the acceptance and collaboration toward group goals, 4) having high performance expectations, 5) providing individualized support, and 6) affording intellectual stimulation. These six transformational leadership behaviors are measured with an adapted version of a 5-point Likert scale ranging from 1 (not at all) to 5 (frequently), where respondents judged how frequently their leaders displayed specific leadership behaviors (Park, 2016).

The Transformational Leadership Skills Inventory (TLSi) is another tool to evaluate expatriate leaders. A comprehensive literature review by Larick and White (2012) identified ten common themes from educational and business settings to provide a holistic view of transformational leadership. Furthermore, according to that literature, review, the TLSi provides a comprehensive framework of transformational leadership (Larick \& White, 2012), and applies to both business and educational organizational settings (Avila, 2016). The component of the TLSi includes, visionary leadership, communication, problem solving and decision making, interpersonal skills, collaboration, diversity and creativity (Larick \& White, 2012). But TLSi has not specifically been explored on expatriate leadership performance.

Expected Relationship between Organizational Justice and Employee Job

\section{Satisfaction}

Studies have indicated that employee job satisfaction has a relationship with perceptions of organizational justice. Typically, organizational justice is positioned as a predictor of job satisfaction and the literature seems clear that indeed it does. Yet, it is entirely possible that job satisfaction can be a significant predictor of organizational 
justice (Cohen-Charash \& Spector, 2001), which the researcher investigates in this research. Thus, if the employee is satisfied with his or her job, they would be more likely to have a positive sense of organizational justice.

In a literature review and meta-analysis conducted by Cohen-Charash \& Spector (2001), the authors found that job satisfaction had a notable correlation with distributive justice (mean weighted $r=.47, N=20,257$ ), procedural justice (mean weighted $r=.43, N$ $=27,437$ ) and interactional justice (mean weighted $r=.41, N=2,337$ ). The authors noted also that "Counterproductive and withdrawal behaviors should be related to all three forms of justice $[\ldots]$ can be seen as reactions to perceived injustice, when an employee changes his/her input to restore equity" (Cohen-Charash \& Specter, 2001; Greenberg \& Scott, 1996), and indicated that "from a procedural justice perspective, perceived injustice will lead to negative perceptions of the organization and, hence, to counterproductive behaviors that will hurt the organization" (Charash \& Specter, 2001).

There are several studies that show that negative attitudes and emotions could lead to negative actions against the organization from discontented employees (Dailey \& Kirk, 1992; Skarlicki \& Folger, 1997). More recently, Shiang-Lih et al. (2010) examined a structured model of how organizational justice (both distributive justice and procedural justice) is related to employee job satisfaction. The study focused on the casino industry and 37 casino employees were interviewed, with results showing that both distributive justice $(\beta=.54, p<.01)$ and procedural justice $(\beta=.51, \mathrm{p}<.01)$ having a positive relationship with job satisfaction. Shiang-Lih et al. (2010) concluded that job satisfaction accounted for $52 \%$ of perception of distributive justice and procedural justice in their sample of casino industry employees. 


\section{Expected Relationship between Employee Job Satisfaction}

and Transformational Leadership

Transformational leadership has been shown to be related to individual outcomes (Braun, Peus, Weisweiler, \& Frey, 2013; Casimir, Waldman, Bartran \& Yang, 2006). Leadership is a multiple-level phenomenon by nature that occurs between leaders and followers (Chun, Yammarino, Dionne, Sosik, \& Moon, 2009). Multiple studies have explored transformational leadership's impact on employees (Casimir et al., 2006; Chun et al., 2009; Judge \& Piccolo, 2004). Employee perceptions of their leader's transformational leadership style is positively related to employee's job satisfaction in many studies (Braun et al., 2013; Judge \& Piccolo, 2004; Podsakoff, MacKenzie, \& Bommer, 1996).

Podsakoff et al. (1996) collected data from 1539 employees to measure their leader behavior, job attitudes, and role perceptions. The study results showed that one of the transformational leadership behaviors, individualized consideration, appears to be an important factor of employee role perceptions of their leader. Individualized consideration was defined by Walumbwa, Orwa, Wang and Lawler (2005) as a leader's ability to recognize and respond "to each individual's abilities, aspirations, and needs" (p. 238). Leaders with individualized consideration adjust their behaviors and relationships to each of their report's specific goals and interests (Chun et al., 2009).

Individualized consideration was found to be positively related to employee job satisfaction, trust in leader, self-reported effort, altruism, job performance and courtesy. Podsakoff et al. (1996) noted that employees who pe3rceive individualized consideration 
from their leaders generally trusted their leaders more, and were more satisfied on the job.

These ideas are supported by Braun et al. (2013), who explored the relationship between individual perceptions of supervisors' transformational leadership and individual followers' job satisfaction. A multilevel mediation model study had a total sample size of 360 employees from a large German research university. Supervisors were professors from leading research laboratories at the university. Employees were PhD students, postdocs, and non-scientific personnel. The study showed that employee job satisfaction was positively related to employee perception of supervisor transformational leadership performance $(r=.73, p<.01)$, and further supported the idea that individual followers' job satisfaction was also positively related to team perceptions of supervisor transformational leadership $(r=.64, p<.01)$. Therefore, for the current research, it was hypothesized that degree of employee job satisfaction would be positively related to employee perceptions of expatriates' transformational leadership performance.

Social Exchange Theory

Social Exchange Theory (SET), developed by Thiabaut and Kelley in 1959, is a theory that attempts to explain and understand human interactive behaviors (Blau, 1964) and is based on the assumption that people are selfish and that each person calculates the expected payoffs from each of their interactions and exchanges (Igwebuike, 1998). These exchange relationships are made following the presumption that people depend on each other and also that no individual is expected to provide services without a return. The SET emphasizes that self-interest is a fundamental focus in interactions and social exchange, and that people's satisfactions are grounded in their relationships and 
interactions with others (Igwebuike, 1998). For example, interactions that are exchanged include smiles, greetings, handshakes, and compensation (Igwebuike, 1998). In most situations, according to SET, rewards can only be achieved through interactions based on social exchange.

Social exchange theory serves as a leading model in understanding workplace behavior (Blau, 1964), and also serves as an explanation to how exchange relationships develop and grow due to expectations of further and continued rewards (Blau, 1964). There are two primarily social exchange relationship types that develop in organizations: a) a leader-member exchange; and b) an employee-organization exchange (Settoon, Bennett, \& Linden, 1996). The leader-member exchange indicates that in an ideal relationship, the leader should develop differentiated relationships with employees that is dependent on employee personalities and contributions to strengthen their relationships (Chan et al., 2011). The expected outcomes of positive leader-member exchanges include: high respect, mutual trust, and more dependable mutual obligations. Low-quality leader-member exchanges are dependent simply on the terms of the employment contract between the leader and member (Hogg et al., 2005).

When employees believe that they are supported by their leaders and organization then SET posits that employees should be more engaged in their roles and responsibilities due to interactions that generate mutual obligations (Blau, 1964). Expatriate leaders who are able to take advantage of higher-quality leader-member exchange interactions with their reports should have employees that indicate higher levels of job satisfaction. 


\section{Organizational Justice and Social Exchange Theory}

Social exchange theory is linked to the perceptions of organizational justice. To date, organizational justice researchers have primarily focused on social exchange relationships versus economic exchange relationships. There are more studies focused on procedural justice and interactional justice and SET than on distributive justice and SET (Masterson, Lewis, Goldman, \& Taylor, 2000).

In a retail and food service industry, Roche \& Shanock (2006) found the quality of leader-employee relationships were positively linked with interactional justice ( $\beta$ $=.49, p<.05)$. Furthermore, the quality of leader-member exchanges were not as impacted by concepts of distributive justice $(p>.05)$, as was pay satisfaction $(\beta=.66, p$ $<.05)$ (Roche \& Shanock, 2006). These results were confirmed by Chan and Jepsen (2011), who concluded that distributive justice was not related to the quality of leadermember exchanges $(\beta=.01, p>.05)$, but related to employees' job satisfaction $(\beta=.49, p$ $<.01)$. Distributive justice focuses on economic return, and is primarily an economic relationship, not a social relationship. Study (e.g., Roche \& Shanock, 2006) showed that procedural justice $(\beta=.27, p<.01)$ and interpersonal justice $(\beta=.24, p<.05)$ predicted the quality of leader-member exchanges, while informational justice did not $(\beta=.16$, $p>.05)$

Loi (2006) investigated employee perceptions of organizational support, social and economic exchange in organizations in China, and a strong pattern was found showing that distributive $(r=0.50, p<0.01)$ and informational $(r=0.53, p<0.01)$ justice were positively related to perceived organizational support. An even stronger correlation was noticed between social exchange and procedural justice $r=0.63, p<$ 
$0.01)$, social exchange and informational justice $(r=0.60, p<0.01)$, social exchange and distributive justice $(r=0.58, p<0.01)$. Finally, social exchange and perceived organizational support also indicated a positive relationship $(r=0.63, p<0.01)$ (Loi, 2006).

Job Satisfaction within Social Exchange Theory

Many studies have examined the effect of job satisfaction within a social exchange framework (e.g., Gerstner \& Day, 1997; Schriesheim, Neider, Scandura, \& Tepper, 1992; Schyns \& Croon, 2006). In a meta-analytic study, Gerstner and Day reviewed leader-member exchange theory and its relationship with overall job satisfaction, satisfaction with supervision, performance, commitment, turnover intentions, to name a few. Gerstner and Day reviewed and analyzed 164 published articles, doctoral dissertations, conference papers from 1975 to 1996 . Results showed that there was a significant relationship between the quality of leader-member exchange and satisfaction with supervisor $(r=.71, p<.05)$, and overall satisfaction $(r=.50, p<.05)($ Gerstner $\&$ Day).

Transformational Leadership within Social Exchange Theory

Social exchange theory is a theoretical foundation of transformational leadership (Park, 2015). Leadership is clearly a social psychological phenomenon that is rooted in social relations (Hogg et al., 2005). Blau (1964), in his classic work on social exchange and power, describes the transformational leadership as the exchange of heart, attitudes, and behavior between leaders and members. Transformational leaders look for ways to motivate subordinates and show consideration to individual concerns and affections. In exchange, subordinates respond by showing commitment to work and obligation. 
Successful transformational leaders are able to empower their followers and entrust their followers to take higher-level responsibilities and actions towards jobs and tasks. Followers tend to perform better when they consider their relationships with their leaders as going beyond a standard economic contract (Park, 2015).

\section{Cross-Cultural Management Issue in China's Hospitality Industry}

In an effort to increase shareholder value, corporations are continually trying to expand and grow. These growth initiatives create new challenges for managers of the organization, particularly when expansion and growth involves international markets (Selmer, 2000). Expatriate managers play an important role in navigating complex, multicultural business environments and achieving business results. Results in one country may not indicate what will happen in another, and even the most developed international corporations display biased tendencies.

In fact, studies indicate that culture and leadership practices differ from country to country, and are influenced by different ways of thinking, emotion and action (Causin, Ayoun \& Moreo, 2011). Because of these cultural differences, management practices, intentions, and results and consequences can also differ widely from country to country (Dong \& Liu, 2010). Expatriate managers from different countries and cultural backgrounds, may find that their actions and intentions in one country can impact the organization and workforce differently in another country, and should take this into account in their management practices (Causin et al., 2011).

Another area that expatriate managers need to navigate is language, which can have a significant impact on the organizational success (Munter, 1993). ChristensenHughes (1992) indicated that cross-functional communication within hotel departments 
suffer when managers and employees speak different languages. A 1993 study by Brislin indicated that an expatriate manager's willingness to learn the host country's language is more indicative of successful adjustment than actual fluency level of the language implying that an expatriate manager's effort to localize plays a significant role in a successful versus unsuccessful adjustment.

Corporations and expatriate managers need to be flexible in adapting managerial practices to different countries and cultures. In spite of the potential pitfalls of expatriation, Kobrin (1988) outlined four potential benefits of international assignments which include: 1) internationalization of staff, 2) facilitation of multi-country and multicultural communication, 3) increase in worldwide community throughout the corporation, and 4) development of worldwide corporate objectives.

Culture is a complex phenomenon when it comes to transformational leadership. Typically, the home country's cultural values and norms unconsciously or unintentionally become dominant (Causin et al., 2011), and are often taken for granted within the organization (Gasper, 1992). In an organization, leaders and subordinators should be aware of culture values and beliefs, to comminute idea freely without constrain. Expatriate managers should attempt to understand the local culture, and integrate positive organizational cultures to archive organizational goals (Gasper, 1992). There are many ways an expatriate manager can promote positive culture, for example promoting and rewarding employees with certain traits, skills, or values. In terms of setting organizational cultures that promote operational excellence, employees are an important asset (Gasper, 1992). The current study hopes to clarify linkages and relationships among 
variables in Chinese settings, and clarify the impact that expatriate managers have in leading organizations towards successful outcomes.

\begin{abstract}
Summary
Chapter 2 examined the literature surrounding the important Stages of Hospitality and Human Resource Development in China and the Importance of Human Resource Development in the Chinese Hospitality Industry. In addition, the current study discussed three key variables - organizational justice, job satisfaction and transformational leadership - and examined scholarly perspectives around those topics. Literature focusing on organizational justice, employee job satisfaction, transformational leadership and their measures were examined and discussed. Chapter 3 will discuss the method used in this study.
\end{abstract}




\section{CHAPTER III}

\section{METHOD}

\section{Purpose of the Study}

The purpose of this study is to investigate the relationship between organizational justice, job satisfaction, and expatriate leadership performance. To fill in this research gap, the purpose of this nonexperimental, quantitative method study will be to utilize local staff perspectives to examine organizational justice, job satisfaction and evaluate expatriate leadership performance.

\section{Research Questions and Hypotheses}

This study focuses on three research questions: (a) What is the relationship between employee job satisfaction and expatriate leadership performance? (b) What is the relationship between organizational justice and employee job satisfaction? and (c) Does organizational justice mediate the job satisfaction-leadership performance relationship? To explore these three research questions, three hypotheses were tested:

H1: There is a positive relationship between employee job satisfaction and employees' perceptions of the expatriate leader's job performance.

$\mathrm{H} 2$ : There is a positive relationship between organizational justice and employee job satisfaction.

H3: The relationship between job satisfaction and leadership performance will be mediated by organizational justice.

\section{Research Design and Data Collection}

This study builds upon previous research, theories, and concepts conducted on leadership and the hospitality industry in China. The present study will employ a 
nonexperimental ex post facto design. Nonexperimental quantitative research is an important tool for researches given that a variety of variables may not be difficult to manipulate in a controlled, experimental setting (Johnson, 2001). A randomized experiment was not utilized in the present case because of practical and ethical considerations in gathering meaningful and relevant data (Christ, 2007), and also because the scope of a random experiment goes beyond the goals of the study. Nonexperimental approaches for assessing independent variables, such as an ex post facto design, are widely used for the purposes of research and policy development, although it is important to utilize methodologies that minimize bias and interference (Wong \& Steiner, 2015).

In a nonexperimental exploratory design, the researcher can explore the links of independent variables to the dependent variables without the impact or control necessitated in an experimental design (Horn, Snyder, Coverdale, Louie, \& Roberts, 2009). Inferences of independent variables are generally made to predict dependent variables by utilizing independent variables. Nonexperimental exploratory studies are used for primarily practical considerations, for example lack of physical or ethical control over the independent variables (MacKinnon, Lockwood, Hoffman, West, \& Sheets, 2002). The goal of the current study is to uncover significant predictors for expatriate leadership, utilizing a nonexperimental exploratory research design.

In the present study, researcher began with a literature review to better frame our investigation. Next, the researcher conducted a pilot study to develop and test the adequacy of the research instruments and the feasibility of the study. After completion of the pilot study, researcher selected the sample and constructed a survey. The researcher emailed to the survey to target sample to finish. This process is similar to data collection 
process of Story et al.'s (2010), where they conducted a study that focused on innovative strategies for evaluating nursing education programs. Finally, the researcher will analyze the responses quantitatively.

A survey was utilized for data collection. A survey provides a quantitative description of opinions of a population by studying a sample of that population (Creswell, 2014). A survey was used because of its scalability - the effort to respond to a survey is minimal compared to other methods such as an in-person or video interview. Surveys also have the benefit of being able to be completed at the respondent's convenience. Respondents can also be located in different cities. Potential downsides of surveys are misinterpretation of questions, inaccurate responses, or response bias. Another consideration for surveys is that surveyors may also display biases in how they write questions.

The survey in the current study was developed to be short and to the point, easily understandable and efficient to get the most accurate responses and highest engagement from the participants. Each variable (employee job satisfaction, organizational justice, employees' perception of expatriate leadership performance) has been measured by different dimensions, and therefore, they are multidimensional. The variables contained in this study were found in the works of other researchers and scholars (Braun, Peus, Weisweiler, \& Frey, 2013; Graves, Sarkis, \& Zhu, 2013; Judge \& Piccolo, 2004; Kara, Uysal, \& Magnini, 2012; Khalilzadeh, Giacomo, Jafari, \& Hamid, 2013; Miller, Konopaske, \& Byrne, 2012; Onorato, 2013). 


\section{Population and Sample}

The target population of this study was local employees who work with expatriate managers in the hospitality industry in Mainland China. China was selected because it has become a leading expatriate destination (HSBC, 2012), in addition to being a popular destination for foreign direct investment and multinational corporate expansion (Leung et al., 2011). The sampling frame is from a cooperative program of two major universities in China and the U.S. All the graduates in this program major in hospitality management and a majority work in the hospitality industry after they graduate. However, a limitation of this frame is the inability to get information that relates to the entire hospitality industry.

\section{Variables and Research Instruments}

Items used in this survey were developed using instruments that have previously been tested, published, and generally accepted by scholars. The survey covers four areas: (1) transformational leadership, (2) organizational justice (3) job satisfaction, and (4) demographics. The demographic questions will include participants' gender, age, education, position, and years of experience. All the other survey questions will be scored using 5-point Likert scales: 1 (strongly disagree), 2 (disagree), 3 (neutral), 4 (agree), 5 (strongly agree). Each measurement tool has been extensively studied by other researchers but the validity with the current study's sample/population and the context in China will also be investigated. The instruments and reliability information for this study are provided below. 


\section{Organizational Justice}

In the present study, organizational justice was measured using the instrument developed by Niehoff and Moorman (1993). The scale is intended to measure distributive justice (5 items), procedural justice (6 items), and interactional justice ( 9 items) in the workforce. The measures used to determine distributive justice include assessments of work outcomes such as scheduling, payment, workload, rewards and responsibilities (Niehoff \& Moorman, 1993). The variables used to measure procedural justice include data gathering mechanisms (such as surveys) and whether or not they are biased, accurate and/or representative, and the structure of an appeal process (Niehoff \& Moorman, 1993). Items measuring interactional justice include determining whether employees felt respected by management, and whether or not work decisions were clearly and adequately articulated or explained (Niehoff \& Moorman, 1993). There are three subscales: distributive justice, procedural justice, interactional justice, with 5, 6, and 9 items, respectively. The items for each subscale are summed or averaged to attain a subscale score. The three subscale scores can be added to obtain an overall organizational justice score as well. The combined 20-item scale asks participants to respond along a 5point Likert continuum from 1 (strongly disagree) to 5 (strongly agree).

In addition, there is a history of prior research using this scale to measure organizational justice and this measure has been validated in a China context $(\mathrm{Fu} \&$ Zhang, 2012; Li, Wu, Johnson \& Wu, 2012; Wang, Liao, Xia, \& Chang, 2010), and in the hospitality industry (Aizzat Mohd. Nasurdin \& Soon, 2011; Shiang-Lih et al, 2010; Zehir, Akyuz, Eren \& Turhan, 2013). The Cronbach's alpha reliabilities were 0.905, 0.841 and 0.907 for distributive justice, procedure justice and interactional justice, 
respectively in a study that was conducted in China utilizing a field survey from a sample of 520 professional managers working in the manufacturing and service industries (Fu \& Zhang, 2012). Consequently, above study demonstrable history of validity and reliability indicates that the scale is also acceptable for this study.

\section{Job Satisfaction}

There are numerous studies to measure employee job satisfaction, such as the Job Descriptive Index (JDI), AJDI (abridged JDI), WAJDI (weighted abridged JDI), PJS (perceived job satisfaction), and MSQ (Minnesota Satisfaction Questionnaire). In this study, employee job satisfaction was measured using the MSQ. The MSQ was first adopted in 1967 and refined in 1985 to a shorter form. The MSQ is commonly used to investigate job satisfaction and has been used in a variety of occupations in professional, managerial, service, sales and trades (Birdsall, 1994). Because of its common usage, and to simplify the survey procedure for respondents, researcher will utilize a short-form MSQ for this study. The MSQ measures satisfaction in terms of working conditions, chances for advancement, feelings of accomplishment, freedom of judgment and so on. The 20-item scale includes two subscales of employee satisfaction: intrinsic (10 items) and extrinsic satisfaction (10 items). The items for each subscale are summed or averaged to attain a subscale score. The two subscale scores can be added to obtain an overall job satisfaction score. The MSQ used a 5-point Likert scale from 1 (extremely dissatisfied) to 5 (extremely satisfied), to measure employees' job satisfaction in the hospitality industry.

The MSQ is helpful in interpreting how employees feel about their work environment (Ge, Fu, Chang \& Wang, 2011), and a more reliable indicator of individualized employee job satisfaction than using general measures of satisfaction such 
as the JDI (Van Saane, Sluiter, Verbeek, \& Frings-Dresen, 2003). Minnesota Satisfaction Questionnaire's reliability coefficients range from 0.8 to 0.9 (Weiss et al., 1967; Van Saane et al., 2003). This questionnaire is one of the most reliable and valid scales currently used by researchers worldwide to gather information associated with job satisfaction (Van Saane et al., 2003). Additionally, there is a history of prior research using the MSQ to measure employee job satisfaction and this measure has been validated in a China context (Chen, 2005; Chung, 2001; Lin, 2003; Pan, Shen, Liu, Yang, \& Wang, 2015), and in the hospitality industry (Kara, Uysal, \& Magnini, 2012). This demonstrable history of validity and reliability indicates that the scale is also acceptable for this study.

\section{Transformational Leadership}

To measure the leadership performance of expatriate managers, this research utilized an instrument that is undergirded by transformational leadership theory. For this study, how local employees perceive expatriate leadership behavior will be measured using scales adapted from the Multifactor Leadership Questionnaire Form (MLQ), developed by Bass and Avolio (1989). The MLQ is now a standard instrument for assessing transformational leadership and has been validated (Bass \& Avolio, 2004). The transformational leadership was measured by four subscales: idealized influence (6 items), inspirational motivation (6 items), intellectual stimulation (6 items), and individualized consideration (5 items) (Bass \& Avolio, 1989). The combined 23-item scale asks participants to respond along a 5-point Likert continuum from 1 (strongly disagree) to 5 (strongly agree). The items for each subscale are summed or averaged to attain a subscale score. The four subscale scores can be added to obtain an overall transformational leadership score as well. 
Additionally, there is a history of prior research using the MLQ to measure managers' transformational leadership performance, which has also been validated in a Chinese context (Shieh, Mills, Mary Etta, Waltz \& Carolyn, 2001; Sik Cho \& Jung, 2014), and separately in the German hospitality industry (Erkutlu, 2008; Rothfelder et al., 2012; Salem, 2015). The $\alpha$ reliabilities were $0.92,0.73,0.79$ and 0.89 for idealized influence, inspirational motivation, intellectual stimulation, and individualized consideration, respectively (Rothfelder et al., 2012). This history of validity and reliability in Chinese and international contexts indicates that the scale is acceptable for this study.

\section{Data Collection}

The primary method to collect data is using of a web-based survey, which was distributed via a mobile questionnaire tool. A mobile questionnaire is a questionnaire completed by participants on any mobile device such as a smartphone or a tablet (Van Heerden, Norris, Tollman, Stein, \& Richter, 2014). Users are also able to use the link to complete the survey on a computer. WeChat, a Chinese social network with approximately 900 million users predominantly in China, was used to distribute the survey. Almost all targeted alumni were organized in an existing group chat. The process is similar to Story et al. (2010) who used the social network Facebook to reach their targeted population.

First, the director of career services for the Florida International University and Tianjin University hospitality management cooperative program were contacted to obtain the program's alumni WeChat Group invitation link; intitation allowed the researcher access to join the alumni group chat. The contact included a suggested script to facilitate 
alumni help in reaching relevant survey participants. Second, alumni were contacted via a WeChat message with a survey link and asked to complete the survey. Third, each alumni was asked to recruit more participants who are not university program alumni by using their social networks. Therefore, there are two types of participants, alumni and other participants who are referred by alumni (Story et al., 2010).

There is a growing use of mobile devices to access the Internet, and consequently researchers are finding that using mobile-enabled communication channels are important forms of communicating with target populations, but also have different considerations (De Bruijne \& Wijnant, 2013). On the basis of previously completed studies, the mobile device response rate is around 18\% (Cunningham, Neighbors, Bertholet, Hendershot, 2013). Mobile device users are also less likely to respond to follow-up surveys compared to those using traditional web browsers (Cunningham et al., 2013). However, compared to participants that utilize traditional web browsers to access surveys, participants who regularly use mobile devices typically respond to surveys more quickly. Among all the participants who open the survey link from a mobile device, $93 \%$ of survey participants submitted the completed survey within one minute of initial access (Cunningham et al., 2013).

\section{Internet-Based Surveys}

Internet-based surveys have been utilized since the 1990s (Schonlau et al., 2001) to collect data. Strengths include global reach, cost, flexibility, speed and timeliness, and convenience (Evans \& Mathur, 2005). As a result of the inconvenience and cost of going to China to collect data, an internet-based survey was determined to be the most efficient way to collect data. Survey results are a vital source of data to investigate expatriate 
leadership performance from the eyes of subordinates and gain new insights into how performance might be improved in the future.

In today's management and leadership development practices, specific tools are often used to evaluate the effectiveness of leadership. Accurate measurement techniques assist in evaluation, validation and comparative study. A professional survey website named "Wenjuanxing" was used and survey results were downloaded to SPSS directly. The specific survey link was sent through WeChat. "Wenjuanxing is a Chinese survey website (https://www.wjx.cn/), where participants can read the consent form and privacy statement on the first page without signing names since the survey is anonymous (Zhan, Sun, Wang, \& Zhang, 2016).

\section{Internet-Based Self-Report Surveys}

Self-administered surveys were used in the study. The survey methodology is an effective way to obtain a great amount of information from a large population and an accurate method of collecting and assessing information (Couper, 2000). A cover letter was emailed out to encourage each respondent to provide truthful and reliable information. The cover letter and online survey was translated to Mandarin Chinese because this is the native language of the target population. A few steps were taken to make sure the translation was accurate. First, an English survey was designed (Lin \& Chang, 2003). Second, a native Mandarin and proficient English speaker was asked to translate the survey from English to Mandarin (Lin \& Chang, 2003). Third, another person proficient in both languages translated the Chinese survey back to English to compare with the original version (Lin \& Chang, 2003). 


\section{Potential for a High Non-Response Rate}

Internet-based surveys have advantages in terms of cost and speed of data collection and data entry compared with conventional surveys using face-to-face or telephone interviews (Heiervang \& Goodman, 2011). However, there are drawbacks such as typically a low response rate and a high incompletion rate (Heiervang et al., 2011), which can lead to nonresponse bias (Parks, Pardi, \& Bradizza, 2006). Another nonresponse reason is the failure to deliver the survey request (Groves et al., 2009). A failure to send out the survey request will contribute to a higher nonresponse rate. Additionally, respondents who lack willingness or motivation to disclose the information solicited will be another cause of nonresponse (Groves et al., 2009). For the purposes of the present study, researcher targeted a $25 \%$ response rate based on the rates of similar studies (Cunningham et al., 2013). To achieve a meaningful number of responses, the survey link was sent to a few alumni WeChat groups with a combined alumni of over 1,300. We collected data over three collection periods, with 10 days in between administrations of the survey (Hoonakker, \& Carayon, 2009).

\section{Survey Procedures and Design Method}

The local hotel employees in this study are of Chinese nationality and have grown up in China. A pilot study was conducted before sending the survey email. A pilot study is helpful for developing and testing the adequacy of the research instruments and assessing its administration feasibility. Then, an internet-based survey was emailed to all the alumni to complete. An internet survey is able to reach larger numbers of potential respondents (Hwang \& Fesenmaier, 2004). A sample size of approximately 300 
participants was sought to strengthen statistical power and reduce the likelihood of Type II error (Schielzeth \& Forstmeier, 2009).

Dillman's Tailored Design Method will be integrated throughout the survey procedures (Dillman, Smyth, \& Christian, 2009). The Tailored Design Method (TDM) is an approach to designing surveys that was initially developed in the early 1970s to develop mail and telephone surveys. Dillman's tailored design method emphasizes paying attention to the entire survey and questionnaire experience, with the idea that a three-part focus on reducing cost, increasing benefits, and generating trust would maximize response rates to make the cost-benefit consideration of respondents more compelling. In the present research, the following specific TDM procedures were employed (Dillman et al., 2009). At the beginning, researcher obtained permission from the FIU dissertation committee members and the IRB (\#106953). After permission was granted, the researcher prepared the survey for distribution. To prepare the survey for distribution, there were several TDM steps to follow. First, the survey was reviewed by knowledgeable colleagues: the researcher's major advisor and committee members. Their expertise provided valuable insights and helped the researcher refine the survey. Second, a pilot study was conducted. The pilot study helped develop and test the adequacy of the research instruments and assessing its administration feasibility. As the last step, a final check of survey was done by researcher. The researcher finalized all changes and also sought the advice of someone not involved in the study to review the instrument for missing information (Dillman et al., 2009).

An interval-scheduling framework was used to make initial contact, administer the survey, and send follow-up reminders to participants for scheduling purposes 
(Dillman et al., 2009). Table 2 introduces the scheduling framework based on the

Tailored Design Method (Dillman et al., 2009).

Table 2

Scheduling Framework

Time Frame

Action

First time

Pre-notification WeChat message for invitation

5 days after initial WeChat survey message

First WeChat survey message sent

15 days after initial WeChat survey message

Second WeChat survey message sent

25 days after initial WeChat survey message

Third WeChat survey message sent

Conclusion of survey

Thank you WeChat message sent

According to Dillman et al. (2016), in a TDM framework, the researcher should send a pre-notification WeChat message to the participant and invite them to participate in the study. To maximize the survey response rate and draw maximum attention, the survey link was sent out three times to the university program alumni WeChat group. Five days after the initial WeChat message, the researcher sent the first WeChat survey message, with accompanying web-link. Fifteen days after the initial WeChat survey message, the researcher sent the second WeChat survey message. Twenty-five days after the initial WeChat survey message, the researcher sent the third and final WeChat survey message. All WeChat survey messages included a confidentiality notice and instructions to complete the survey. The second and third survey message links included a precaution message to remind participants not to take the survey again if they already filled it out before to reduce duplication. 
The survey used the survey tool "wenjuanxing." Each survey was assigned a different URL address linked to the survey instrument by the researcher. After participants submitted the completed survey, the data results were recorded in an electronic file that only the researcher could access. The collected electronic file did not include any information related to personal information, so participant confidentiality was assured.

Participant responses will not be shared with any member of the participating organization. All the collected data were downloaded and saved on Google drive for the further analysis. Data will be kept for five years from the completion of the study.

\section{Steps Taken to Reduce the Non-Response Rate}

Survey design has been shown to impact response rate. For the purposes of the present study, researcher minimized the length and quantity of questions as well as simplified questioned complexity to be more respondent friendly. An experimental study of alternatives to the current U.S. decennial census questionnaire shows that shortening the questionnaire and a respondent friendly questionnaire design improves response rate (Dillman, Sinclair, \& Clark, 1993). The study showed three potential influencers on survey response rates, including: (1) questionnaire length, (2) respondent friendly survey design, and (3) asking a possibly hard question (Dillman et al., 1993).

The survey was designed to be easy to read and complete, with minimal potential points of confusion about how to answer, and utilized a design that maximized survey awareness and minimized respondent burden (Crawford, McCabe, Couper \& Boyd, 2002). To achieve this purpose, cognitive interviews were conducted to evaluate the length of the survey and determine whether the survey is a respondent friendly design. 


\section{Data Analysis}

All quantitative data was entered into the SPSS Database and examined for statistically significant relationships utilizing correlations. The mediation path analysis was conducted using AMOS. AMOS is a statistical software that is used in latent variables and structural equation modeling (Keith, 1993). The program AMOS covers a variety of types of models that include exploratory and confirmatory factor analysis, regression, and path analysis (Naftchi-Ardebili, 1988). In the present study, all the variables were continuous. The independent variable for the current study was employee job satisfaction. The dependent variable was expatriate leadership performance and the mediator variable organizational justice.

H1: There is a positive relationship between organizational justice and employee job satisfaction.

To test H1, a correlational analysis was conducted to test the link between organizational justice and employee job satisfaction. The resulting correlation coefficient indicated the strength and direction of the linkage between these two variables.

H2: There is a positive relationship between employee job satisfaction and employees' perceptions of the expatriate leader's job performance.

To test $\mathrm{H} 2$, a correlational analysis was conducted to test the link between employee job satisfaction and employees' perception of the expatriate leader's job performance. The resulting correlation coefficient indicated the strength and direction of linkage between these two variables.

H3: The relationship between job satisfaction and leadership performance will be mediated by organizational justice. 
To test H3, a mediation model analysis was conducted. Sobel's test will be performed to examine if the relationship between employee job satisfaction and employees' perception of the expatriate leader's job performance has been significantly reduced after inclusion of organizational justice (Sobel, 1982). This test assesses whether organizational justice has a significant mediation effect.

\section{Summary}

Chapter 3 detailed the research processes including the research design, population and sample, variables and instrument, data collection in the present study. Chapter 4 will present detailed findings. 


\section{CHAPTER IV}

\section{RESULTS}

This chapter presents the results of the study and is organized into three main sections: background of the sample, examination of the hypotheses, and a brief summary of the chapter. To examine the hypotheses, correlation and path analysis/structural equation modeling were used to test the hypothesized model of the relationship between organizational justice, job satisfaction, and expatriate leadership performance.

\section{Background of the Sample}

Two hundred and eighty-three respondents participated in this study. The participants' demographic information including gender, years worked in the hospitality industry, position level in hotel, overall satisfaction to expatriate manager leadership performance, and satisfaction level with job in the hospitality industry, are examined in the following sections.

Gender and Years Worked in the Hospitality Industry Approximately 64\% $(n=182)$ of the sample was female and $36 \%(n=101)$ of the sample was male. A frequency analysis of years worked in the hospitality industry indicated that $8.5 \%(n=24)$ of the respondents reported working in the hospitality industry 1-2 years, $45.9 \%(n=130)$ of the respondents reported working in the hospitality industry 3-5 years, $45.6 \%(n=129)$ of the respondents reported working in the hospitality industry 6-10 years, and no respondent reported working in the hospitality industry over 10 years. 


\section{Position Level in Hotel}

Question three asked respondents to choose a term that best described their position within the organization they currently work. A frequency analysis indicated that $3.5 \%(n=10)$ indicated they were frontline employees, $20.1 \%(n=57)$ were back office employees, $27.2 \%(n=77)$ were supervisors, $39.9 \%(n=113)$ were managers/Assistant Managers, and 9.2\% $(n=26)$ were at a Director/Assistant Director level.

Table 3 provides a frequency table of all demographic variables examined in this study.

Table 3

Frequency Table of Demographic Variables

\begin{tabular}{|c|c|c|c|}
\hline Category & Variable & $f$ & Percent \\
\hline \multirow[t]{2}{*}{ Gender } & Male & 101 & 35.7 \\
\hline & Female & 182 & 64.3 \\
\hline \multirow[t]{4}{*}{ Years } & $1-2$ years & 24 & 8.5 \\
\hline & $3-5$ years & 130 & 45.9 \\
\hline & $6-10$ years & 129 & 45.6 \\
\hline & Over 10 years & 0 & 0 \\
\hline \multirow[t]{5}{*}{ Positions } & Front-line & 10 & 3.5 \\
\hline & employee & 57 & 23.7 \\
\hline & Back-office & 77 & 27.2 \\
\hline & employee & 113 & 39.9 \\
\hline & Supervisor & 26 & 9.2 \\
\hline
\end{tabular}


Manager

Director

\section{Examination of Hypotheses}

The first two hypotheses were tested using correlational and regression analyses. The third hypothesis was tested through structural equation modeling. Before testing the model, underlying assumptions about correlational and structure equation modeling analysis techniques were examined. Two conditions examined are multicollinearity and linearity. (Hinkle et al., 2005). Underlying implications from the three conditions examined may make inferences drawn from the results of this study untrustworthy, and were thus carefully reviewed.

\section{Multicollinearity}

Multicollinearity can result when variables are correlated to such an extent that reliable estimates of individual regression coefficients are difficult to extract (Cohen \& Cohen, 1983). Two highly correlated variables can indicate that the same phenomenon or construct is being measured -- in addition to increasing the standard error of beta coefficients and potentially negating the utility of assessing the roles of predictor variables (Green \& Salkind, 2005; Tabachnick \& Fidell, 2001). This potential error can be mitigated by removing or combining variables with a correlation greater than 0.90 (Green, 1991). In this study, intercorrelations were checked and no correlation between predictor variables was found to be greater than .90 . 


\section{Linearity}

Linearity inherently assumes a linear relationship between independent and dependent variables (Cohen \& Cohen, 1983). Bivariate scatterplots can be used to indicate linearity (Green, 1991). An examination of bivariate scattterplots in this study indicated linear lines, and implying no violations of linearity.

Measures

Table 4 presents the Means and Standard Deviations for the questionnaire items measuring all variables, along with the reliability of the items measuring the latent variables. Reliability estimates ranged from good (Cronbach's $\alpha=.82$ ) to excellent (Cronbach's $\alpha=.92$ ).

The first variable, distributive justice, was measured with 5 items on a 1-5 Likert scale with 1 being "strongly disagree" and 5 being "strongly agree." The reliability among the items was high (Cronbach's $\alpha=.84)$.

The second variable, procedural justice, was measured with 6 items on a 1-5 Likert scale with 1 being "strongly disagree" and 5 being "strongly agree." The reliability among the items was high (Cronbach's $\alpha=.92)$.

The third variable, interactional justice, was measured with 9 items on a 1-5 Likert scale with 1 being "strongly disagree" and 5 being "strongly agree." The reliability among the items was high (Cronbach's $\alpha=.95)$.

The fourth variable, intrinsic satisfaction, was measured with 10 items on a 1-5 Likert scale with 1 being "strongly disagree" and 5 being "strongly agree" The reliability among the items was high (Cronbach's $\alpha=.87)$. 
The fifth variable, extrinsic satisfaction, was measured with 10 items on a 1-5

Likert scale with 1 being "strongly disagree" and 5 being "strongly agree." The reliability among the items was high (Cronbach's $\alpha=.88)$.

The sixth variable, idealized influence, was measured with 6 items on a 1-5 Likert scale with 1 being "strongly disagree" and 5 being "strongly agree." The reliability among the items was high (Cronbach's $\alpha=.83$ ).

The seventh variable, inspirational motivation, was measured with 6 items on a 15 Likert scale with 1 being "strongly disagree" and 5 being "strongly agree." The reliability among the items was high (Cronbach's $\alpha=.91)$.

The eighth variable, intellectual stimulation, was measured with 6 items on a 1-5 Likert scale with 1 being "strongly disagree" and 5 being "strongly agree." The reliability among the items was high (Cronbach's $\alpha=.86)$.

The ninth variable, individualized consideration, was measured with 6 items on a 1-5 Likert scale with 1 being "strongly disagree" and 5 being "strongly agree." The reliability among the items was high (Cronbach's $\alpha=.82)$.

In summary, the reliability of the items measured by Cronbach's $\alpha$ range from .82 to 95 , which ranks from acceptable to excellent.

Table 4

Scale Reliability Scores and Means/Standard Deviations of Questionnaire Items

\begin{tabular}{llcc}
\hline Variables & \multicolumn{1}{c}{ Items } & Mean & $S D$ \\
\hline Distributive & My work schedule is fair & 3.18 & .84 \\
justice & I think that my level of pay is fair & 2.43 & .99 \\
$(\alpha=.84)$ & & 2.96 & .86 \\
\hline
\end{tabular}




\begin{tabular}{|c|c|c|c|}
\hline & I consider my work load to be & 3.08 & .81 \\
\hline & quite fair & & \\
\hline & Overall, the rewards I receive here & & \\
\hline & are quite fair & 3.34 & .77 \\
\hline & I feel that my job responsibilities & & \\
\hline & are fair & & \\
\hline Procedures & Job decisions in an unbiased & 3.47 & .78 \\
\hline justice & manner & 3.37 & .68 \\
\hline$(\alpha=.92)$ & Employee concerns are heard & 3.33 & .74 \\
\hline & Collects accurate and complete & 3.54 & .75 \\
\hline & information & 3.54 & .94 \\
\hline & Clarifies decision & & \\
\hline & Job decisions are applied & 339 & 82 \\
\hline & consistently & אנ. & .02 \\
\hline & Allow to challenge job decisions & & \\
\hline Interactional & Treat me with kindness & 3.46 & .75 \\
\hline justice & Treat me with respect & 3.66 & .59 \\
\hline$(\alpha=.95)$ & Sensitive to my personal needs & 3.42 & .67 \\
\hline & Truthful manner & 3.63 & .59 \\
\hline & Shows concern & 3.62 & .72 \\
\hline & Discuss the implication & 3.66 & .68 \\
\hline & Offer adequate justification for & 3.67 & .71 \\
\hline & decisions & 3.64 & .67 \\
\hline & Offer explanations & & \\
\hline & Explains clearly decision made & 3.65 & .66 \\
\hline & about my job & & \\
\hline Intrinsic & Chance to make use of my abilities & 3.57 & .74 \\
\hline Satisfaction & Feeling of accomplishment & 3.64 & .74 \\
\hline$(\alpha=.87)$ & Keep busy all the time & 3.65 & 1.04 \\
\hline & Chances for advancement & 3.65 & .84 \\
\hline
\end{tabular}




\begin{tabular}{|c|c|c|c|}
\hline & Happy with my pay & 2.69 & .93 \\
\hline & Get along with co-workers & 3.49 & .97 \\
\hline & Try my own methods of doing the & 3.51 & .82 \\
\hline & job & 3.73 & .79 \\
\hline & Work alone on the job & 3.80 & .69 \\
\hline & Do things for other people & 86 & 76 \\
\hline & Chance to be "somebody" & & .10 \\
\hline Extrinsic & Tell other people what to do & 3.61 & .72 \\
\hline Satisfaction & Like company policies & 3.57 & .82 \\
\hline$(\alpha=.88)$ & Do things not against my & 3.73 & .93 \\
\hline & conscience & 3.53 & .80 \\
\hline & Get praise for doing a good job & 3.58 & .69 \\
\hline & Freedom to use my own judgment & 3.70 & .73 \\
\hline & Steady employment & 3.45 & .72 \\
\hline & Like the relationship & 3.53 & .86 \\
\hline & Competence in making decision & 3.46 & 69 \\
\hline & Do different things & & \\
\hline & Like my working conditions & & \\
\hline Idealized & Articulate a clear vision & 3.51 & .74 \\
\hline Influence & Set a personal example & 3.57 & .69 \\
\hline$(\alpha=.83)$ & Talk about the most important & 3.65 & .68 \\
\hline & values & 3.64 & .64 \\
\hline & Consistent with expressed values & 3.49 & 67 \\
\hline & Makes to proud to be associated & & \\
\hline & with & 365 & 56 \\
\hline & Have faith in my expatriate & & \\
\hline & manager & & \\
\hline Inspirational & Talk and act optimistically and & 3.54 & .82 \\
\hline motivation & enthusiastic & 3.56 & .76 \\
\hline$(\alpha=.91)$ & Sets high standards & 3.56 & .72 \\
\hline
\end{tabular}




\begin{tabular}{llll}
\hline & Express confidence & 3.60 & .65 \\
& Feel motivated and inspired & 3.53 & .71 \\
& Provides meaning to work & & \\
& Committed to organizational goals & 3.69 & .63 \\
Intellectual & Challenge me & 3.53 & .85 \\
Stimulation & Provide me with challenging roles & 3.56 & .82 \\
$(\alpha=.86)$ & Achieve individual and & 3.56 & .83 \\
& organizational goals & 3.61 & .80 \\
& Participate intellectually & 3.69 & .76 \\
& Back up my opinion & 3.64 & .61 \\
Individualized & Openly communicate my ideas & & \\
Consideration & Develop my strengths & 3.53 & .60 \\
$(\alpha=.82)$ & Freat each of us as individuals & 3.70 & .58 \\
& Find out what I want and help me & 3.41 & .83 \\
& Listen attentively & 3.64 & .84 \\
& Act as a coach & 3.37 & .96 \\
\hline
\end{tabular}

\section{Variance Analysis}

In this study, an independent sample $t$-test and a one-way ANOVA was used to review the relationships between two variables.

The relationship between gender and organizational justice, employee satisfaction, and leadership performance are summarized in Table 5-1. Significant gender differences were found between male and female respondents in their view of organizational justice $(t=2.136, p<.05)$, however no significant gender differences in employee satisfaction and leadership performance were found.

Table 5-1

Gender and Organizational Justice, Employee Satisfaction and Leadership Performance 


\begin{tabular}{llcccc}
\hline & Gender & Mean & Std. Deviation & $t$-value & $p$-value \\
\hline Organizational & Male & 3.49 & .58 & 2.14 & .03 \\
Justice & Female & 3.35 & .51 & & \\
Employee & Male & 3.54 & .57 & -0.06 & .95 \\
Satisfaction & Female & 3.54 & .48 & & \\
Leadership & Male & 3.57 & .52 & -0.00 & .10 \\
Performance & Female & 3.57 & .52 & & \\
\hline
\end{tabular}

Table 5-2 explores the relationship between years of experience and organizational justice, employee satisfaction and leadership performance. According to the analysis, there is no significant relationship between years of experience and evaluations of organizational justice, employee satisfaction and leadership performance, as the $p$-values were all greater than .05 .

Table 5-2

One-Way ANOVA of Group Years of Experience by Research Variable

\begin{tabular}{|c|c|c|c|c|c|}
\hline & Years & Mean & $S D$ & $F$ & $p$ \\
\hline \multirow{3}{*}{ Organizational Justice } & $1-2$ years & 3.46 & .47 & \multirow{3}{*}{1.12} & \multirow{3}{*}{.33} \\
\hline & $3-5$ years & 3.35 & .55 & & \\
\hline & 5-10 years & 3.44 & .54 & & \\
\hline \multirow{3}{*}{ Employee Satisfaction } & 1-2 years & 3.54 & .47 & \multirow{3}{*}{2.69} & \multirow{3}{*}{.07} \\
\hline & & & & & \\
\hline & 3- 5 years & 3.47 & .51 & & \\
\hline
\end{tabular}




\begin{tabular}{llllll}
\hline & $5-10$ years & 3.61 & .52 & & \\
& $1-2$ years & 3.72 & .45 & & \\
Leadership Performance & $3-5$ years & 3.51 & .54 & 2.45 & .09 \\
& $5-10$ years & 3.62 & 0.50 & & \\
\hline
\end{tabular}

As explored in Table 5-3, there is no significant relationship between position level and organizational justice, employee satisfaction and leadership performance, as the $p$-values are all greater than .05 .

Table 5-3

One-Way ANOVA of Position Level by Research Variable

\begin{tabular}{llllll}
\hline & Position & $M$ & $S D$ & $F$ & $p$ \\
\hline & Front-line & 3.53 & .45 & & \\
& employee & & & & .84 \\
& Back-office & & & & \\
Organizational Justice & employee & 3.36 & .47 & & \\
& Supervisor & 3.42 & .52 & & \\
& Manager & 3.41 & .59 & & .71 \\
& Director & 3.34 & .55 & & \\
& Front-line & & & & \\
Employee Satisfaction & employee & 3.69 & .31 & & \\
& Back-office & & & & \\
& employee & & & & \\
\end{tabular}




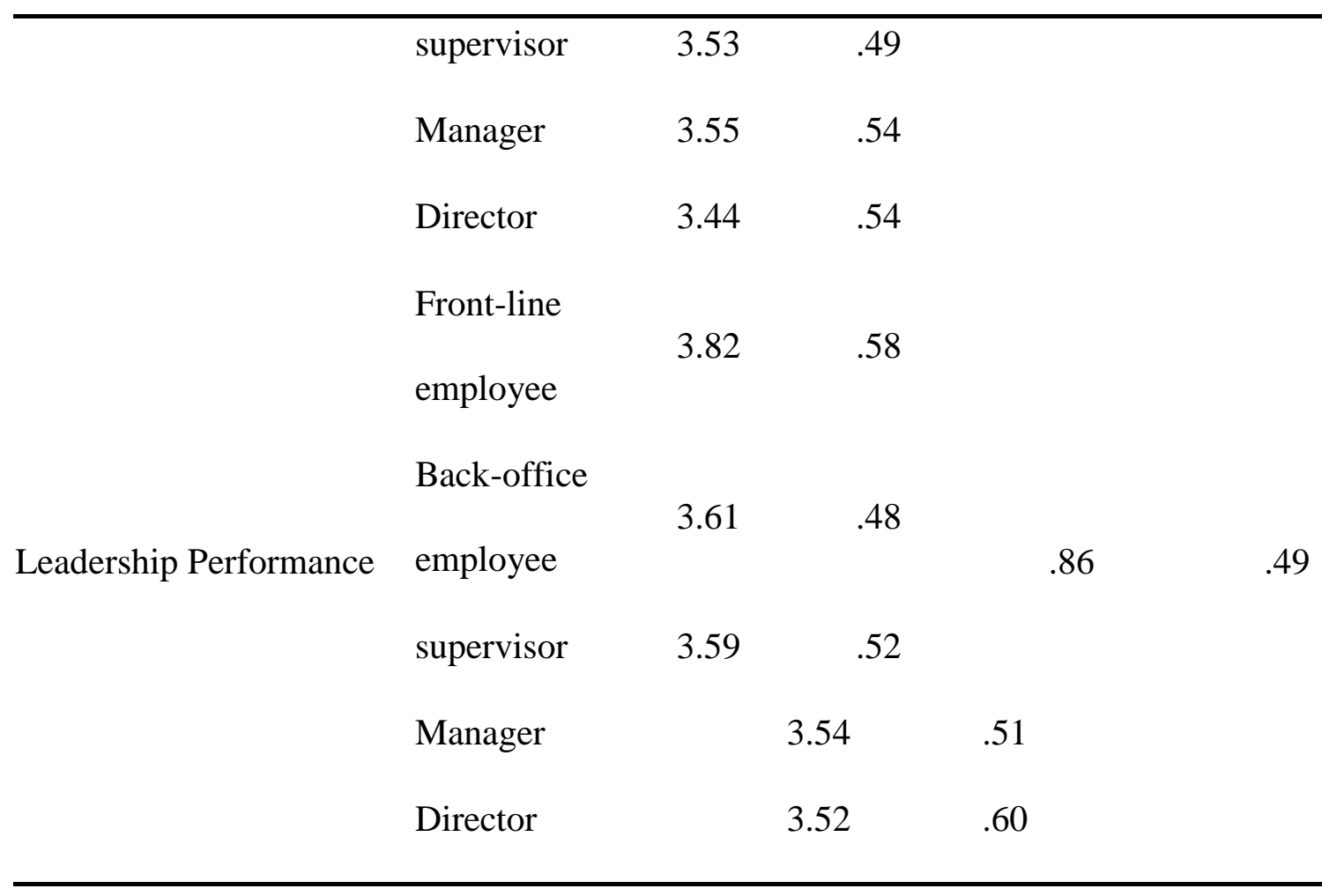

Table 6 indicates that organizational justice has a significant positive relationship with employee satisfaction and leadership performance, the Pearson correlations coefficient are $.40(p<.01)$ and $.49(p<.01)$, respectively. Employee satisfaction has a positive significant relationship with leadership performance with Pearson correlations coefficient $.46(p<.01)$.

Table 6

Pearson Correlations among Research Variables

\begin{tabular}{lllll}
\hline & & Organizational & Employee & Leadership \\
& & Justice & Satisfaction & Performance \\
\hline Organizational & Pearson & 1 & $.40^{* *}$ & $.49^{* *}$ \\
Justice & Correlation & & & \\
\hline
\end{tabular}




\begin{tabular}{lllll}
\hline & Sig. (2-tailed) & & .00 & .00 \\
Employee & $N$ & 283 & 283 & 283 \\
Satisfaction & Pearson & $.40^{* *}$ & 1 & $.46^{* *}$ \\
& Correlation & & & \\
& Sig. (2-tailed) & .00 & & .00 \\
Leadership & $N$ & 283 & 283 & 283 \\
Performance & Pearson & $.49^{* *}$ & $.46^{* *}$ & 1 \\
& Correlation & & & \\
& Sig. (2-tailed) & .00 & & .00 \\
& $N$ & 283 & & \\
& & & & \\
& & & & \\
\end{tabular}

**. Correlation is significant at the 0.01 level (2-tailed).

Correlational Analysis for Testing $\mathrm{Hl}$

$H 1$ stated that there is a positive relationship between employee job satisfaction and employees' perceptions of the expatriate leader's job performance. To review the meaningfulness of our measurements, zero-order correlation coefficients between variables were examined under Cohen's effect size evaluation criterion (Cohen, 1988). Correlation coefficients less than +/- 0.28 imply small effects; between $+/-0.28$ and 0.49 imply medium effects; and greater than +/- 0.49 imply large effects.

First, each scale was examined with subscales aggregated together to give a total composite score. Employee job satisfaction was positively and significantly correlated with employees' perceptions of the expatriate leader's job performance $(r=.46, p<.01)$.

Second, each subscale within each major scale was examined for meaningful relations. Employee satisfaction was positively correlated with intrinsic satisfaction $(r$ 
$=.91, p<.01)$, extrinsic satisfaction $(r=.90, p<.01)$. Expatriate managers' leadership performance was positively correlated with idealized influence $(r=.86, p<.001)$, inspirational motive $(r=.93, p<.01)$, intellectual stimulation $(r=.94, p<.01)$, and individualized consideration $(r=.89, p<.01)$. Intrinsic satisfaction was positively correlated with idealized influence $(r=.35, p<.01)$, inspirational motivation $(r=.42, p$ $<.01)$, intellectual stimulation $(r=.41, p<.01)$, individualized consideration $(r=.42, p$ $<.01)$. Extrinsic satisfaction was positively correlated with idealized influence $(r=.29, p$ $<.01)$, inspirational motivation $(r=.39, p<.01)$, intellectual stimulation $(r=.38, p$ $<.01)$, individualized consideration $(r=.36, p<.01)$.

In summary, results indicated that employee job satisfaction was positively correlated with employees' perceptions of the expatriate leader's job performance. Thus, the research evidence supports $\mathrm{H} 1$. Table 7 provides detailed correlational statistics regarding the relations between employee job satisfaction and employees' perceptions of the expatriate leader's job performance.

Table 7

Zero-Order Correlation Coefficients for Employee Job Satisfaction and Leadership Performance

\begin{tabular}{lllllllll}
\hline & IS & ES & II & IM & IS & IC & ES & LP \\
\hline IS & 1 & & & & & & \\
ES & $.65 * *$ & 1 & & & & & \\
II & $.35 * *$ & $.29 * *$ & 1 & & & & \\
IM & $.42 * *$ & $.39 * *$ & $.75 * *$ & 1 & & & \\
\hline
\end{tabular}




\begin{tabular}{|c|c|c|c|c|c|c|c|c|}
\hline IS & $.41 * *$ & $.38 * *$ & $.73 * *$ & $.85 * *$ & 1 & & & \\
\hline IC & $.42 * *$ & $.36 * *$ & $.67 * *$ & $.75 * *$ & $.83 * *$ & 1 & & \\
\hline $\mathrm{ES}$ & $.91 * *$ & $.90 * *$ & $.35 * *$ & $.44 * *$ & $.44 * *$ & $.43 * *$ & 1 & \\
\hline IP & $.44 * *$ & $.39 * *$ & $.86 * *$ & $.93 * *$ & $.94 * *$ & $.89 * *$ & $.46^{* *}$ & 1 \\
\hline
\end{tabular}

Note. $N=283 . * * p<.01$. IS = intrinsic satisfaction. ES = extrinsic satisfaction. II = Idealized Influence. IM = Inspirational Motivation. IS = Intellectual Stimulation. IC = Individualized Consideration. ES = Employee Satisfaction. LP = Leadership Performance.

Correlational Analysis for Testing $H 2$

$H 2$ stated that there would be a positive relationship between employee job satisfaction and organizational justice. Zero-order correlational coefficients between the variables of interest were examined for significance according to effect size standards (Cohen, 1988).

To conduct the examination, composite scores were generated by examining each scale with subscales aggregated together. Employee job satisfaction was positively and significantly correlated with organizational justice $(r=.40, p<.01)$.

Second, each subscale within each major scale was examined for meaningful relations. Employee satisfaction was positively correlated with distributive justice ( $r$ $=.32, p<.01)$, procedural justice $(r=0.41, p<.01)$, and international justice $(r=.31, p$ $<.001)$. Organizational justice was positively correlated with intrinsic job satisfaction $(r$ $=.39, p<.01)$, and extrinsic job satisfaction $(r=.33, p<.01)$. Distributive justice was positively correlated with intrinsic job satisfaction $(r=.30, p<.01)$, and extrinsic job satisfaction $(r=.27, p<.01)$. Procedure justice was positively correlated with intrinsic job satisfaction $(r=.39, p<.01)$, and extrinsic job satisfaction $(r=.36, p<.01)$. 
Interactional justice was positively correlated with intrinsic job satisfaction $(r=.33, p$ $<.01)$, and extrinsic job satisfaction $(r=.24, p<.01)$.

In summary, the results indicated that employee job satisfaction was positively correlated with organizational justice. Thus, the research evidence supports $\mathrm{H} 2$. Table 8 provides detailed correlational statistics regarding the relations between employee job satisfaction and organizational justice.

Table 8

Zero-Order Correlation Coefficients for Employee Job Satisfaction and Organizational Justice

\begin{tabular}{|c|c|c|c|c|c|c|c|}
\hline & DJ & $\mathrm{PJ}$ & IJ & IS & ES & OJ & ES \\
\hline$\overline{\mathrm{DJ}}$ & 1 & & & & & & \\
\hline PJ & $.60 * *$ & 1 & & & & & \\
\hline IJ & $.59 * *$ & $.67 * *$ & 1 & & & & \\
\hline IS & $.30 * *$ & $.39 * *$ & $.33 * *$ & 1 & & & \\
\hline $\mathrm{ES}$ & $.27 * *$ & $.36 * *$ & $.24 * *$ & $.65^{* *}$ & 1 & & \\
\hline $\mathrm{OJ}$ & $.81^{* *}$ & $.87 * *$ & $.90 * *$ & $.39 * *$ & $.33 * *$ & 1 & \\
\hline $\mathrm{ES}$ & $.32 * *$ & $.41 * *$ & $.31 * *$ & $.91 * *$ & $.90 * *$ & $.40 * *$ & 1 \\
\hline
\end{tabular}




\section{Structural Equation Modeling (SEM) Analysis for Testing $H 3$}

Structural Equation Modeling (SEM) was used to test the third hypothesis. Structural Equation Modelling (SEM) is a statistical method based on the covariance matrix of variables, which uses factor analysis, multiple regression analysis and path analysis to analyze the relationship between variables (Hooper, Coughlan, \& Mullen, 2008). The SEM has the advantages of simultaneously processing multiple dependent variables, allowing the independent and dependent variables to contain measurement errors, simultaneously estimating the factor structure and factor relationship, allowing a more flexible measurement model, and estimating the degree of fit of the entire model (Kline, 2009; Reynolds \& Walberg, 1991). Model fit indices in AMOS include Chi square test, Root Mean Square Error of Approximation (RMSEA), and Comparative Fit Index (CFI). A model was considered a good fit to the data if RMSEA $<.06$, and CFI > .95 (Cheung \& Lau, 2007; Marsh, Hau, \& Wen, 2004).

\section{Confirmatory Factor Analysis}

Confirmatory factor analysis (CFA) is a form of factor analysis, most commonly used in social science research. It is used to test how well the measured variables represent the number of constructs. As such, the objective of confirmatory factor analysis is to test whether the data fit a hypothesized measurement model. This study used AMOS 21.0 statistical software to test the validity of the sample and confirmatory factor analysis. AMOS 21.0 has a graphical user interface that makes it one of the easiest-to-use SEM software programs (Chan et al., 2007). AMOS 21.0 stands for analysis of a moment structures and is specially used for SEM, path analysis, and CFA (Chan et al., 2007). 
Table 9-1 indicates that the proposed confirmatory factor analysis model indicator is better than the standard criteria. The original data fit the model, additional model fitting procedures were not required. Model fit indices in Amos 21.0 include Chi square test, Root Mean Square Error of Approximation (RMSEA), Goodness-of-fit statistic (GFI), Adjusted Goodness-of-Fit Statistic (AGFI), Normed Fit Index (NFI), Comparative Fit Index (CFI). A model was considered a good fit to the data if RMSEA $<.06$, GFI >.09, AGFI >.09, NFI >.09, CFI > .95 (Daire et al., 2008; Hooper, Coughlan, \& Mullen, 2008; Marsh, Hau, \&Wen, 2004; Schreiber, Nora et.al, 2006). The value of all indicators are $\chi 2$ df (1.60), RMSEA (0.05), GFI (0.97), AGFI (0.95), NFI (0.98), and CFI (0.99).

Table 9-1

Model Fit

\begin{tabular}{lcccccc}
\hline Index & $\chi^{2} / d f$ & RMSEA & GFI & AGFI & NFI & CFI \\
\hline Standard criteria & $<3.00$ & $<0.06$ & $>0.9$ & $>0.9$ & $>0.9$ & $>0.95$ \\
proposed model & 1.60 & .05 & .97 & .95 & .98 & .99 \\
\hline
\end{tabular}

As can be seen from Table 9-2, the factor loadings of extrinsic, intrinsic, distributive, procedure, interactional, idealized, inspirational, intellectual, and individualized are all above 0.5 , and average variance extraction values are above 0.5 . According to Hair (2010), the absolute value of the factor load estimate should be at least 0.5 , the best index value is 0.7 or more; the AVE index should be above 0.5 ; the CR index value should be higher than 0.7. Therefore, extrinsic, intrinsic, distributive, procedure, interactional, idealized, inspirational, intellectual, and individualized have 
good explanatory power for employee satisfaction, organizational justice, and leadership performance.

Table 9-2

Confirmatory Factor Analysis

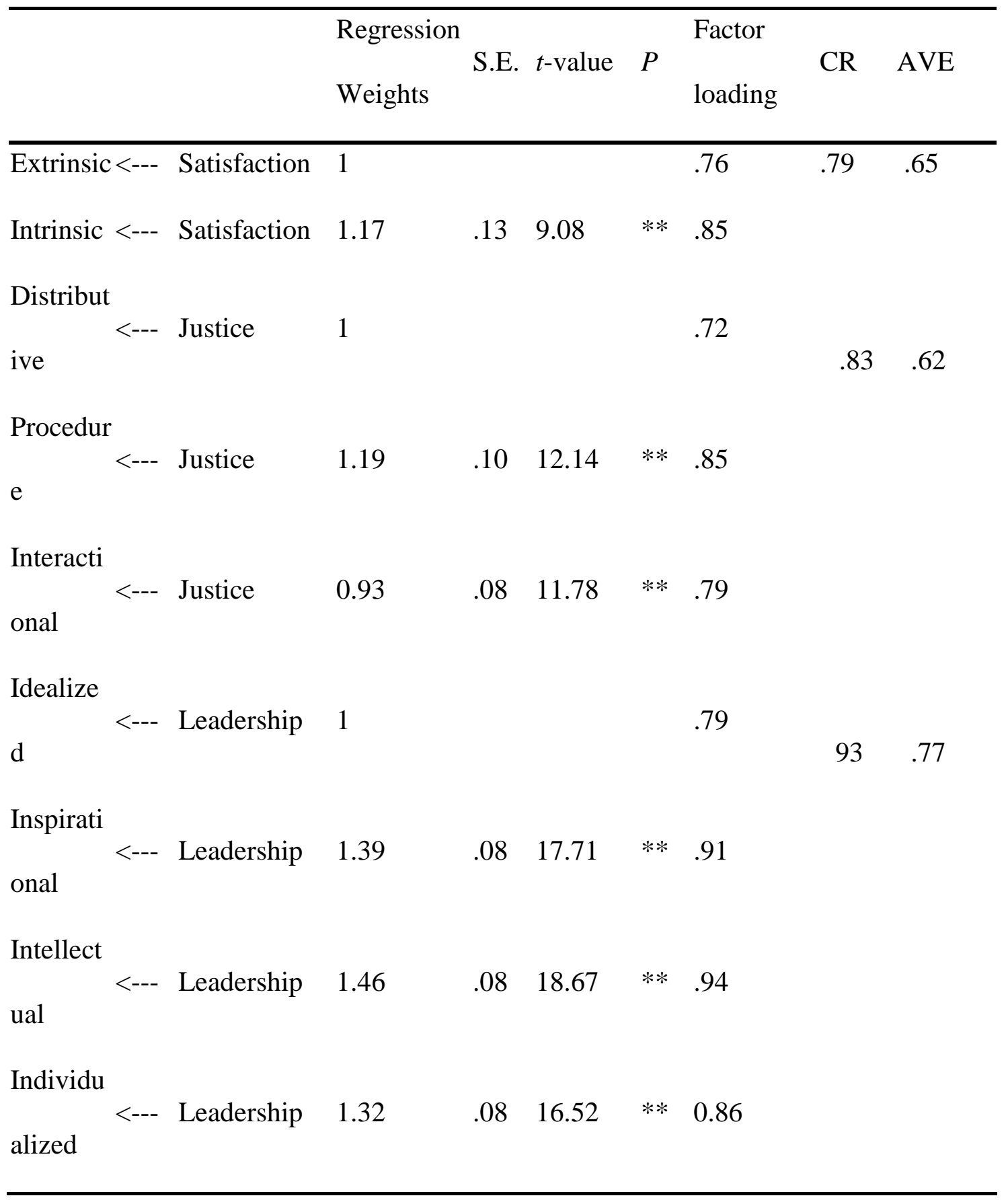


Note. $* * p<.01$.

Figure 4

Confirmatory Factor Analysis Model

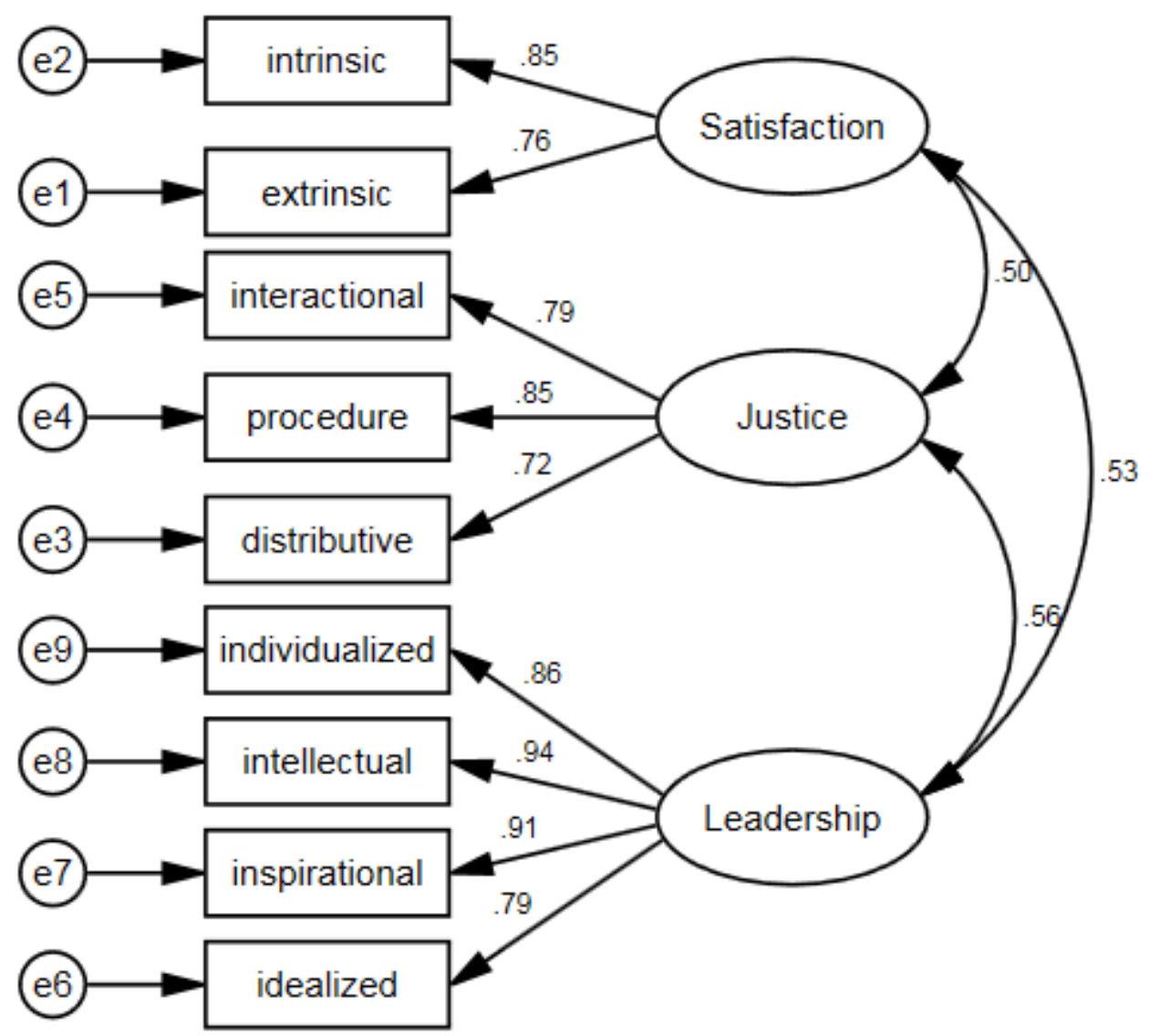

Table 10-1 indicates that the proposed structure equation modeling (SEM) is superior to the standard criteria. The original data fit the model, additional model fitting procedures were not required. Model fit indices in Amos 21.0 include Chi square test, Root Mean Square Error of Approximation (RMSEA), Goodness-of-fit statistic (GFI), Adjusted Goodness-of-Fit Statistic (AGFI), Normed Fit Index (NFI), and Comparative Fit 
Index (CFI). The value of $\chi^{2} / d f$ is 1.60 ; the value of RMSEA is .05; the GFI value is .97; the AGFI value is .95; the value of CFI is .99; and the value of IFI is .99.

Table 10-1

Model Fit

\begin{tabular}{lllllll}
\hline Index & $\chi^{2} / d f$ & RMSEA & GFI & AGFI & NFI & CFI \\
\hline Standard criteria & $<3.00$ & $<0.08$ & $>0.9$ & $>0.9$ & $>0.9$ & $>0.95$ \\
proposed model & 1.60 & .05 & .97 & .95 & .98 & .99 \\
\hline
\end{tabular}

The third hypothesis stated that the relationship between job satisfaction and leadership performance will be mediated by organizational justice. Results from the structure equation modeling analysis (Table 10-2 \& Figure 5) presented evidence that the mediation effect is significant. Organizational justice plays a significant intermediary role between employee job satisfaction and how employee perceive expatriate leadership performance.

Table 10-2

\section{Mediation Effect}

Unstandardized

Bias-corrected

Bootstrap 95\%CI

$B(\mathrm{SE}) \quad \beta(\mathrm{SE}) \quad p \quad \overline{\text { LOWER UPPER }}$

Total

$\begin{array}{llllll}\text { Satisfaction } \rightarrow \text { Leadership } & .49(.08) & .53(.08) & p<.00 & .36 & .66\end{array}$ 
Direct

$\begin{array}{llllll}\text { Satisfaction } \rightarrow \text { Leadership } & .31(.08) & .33(.06) & p<.00 & .14 & .48\end{array}$

Mediator effects

$\begin{array}{llllll}\text { Satisfaction } \rightarrow \text { Leadership } \quad .18(.08) & .20(.09) & p<.00 & .10 & .34\end{array}$

Figure 5

Structural Equation Modelling

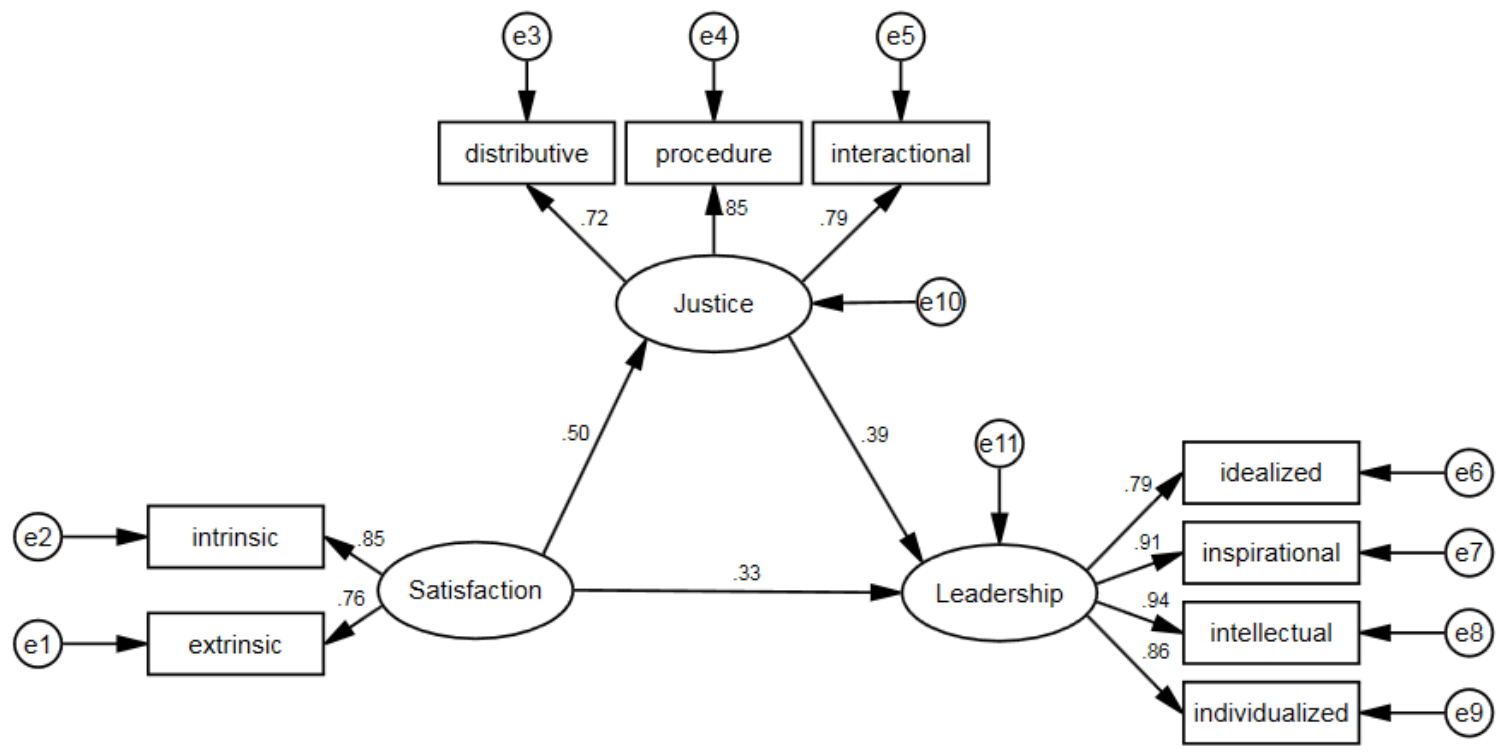

Summary

The results of this study completely support the three proposed hypotheses in this study. Job satisfaction and organizational justice explained $39.8 \%$ of the variance in leadership, and $25.5 \%$ of the variance in organizational justice was explained by employee job satisfaction in this structure equation model. There is a positive relationship between employee job satisfaction and employees' perceptions of the expatriate leader's job performance. Also confirmed was a positive relationship between organizational 
justice and employee job satisfaction. Furthermore, it confirmed that relationship between job satisfaction and leadership performance was mediated by organizational justice.

Chapter 5 discusses the result of these findings and implications for research, theory, and practical applications. 


\section{CHAPTER V}

\section{DISCUSSION}

Chapter 5 provides a brief summary of the study, followed by a discussion of results. Implications for research, theory, and practical applications are also offered in this chapter followed by limitations of the study and recommendations for future research.

\section{Summary of the Study}

In this study, researcher focused on the gap in human resource development research concerning hospitality employees in China, expatriate management, and the relationship between organizational justice, job satisfaction, and expatriate leadership performance.

In Chapter 1, researcher established that the Chinese hospitality is growing quickly, and is expected to continue unabated over the next decade (Kearny, 2013). The researcher also noted that the business success of multinational corporations depends on competent and culturally adaptable managers, organizational culture, and processes (Causin et al., 2011). Due in large part to the country's explosive growth -- finding, developing and retaining talent are important business problems to solve in China for companies seeking to grow their presence in the country (Kaye \& Taylor, 1997).

Important concepts explored in this study are organizational justice, job satisfaction, and expatriate leadership performance. Organizational justice involves employee perception of fairness, and can be influenced by the cultural and individual contexts of the individual perceiver (Cropanzano \& Greenberg, 1997; Greenberg, 1990; You-De et al., 2013). Understanding how local Chinese employees perceive expatriate 
management performance is an important topic for researchers and practitioners interested in understanding or growing operations in China (Alice et al., 2013). Job satisfaction, which has been shown in several studies to correlate with perceptions of organizational justice, is important because of the relationship shown between job satisfaction and positive organizational outcomes (López-Cabarcos et al., 2015; ShiangLih et al. 2010).

The purpose of this nonexperimental, quantitative study was to investigate the relationship between organizational justice, job satisfaction, and expatriate leadership performance. In addition, this study hopes to test the validity and applicability of human resource development concepts in a Chinese cultural context. To accomplish both goals, this study focused on three research questions which were studied specifically within the Chinese hospitality industry: (a) What is the relationship between employee job satisfaction and expatriate leadership performance? (b) What is the relationship between organizational justice and employee job satisfaction? and (c) Does organizational justice mediate the job satisfaction-leadership performance relationship? To explore these three research questions, three hypotheses were tested:

H1: There is a positive relationship between employee job satisfaction and employees' perceptions of the expatriate leader's job performance.

$\mathrm{H} 2$ : There is a positive relationship between organizational justice and employee job satisfaction.

H3: The relationship between job satisfaction and leadership performance will be mediated by organizational justice. 
Based on survey responses, correlational and structural equation modeling analyses were used to test the hypothesized model and examine the hypotheses. Results suggested that there was a positive relationship between employee job satisfaction and employees' perceptions of the expatriate leader's job performance. Also confirmed was a positive relationship between organizational justice and employee job satisfaction. Furthermore, the results indicated that the relationship between job satisfaction and leadership performance was mediated by organizational justice.

\section{Discussion of the Results}

In this section, researcher discuss the results from this study and their implications, going through each of the three proposed hypotheses. The results were statistically significant and indicated potential relationships among the variables of interest.

\section{Hypothesis 1}

The first hypothesis stated that there is a positive relationship between employee job satisfaction and employees' perceptions of the expatriate leader's job performance. Results from the correlational analysis indicated employee job satisfaction was positively and significantly correlated with employees' perceptions of the expatriate leader's job performance $(r=.46, p<.01)$.

Leadership is a multiple-level phenomenon by nature that occurs between leaders and followers; and findings from this study are consistent with research by other scholars (Braun et al., 2013; Casimir et al., 2006; Chun et al., 2009; Judge \& Piccolo, 2004) who have studied the relationship between employee job satisfaction and transformational leadership performance. Our results from surveying employees within the Chinese 
hospitality industry is consistent with Braun et al. (2013) who explored the relationship between individual perceptions of supervisors' transformational leadership and individual followers' job satisfaction, although the relationship was weaker in our Chinese study, which showed that employee job satisfaction was positively and significantly correlated with employees' perceptions of the expatriate leader's job performance $(r=.46, p<.01)$. Braun et al. (2013) showed that employee job satisfaction was positively related to employee perceptions of supervisor transformational leadership performance $(r=.73, p$ $<.01$ ), and individual followers' job satisfaction was also positively related to team perceptions of supervisor transformational leadership $(r=.64, p<.01)$.

In addition, other study results showed that one of the transformational leadership behaviors, individualized consideration, appears to be an important factor of employee role perceptions of their leader (Podsakoff et al.,1996). Individualized consideration was found to be positively related to employee job satisfaction, trust in leader, self-reported effort, altruism, job performance and courtesy. In the results, researcher found that employee satisfaction was positively correlated with intrinsic satisfaction $(r=.91, p$ $<.01)$ and extrinsic satisfaction $(r=.90, p<.01)$. Furthermore, expatriate managers' leadership performance was positively correlated with idealized influence $(r=.86, p$ $<.001)$, inspirational motive $(r=.93, p<.01)$, intellectual stimulation $(r=.94, p<.01)$, and individualized consideration $(r=.89, p<.01)$. Podsakoff et al. (1996) noted that employees who perceived individualized consideration from their leaders generally trusted their leaders more, and were more satisfied on the job, which is an idea supported in a Chinese context by an analysis of our survey data. 


\section{Hypothesis 2}

$H 2$ stated that there would be a positive relationship between employee job satisfaction and organizational justice. Organizational justice can be broken down into three subcomponents, which include distributive justice, procedural justice, and interactional justice. Results from the correlational analysis indicated employee job satisfaction was positively and significantly correlated with organizational justice $(r$ $=.40, p<.01)$. Employee satisfaction was positively correlated with distributive justice $(r$ $=.32, p<.01)$, procedural justice $(r=0.41, p<.01)$, and interactional justice $(r=.31, p$ $<.001)$.

Many studies have indicated mixed results on whether distributive justice or procedural justice is a more important indicator of job satisfaction (Chan \& Jepsen, 2011; Choi \& Chen, 2007; Folger \& Konovsky, 1989; Lopez-Cabarcos (2015). Folger \& Konovsky (1989) suggested that distributive justice has a bigger impact on employee job satisfaction than procedural justice, which is in conflict with the results from the current study. This study indicates employee satisfaction is positively correlated with distributive justice $(r=.32, p<.01)$ and procedural justice $(r=0.41, p<.01)$. According to our results, procedural justice has a slightly bigger relationship with employee job satisfaction.

The findings of this study also conflicts with the findings of Baskshi et al. (2009), which claimed that procedural justice was not related to job satisfaction. Further, no existing study was found that discusses the relationship between employee job satisfaction and interactional justice. This study shows employee satisfaction was positively correlated with interactional justice $(r=.31, p<.01)$. 
Other studies were supported by the results of this study. In 2010, a study by Chen et al. (2010) indicated a meaningful positive relationship between organizational justice and job satisfaction. In 2008, Guo and Wang indicated relationships between distributive justice and procedural justice, and salary satisfaction, a subcomponent of job satisfaction. Loi et al. (2009) indicated that organizational justice can influence job satisfaction. Besides these two studies, other investigations showed slightly mixed results in the relationship between subcomponents of organizational justice and job satisfaction (Colquitt et al., 2001; Heponiemi et al., 2011; Kwak et al., 2010; McAuliffe et al., 2009). These studies indicated that procedural justice was positively correlated to job satisfaction. A 2006 study by Cedwyn and Awamleh indicated that employee satisfaction shows high and significant correlations with distributive justice $(r=.56, p<.05)$, interactional justice $(r=.68, p<.05)$ and procedural justice $(r=.71, p<.05)$.

In summary, although the bulk of studies indicated that a positive relationship is likely, different studies have returned different results on the relationship between subcomponents of organizational justice and job satisfaction. These discordant results could be a facet of a mediating third variable such as culture, which was not a topic for this particular study but could be pursued in future studies. However, the results from this study supports the hypothesis that all three subcomponents of organizational justice, which include distributive justice, procedural justice, and interactional justice have a positive correlation with job satisfaction. Few studies were found that investigated the relationship of all three subcomponents of organizational justice on job satisfaction within the same study. 


\section{Hypothesis 3}

The third hypothesis stated that the relationship between job satisfaction and leadership performance will be mediated by organizational justice. Having a mediation effect means that organizational justice can potentially explain patterns between job satisfaction and leadership performance. Researcher used structural equation modeling to investigate the direct and indirect relationships between variables to investigate this hypothesis. Results from the structure equation modeling analysis presented evidence that the mediation effect is significant. The direct effect of employee satisfaction on leadership performance is $.33(p<.01)$. The indirect effect of employee satisfaction on leadership performance is .20 ( $p<.01)$. The total effect is $.53(p<.01)$.

Therefore, organizational justice has a mediation effect between job satisfaction and leadership performance, which means employee job satisfaction has an impact on how they perceive expatriate's leadership performance through organizational justice. Organizational justice therefore plays a significant intermediary role between employee job satisfaction and how employees perceive expatriate leadership performance.

This result seems logical because an individual's sense of injustice or unfairness can likely impact their interpretation of job satisfaction or perception of leadership performance, particularly when the leader's actions directly led to the individual's sense of injustice or unfairness. Empirical research has shown that lack of organizational justice can lead to negative emotions such as resentment and anger (Yin, 2018). As far back as 1965, Adams posited that absolute earnings and comparative salary were important to employees, which this study supports with the mediation effect of organizational justice on perceptions of job satisfaction and leadership performance. 
Shiang-Lih et al. (2010) examined a structured model of how organizational justice (both distributive justice and procedural justice) impacts employee job satisfaction, with employee's ethical behavior as a mediator. The study focused on the casino industry and 37 casino employees were interviewed, with results showing that both distributive justice $(\beta=.54, p<.01)$ and procedural justice $(\beta=.51, p<.01)$ having a positive, direct effect on job satisfaction. Shiang-Lih et al.'s (2010) result was consistent with what was found in the current study.

Lopez-Cabarcos (2015) tested a structure equation model to examine the relationship between organizational justice, employee job satisfaction and organizational commitment in Portugal's hotel industry. Lopez-Cabarcos (2015) indicated a positive relationship between distributive justice and job satisfaction, while stating that the relationship between procedural justice and job satisfaction was not supported. This was partially confirmed in the current study. The current study shows job satisfaction has a positive relationship with not only distributive justice, but also procedural justice.

The findings of this study align with research conducted by others that indicate organizational justice perception affects worker job satisfaction (Hao et al., 2016). Furthermore, although this study specifically investigates relationships within a Chinese context, the results are aligned with similar results from studies outside of China, such as the United States (Moorman, 1991; McFarlin \& Sweeney, 1992).

This research also tries to test whether employee job satisfaction has a mediation effect between organizational justice and expatiate leadership performance, as has been suggested in the literature. Results from the structure equation modeling analysis (Table 11) present evidence that the mediation effect is significant, with a mediation effect of .17 
$(p<.01)$ between organizational justice and leadership performance. Although significant, the mediation effect is less, than organizational justice as a mediator between job satisfaction and employee perceptions of expatriate leadership performance. Therefore, employee job satisfaction plays a significant intermediary role between organizational justice and how employees perceive expatriate leadership performance. Table 11

Mediation Effect

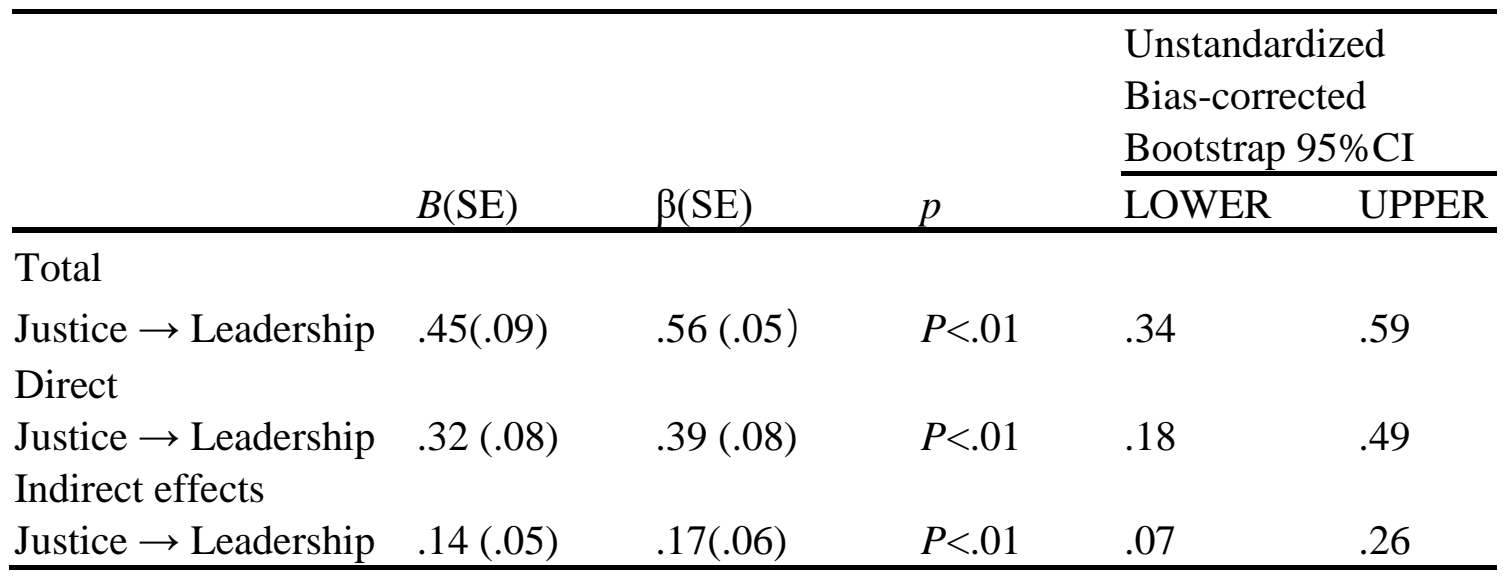

Implication for Research, Theory, and Practice

Due to intense competition, quickly evolving workplace environments, high employee turnover and a work environment that is labor intensive, leadership skills are particularly important within the hospitality industry (Gillet \& Morda, 2003; Tracey \& Hinkin, 1994), especially for a quickly growing and maturing market like China. Furthermore, due to China's high growth, recruiting new professionals is a major challenge. Each hotel leader's impact and influence are multiplied by the number of direct and indirect staff and team members they lead. The level of professionalism, 
empathy, and intelligence of expatriate managers are constantly being assessed and perceived by their staff.

International hotel chains that utilize expatriate managers must carefully navigate modern best practices and a modern competitive environment along with local cultural characteristics and people. In many cases, long term this implies imparting knowledge, tools and expertise to local talent. By demonstrating high standards and international practices along with effective management techniques and focus, expatriate managers serve as important role models and conduits for modernization. This study makes contributions with both human resource development academic and practical implications in the hospitality management field. The following sections review this study's implications on human resource theory, research and practice.

\section{Implications for Research}

This research is designed to fill a gap in knowledge about leadership performance in the hospitality industry, particularly in a Chinese context. The results of the study provide evidence of the direction and magnitude of relationships between organizational justice, job satisfaction and expatriate leadership performance.

The findings indicate that all nine variables measured in this study are reliable indicators of organizational justice, job satisfaction and leadership performance. In summary, the reliability of the items measured by Cronbach's $\alpha$ range from .82 to 95 , which ranks from acceptable to excellent. This indicates that potential measures of organizational justice, job satisfaction and leadership performance can be useful in a Chinese cultural context, warranting examination for potential use across other cultures as well. 
Furthermore, the relationship between gender and organizational justice, employee satisfaction and leadership performance was analyzed. Significant gender differences, albeit small, were found between male and female respondents in their view of organizational justice $(t=2.136, p<.05)$; however, no significant gender differences in employee satisfaction and leadership performance were found. Potential causes of gender differences in viewing organizational justice could include structural differences in how each gender is treated at the workforce, cultural interpretations, or even potential data validity issues. Gender differences in viewing the quality of organizational justice could be an avenue for further research and exploration for researchers to examine the potential causes and implications on job satisfaction.

Other relationships investigated, such as the relationship between years of experience and position level with organizational justice, employee satisfaction and leadership performance, found no clear relationship as $p$-values are all greater than 0.05 .

The results of our study confirmed a positive relationship between organizational justice with both employee job satisfaction and leadership performance in the context of China. This supports the relationships found in a number of studies conducted in the United States that examined the relationship between organizational justice and job satisfaction (Moorman, 1991; McFarlin \& Sweeney, 1992). Thus, this study's findings provides evidence of cross-cultural validity of the relationship between organizational justice and job satisfaction because the strength and directions of relationships were consistent across cultures 
Implications for Theory

Through this study, researcher hope to extend existing social exchange theory and transformational leadership theory within human resource development (HRD) into the Chinese context and additionally to the hospitality industry. China is one of the biggest markets in the world, yet how cultural factors may impact the validity of existing theories such as social exchange theory and transformational leadership theory in Eastern cultures and the hospitality industry has not been tested (Qin et al., 2014). Furthermore, HRD and the validity of social exchange theory and transformational leadership theory can be particularly meaningful within the hospitality industry due to the industry's overall reliance on people to function. Therefore, the results of this study can potentially improve our understanding of social exchange theory and transformational leadership theory in Eastern cross-cultural and hospitality industry contexts within HRD. In this section, researcher will discuss the implications of the study's results on human resource development specifically concerning transformational leadership theory and social exchange theory in the China context.

\section{Transformational Leadership Theory Implications}

Transformational leadership has been extensively studied both in Western and Chinese literature. In 1985, Bass developed a transformational leadership model that has been widely used to this day, the definition being that transformational leadership approaches can result in change in individuals and organizations, potentially leading to increased morale, motivation and performance. His model was built off the previous work put forward by Burns (1978) and Downton (1973). In 2008, Li and Shi localized Bass' transformational leadership model based on Bass' model and their own analysis of the Chinese context. 
Because transformational leadership's impact is measured based on how individuals and organizations respond, HRD researchers are interested in how theories and applications may change or be consistent in different cultural contexts. Among Chinese researchers, a significant number are utilizing Li and Shi's (2008) more localized transformational leadership model, although Bass' definition still predominates. According to Liu (2018), from the period of 2005 to 2015, Bass' theory on transformational leadership was utilized in $58.8 \%$ of the literature investigated, while $\mathrm{Li}$ and Shi's transformational leadership theory was utilized by $33.3 \%$. One of the biggest localizations in Li and Shi's model was a consideration for the employee's family which is important in Chinese culture -- a broader context than what is provided for in Bass' theory (Liu, 2018).

According to this study, researcher find that the results are largely consistent with Western HRD transformational leadership theories being applicable to the Chinese and hospitality industry context. Results from the correlational analysis indicated there was a significant positive relationship between employee job satisfaction and employees' perceptions of the expatriate leader's job performance.

However, although researcher found signs that transformational leadership variables studied such as idealized influence were predictive of job satisfaction; even more important was how local employees perceived organizational justice factors, particularly procedural justice and interactional justice.

Social Exchange Theory Implications

Social exchange theory is based on sociological, psychological and economic ideas. Social exchange theory involves the interaction of two parties, and is premised 
upon the idea that successful transactions are based on an exchange that both parties value (Blau, 1964). Transactions can involve the exchange of tangible and intangible items and activities (Homans, 1958). In HRD, social exchange theory is important in that an employer and employee relationship is an ongoing transaction. Every day in an employer and employee relationship, services, goods, remuneration, training, and all kinds of potential rewards and costs are exchanged between the two parties or on behalf of one or both of the parties.

Therefore, both parties can be expected to compare their rewards in relation to their costs. A positive outcome for both parties involves rewards exceeding the costs (Lambe et al., 2001). Practitioners and researchers of HRD are constantly looking for ways to help tip the balance and improve the likelihood of a positive social exchange, as well as look for ways to leverage greater rewards relative to costs in that relationship. Tools explored in this research specifically investigate the perspective of local Chinese employees in the hospitality industry, and how they may value different factors in their social exchange with their employers and managers. For example, the results from this study indicated that variables of procedural justice $(r=.41, p<.01)$, distributive justice $(r$ $=.32, p<.01)$ and interactional justice $(r=.31, p<.01)$ were significantly correlated with employee satisfaction.

\section{Implications for HRD Practice}

The results of this research may help hospitality industry leaders face the reality of how local employees perceive their performance, and play a vital role to identify possible opportunities and shortcomings in human resource development policies and procedures. HRD professionals could focus on creating developmental interventions that 
promote organizational justice, employee job satisfaction, and encourage a positive psychological climate. For example, in each of these areas employers can collect surveys like the one utilized for this study to monitor variables that are linked to desired outcomes. To promote organizational justice, corporations can utilize tailored trainings and support systems, which in a study of casino employees in Macau showed positive outcomes including job satisfaction (Gu \& Sen Siu, 2009).

In addition, the information gained from this study may help multinational hotel companies better understand China's organizational justice, job satisfaction and the type of leadership that best relates with that workforce. Because this study specifically focuses on workers in China, the results can be indicative of where HRD professionals and organizations can prioritize time and resources. Furthermore, multinational corporations can take actions to better understand the similarities and differences among employees of different cultural groups, especially for those in key markets to better serve their needs.

Leadership plays a significant role in terms of hospitality industry development and organizational success (Rothfelder et al., 2012; Tracey \& Hinkin, 1994). In addition to mastering management techniques, skills and practices, to be successful in international business requires leaders to be aware of the cultural differences and local dynamics of their local workforce, which may influence business practices in a foreign country and how employees perceive corporate or leadership action (CB Richard Ellis Hotels, 2009). Leaders in an international business setting need to have a comprehensive understanding of what is expected of leaders in local contexts.

Expatriate failures may damage firm reputation, disrupt local relationships (Bhaskar-Shrinivas et al., 2005), are costly (Pires et al., 2006), and often exact a cost on 
the failing expatriates' own psychological well-being (Solomon, 1996). Therefore, reducing the failure rate of expatriation and making it more successful should be a high priority for global business operations (Qin \& Baruch, 2010).

In addition, this study may help leaders in multinational organizations, and organizations that might want to extend business in China, by potentially assisting organizations to develop diversity training to help their leaders effectively fit into the local leadership perspective (Dunbar \& Ehrlich, 1986). Because expatriate managers experience high failure rates (Feng \& Pearson, 1999), by exploring their perspectives in this research, this study may have much practical utility in helping organizations better recruit, support and/or retain good managers, thereby avoiding the high costs associated with expatriate manager failure.

Knowledge of how different cultures and countries may view organizational justice can impact how international businesses better prioritize and localize policies, procedures and practices in order to optimize business performance. According to the results of this study, variables concerning intrinsic satisfaction $(r=0.91, p<.01)$ and extrinsic satisfaction $(r=0.90, p<.01)$ show excellent utility in predicting job satisfaction from local employees in the Chinese hospitality industry. Knowing this, managers and human resource development professionals may now better prioritize their time and efforts when focusing on specific variables to improve organizational outcomes.

Given that interactional justice scored the highest $r$, managers and human resource practitioners might do well to focus on improving interactional justice by focusing on initiatives targeted to items measured in this study, which includes treating 
employees with respect, being sensitive to personal needs, and offering justifications and explanations for decisions. Some of these items are likely inherently localized. Showing respect in one country can involve different practices and considerations than showing respect in another country. In fact, variations may exist even within countries depending on geographic region and employee ethnicity. While this study can provide some clarity on overall areas that matter to local Chinese hospitality industry employees, there are still limitations that international businesses, managers and HRD professionals need to consider as well as further questions that can be explored in future studies.

\section{Limitations of the Study}

In this section, researcher discuss the limitations of the study. The possible limitations include constraints from utilizing convenience sampling, self-reported data, social desirability bias, limitations related to our data collection tool and an inability to check response rates.

The first limitation from this study results from the use of convenience sampling, which focused on members from a range of organizations who were affiliated with a particular alumni group that graduated from TUC-FIU. Although heterogeneous convenience samples are common in exploratory human resource development research (Reio \& Ghosh, 2009; Yaghi, Goodman, Holton, \& Bates, 2008), the use of convenience sampling can impact the utility of generalizing our results beyond the current study. By utilizing a purposive sampling of subjects to give surveys to, this study decreases the potential generalizability of its findings (DeFeo, 2013).

A second limitation from this study involves the use of self-reported data from employee questionnaires. Self-reported data is a common form of collecting data 
concerning a subject's feelings and perceptions. Self-report measures offer benefits to the researcher, such as inexpensive use and ease of distribution (McCabe, 2004), but using these measures raises the possibility of introducing common method variance bias (CMV). Perceptions are inherently personal, and not only can differ from reality (Ludtke et al., 2009), but levels of perception can vary based on who is self-reporting the data, and also result in common method variance which can result from data collected from a single source. Single-source, self-report results may produce inflated or deflated correlations among the variables of interest (Podsakoff et al., 2003). Reio (2010) suggested a few ways to reduce the likelihood of CMV bias. First, ensure participant anonymity and confidentiality. Second, let participants be aware that there is no correct or preferred answer, focusing instead on an honest response. Third, offer clear instructions for the survey and work to eliminate or minimize confusion. For example, surveys can be reviewed prior to use by knowledgeable experts and furthermore, conducting a pilot study can reduce the chance of nonresponse error, sampling error, measurement during the collection process. Each of these steps were undertaken in this research.

A third limitation of this study is social desirability bias, which may occur as participants were asked to report sensitive information about their manager (Nederhof, 1985). Social desirability reflects the tendency on behalf of the subjects to deny socially undesirable traits and claim instead socially desirable ones (Hebert, Clemow, Pbert, Ockene, \& Ockene, 1995). This method asked individuals to report their own thoughts and feelings about their place of work. Social desirability bias could influence responses as participants were also asked to report their own frequency of involvement in certain 
behaviors (Pearson \& Porath, 2004). To reduce social desirability bias, researcher worked to: 1) assure participant anonymity; 2) maximize question neutrality; 3) utilize selfreported questionnaires; and 4) utilize forced-choice items. Research has demonstrated that self-reported questionnaires help reduce social desirability bias due to negating subject interaction with others (Durant, Carey \& Schroder, 2002; Nederhof, 1985).

Other limitations to this study included the need for respondents to complete the survey in one session and the inability for respondents to return to previously filled out surveys to correct data if needed.

\section{Recommendations for Future Research}

The results from this study represents a snapshot in one time period in one industry. There are many avenues for further study in this area that could extend the findings of this study and other studies in this area.

A longitudinal study can be used to find possible relationships and trends among the subjects studied, as well as potential future shifts of employee perceptions and values. Given that human society evolves over time, utilizing multiple years of data and analyzing results over time not only can reveal trends, but can also reveal underlying variables that are important across different factors such as time, age, culture, etc.

Furthermore, future research can consider utilizing a mixed-research method to collect more comprehensive data. This type of research can utilize a combination of tools such as surveys, interviews, observations and experiments to cross-check data and validate findings. In addition, future research can investigate other factors besides organizational justice that could mediate or moderate between job satisfaction and how 
employees evaluate expatriate manager leadership performance, including factors such as employee empowerment, corporate culture, and compensation.

A future study can target a larger sample by incorporating more cities and/or industries in China, for example investigating any potential differences among regions such as the Pearl River Delta, Northeastern China, and the minority-majority areas that tend to be less developed than the majority Han areas. The implications for further research within China exploring different regions and industries may be useful to policymakers and corporations looking for areas that maximize cultural fit and other characteristics that may lead to more successful operations. Other industries that are human capital intensive that may benefit from further research include manufacturing, tourism, and food and beverage.

Another idea for future study is to go deeper into some of the variables explored in this study, for example interviewing Chinese employees to better define their perspectives of concepts that have been more thoroughly explored in Western societies, such as taking stock of specific examples or perspectives concerning leadership performance or organizational justice in a China context. An interesting question would be if some cultures prioritized factors such as organizational justice, while other cultures prioritized other factors such as transformational leadership. Differences in prioritization can impact how researcher utilize human resource development theory in different cultures, and impact how organizations determine their human resource prioritization in different countries.

Outside of China, further studies can investigate the applicability of this study's findings and prior HRD research in other regions and cultures around the world. 
Furthermore, future studies can also take different approaches to explore the same topics explored in this study, which included concepts of organizational justice, employee job satisfaction and leadership performance. For example, researchers can utilize other research methods such as focus groups, observation and participant observation, experiments, and a combination of research methods to get a better understanding of the variables that drive employee job satisfaction, leadership performance and organizational justice.

Finally, there is a lot of potential for interdisciplinary research in this area as well. Human resource development research is inherently inter-departmental, for example incorporating concepts, theories and considerations from sociological, psychological, economic and other perspectives. Fully exploring employee job satisfaction, leadership performance and organizational justice may inherently need to involve researchers from other academic areas as well.

\section{Conclusions}

The findings of this study help contribute to our understanding of organizational justice, employee satisfaction and leadership performance concepts not only in the hospitality industry and in China, but also help contribute to our understanding of the intercultural considerations and importance of different variables on the concepts studied.

The results of this paper has demonstrated the positive relationship between organizational justice and employee job satisfaction, the positive relationship between employee job satisfaction and employee perceptions of expatriate leader job performance, and finally, the relationship between job satisfaction and leadership performance is mediated by organizational justice. 
The findings of this study furthermore confirm the applicability of concepts behind social exchange theory, transformational leadership theory, employee job satisfaction and organizational justice in a Chinese cultural context. China is the largest growing market in the world today, and therefore it is an important area for government, corporations, human resource development professionals, and researchers to explore and better understand the nuances that can impact processes and outcomes in important industries like the hospitality industry in China specifically.

In addition to collecting statistically significant results that explore these concepts, this paper also summarizes the significance of what was analyzed, and makes recommendations for future research opportunities to improve our understanding of human resource development concepts in China and intercultural contexts specifically. 


\section{References}

Abbott, G. N., \& Stening, B. W. (2009). Coaching expatriate executives: Working in context across the affective, behavioral and cognitive domains. In M. Moral, \& G. Abbott (Eds.), Routledge companion to international business coaching (pp. 181202). London: Taylor \& Francis.

Adams, J. S. (1965). Inequity in social exchange. In L. Berkowitz (Ed.), Advances in experimental social psychology, 2, 267-299. New York: Academic Press.

Adeniyi, A. (2015). A study of the impact of expatriate managers on local managerial capacity development in emerging markets: The case of Nigeria. International Journal of Public Administration and Management Research, 2(5), 1-11

Agho, A., Price, J., \& Muller, C. (1992), Discriminant validity of measures of job satisfaction, positive affectivity and negative affectivity, Journal of Occupational and Organizational Psychology, 65, 185-196.

Aizzat Mohd. Nasurdin, \& Soon, L. K. (2011). Organizational justice, age, and performance connection in Malaysia. International Journal of Commerce and Management, 21, 273-290. doi:http://dx.doi.org.ezproxy.fiu.edu/10.1108/10569211111165316

Alexander, J. F., \& King, N. D. (1995). Assessment of the hotel rating system in China. Journal of International Consumer Marketing, 8(1), 116-121. Retrieved from http://ezproxy.fiu.edu/login?url=http://search.proquest.com.ezproxy.fiu.edu/docvi $\underline{\text { ew/205828301? accountid }=10901}$

Alice H.Y. Hon, \& Lu, L. (2013). Be good for love or for money? The roles of justice in the Chinese hotel industry. International Journal of Contemporary Hospitality Management, 25, 883-902. Retrieved from http://ezproxy.fiu.edu/login?url=https://search-proquestcom.ezproxy.fiu.edu/docview/1425378684? accountid=10901

Arnett, D. B., Laverie, D. A., \& McLane, C. (2002). Using job satisfaction and pride as internal-marketing tools. Cornell Hotel and Restaurant Administration Quarterly, 43, 87-96. Retrieved from http://ezproxy.fiu.edu/login?url=http://search.proquest.com.ezproxy.fiu.edu/docvi $\underline{\text { ew/209705884? accountid=10901 }}$

Arendt, S., Brown, W., \& Eric, A. (2011). Perceptions of transformational leadership behaviors and subordinates performance in hotels. Journal of Human Resources in Hospitality and Tourism, 10, 45-59. 
Arkin, R., Appelman, A., \& Burger, J. (1980). Social anxiety, self-presentation, and the self-serving bias in causal attribution. Journal of Personality and Social Psychology, 12, 27-41.

Avila, S. A. (2016). The relationship between deans' transformational leadership skills and student graduation rates in vocational colleges (Order No. 10036397).

Available from ProQuest Dissertations \& Theses A\&I; ProQuest Dissertations \& Theses Global. (1775742285). Retrieved from http://ezproxy.fiu.edu/login?url=http://search.proquest.com.ezproxy.fiu.edu/docvi ew/1775742285?accountid=10901

Avolio, B. J., \& Bass, B. M. (2002). Developing potential across a full range of leadership cases on transactional and transformational leadership. Mahwah, NJ: Lawrence Erlbaum Associates.

Bakhshi, A., Kumar, K., \& Rani, E. (2009). Organizational justice perceptions as predictor of job satisfaction and organizational commitment. International Journal of Business Management 4, 145-154. doi:10.5539/ijbm.V4n9P145.

Barboza, D. (2010, August 15). China passes Japan as second-largest economy. The New York Times.

Barber, N., \& Pittaway, L. (2000). Expatriate recruitment in south East Asia: Dilemma or opportunity? International Journal of Contemporary Hospitality Management, 12, 352-359. Retrieved from http://ezproxy.fiu.edu/login?url=http://search.proquest.com.ezproxy.fiu.edu/docvi $\underline{\text { ew/228409810?accountid=10901 }}$

Bartlett, K. R., Johnson, K. R., \& Schneider, I. E. (2016). Comparing strategic human resource development approaches for tourism and hospitality workforce planning. Journal of Human Resources in Hospitality \& Tourism, 15(4), 440-456. Retrieved from http://ezproxy.fiu.edu/login?url=http://search.proquest.com.ezproxy.fiu.edu/docvi ew/1797867666? accountid=10901

Barling, J., Weber, T., \& Kelloway, E.K. (1996). Effects of transformational leadership training on attitudinal and financial outcomes: A field experiment. Journal of Applied Psychology, 81, 827-832.

Bass, B.M. (1990). From transactional to transformational leadership: Learning to share the vision. Organizational Dynamics, 18, 19-31.

Bass, B., \& Avolio, B. (1990). Developing transformational leadership. Journal of European Industrial Training, 15, 21-27. 
Bass, M., \& Avolio, J. (1997). Full range leadership development: Manual for multifactor leadership questionnaire.

Bass, B.M., Avolio, B.J., Jung, D.I. \& Benson, Y. (2003), Predicting unit performance by assessing transformational and transactional leadership, Journal of Applied Psychology, 88, 207-218.

Bass, B.M. and Avolio, B.J. (2004), Multifactor Leadership Questionnaire: Manual and sample set (3rd ed.), Redwood City, CA: Mind Garden.

Bell, C. M., \& Hughes-Jones, J. (2008). Power, self-regulation and the moralization of behavior. Journal of Business Ethics, 83, 503-514. doi:http://dx.doi.org.ezproxy.fiu.edu/10.1007/s10551-007-9635-6

Bhaskar-Shrinivas, P., Harrison, D., Shaffer, M., \& Luk, D. (2005), Input-based and time-based models of international adjustment: Meta-analytic evidence and theoretical extensions. Academy of Management Journal, 48, 257-281.

Biernacki, P., \& Waldorf, D. (1981). Snowball sampling: Problems and techniques of chain referral sampling. Sociological Methods and Research, 28, 141-163.

Black, J. S., \& Mendenhall, M. (1989). A practical but theory-based framework for selecting cross-cultural training methods. Human Resource Management, 28, 511539.

Black, J., \& Gregersen, H. (1999). The right way to manage expats. Harvard Business Review, 35, 52-63.

Black, J., \& Stephens, G. (1989). The influence of the spouse on American expatriate adjustment and intent to stay in Pacific Rim overseas assignments. Journal of Management, 28, 429-544.

Blau, P. M. (1964). Exchange and power in social life. John Wiley \& Sons. Retrieved from http://ezproxy.fiu.edu/login?url=http://search.proquest.com.ezproxy.fiu.edu/docvi ew/60546672? accountid=10901

Braun, S., Peus, C., Weisweiler, S., \& Frey, D. (2013). Transformational leadership, job satisfaction, and team performance: A multilevel mediation model of trust.

Leadership Quarterly, 24, 270-288. Retrieved from http://ezproxy.fiu.edu/login?url=http://search.proquest.com.ezproxy.fiu.edu/docvi ew/1269794825?accountid=10901

Browne, K. (2005). Snowball sampling: Using social networks to research nonheterosexual women. International Journal of Social Research Methodology: 
Theory \& Practice, 8, 47-60.

doi:http://dx.doi.org.ezproxy.fiu.edu/10.1080/1364557032000081663

Burns, J.M. (1978). Leadership. Harper \& Row, New York, NY.

Causin, G. F., Ayoun, B., \& Moreo, P. (2011). Expatriation in the hotel industry. International Journal of Contemporary Hospitality Management, 23, 885-901. doi:http://dx.doi.org.ezproxy.fiu.edu/10.1108/09596111111167515

Carruthers, J. R. (1988). Relationships among selected characteristics and job satisfaction of first line police supervisors: Implications for adult education (Order No. 8907196). Available from ProQuest Dissertations \& Theses A\&I; ProQuest Dissertations \& Theses Global. (303712070). Retrieved from http://ezproxy.fiu.edu/login?url=http://search.proquest.com.ezproxy.fiu.edu/docvi ew/303712070?accountid=10901

Castanheira, F. (2014). Job description index. In A. C. Michalos (Ed.), Encyclopedia of quality of life and well-being research (pp. 3439-3441). Dordrecht, The Netherlands: Springer.

Casimir, G., Waldman, D. A., Bartran, T., \& Yang, S. (2006). Trust and the relationship between leadership and follower performance: Opening the black box in Australia and China. Journal of Leadership and Organizational Studies, 12, 68-84, http://dx.doi.org/10.1177/107179190601200305.

CB Richard Ellis Hotels. (2009). Hotel operators in China: New opportunities in a more sophisticated marketplace. CBRE Research, Asia and CBRE Hotels.

Central Intelligence Agency (CIA) (2009). Field listing - GDP - composition by sector. Accessed in 9 Sep. 2010. https://www.cia.gov/library/publications/the-world-factbook/ index.html

Chan, S., \& Jepsen, D. M. (2011). Workplace relationships, attitudes, and organizational justice: A hospitality shift worker contextual perspective. Journal of Human Resources in Hospitality \& Tourism, 10, 150-167. Retrieved from http://ezproxy.fiu.edu/login?url=http://search.proquest.com.ezproxy.fiu.edu/docvi ew/874080865? accountid=10901

Chathoth, P. K., \& Olsen, M. D. (2002). Organizational Leadership and Strategy in the Hospitality Industry. Journal of Services Research, 2, 5-29. Retrieved from http://ezproxy.fiu.edu/login?url=http://search.proquest.com/docview/195568368? accountid=10901

Chen, C. C., Chen, Y. R. \& Xin, K. (2004). Guanxi practices and trust in management: A procedural justice perspective, Organization Science, 15, 200-209. 
Chen, K. (2005). Factors affecting job satisfaction of public sector employees in Taiwan (Order No. 3193840). Available from ABI/INFORM Collection; ProQuest Dissertations \& Theses A\&I; ProQuest Dissertations \& Theses Global. (305354854). Retrieved from http://ezproxy.fiu.edu/login?url=http://search.proquest.com.ezproxy.fiu.edu/docvi ew/305354854?accountid=10901

Choi, J., \& Chen, C. C. (2007). The relationships of distributive justice and compensation system fairness to employee attitudes in international joint ventures. Journal of Organizational Behavior, 28, 687-703. doi: http://dx.doi.org.ezproxy.fiu.edu/10.1002/job.438

Christ, T. J. (2007). Experimental control and threats to internal validity of concurrent and non-concurrent multiple baseline designs. Psychology in the Schools, 44, 451459. doi:http://dx.doi.org.ezproxy.fiu.edu/10.1002/pits.20237

Chun, J. U., Yammarino, F. J., Dionne, S. D., Sosik, J. J., \& Moon, H. K. (2009). Leadership across hierarchical levels: Multiple levels of management and multiple levels of analysis. The Leadership Quarterly, 20, 689-707, http://dx.doi.org/10.1016/j.leaqua.2009.06.003.

Collings, D. G., \& Scullion, H. (2009). Global staffing. The International Journal of Human Resource Management, 20, 1249-1252.

Colquitt, J. A. (2001). On the dimensionality of organizational justice: A construct validation of a measure. Journal of Applied Psychology, 86, 386-400. Retrieved from http://ezproxy.fiu.edu/login?url=http://search.proquest.com.ezproxy.fiu.edu/docvi ew/619619585?accountid=10901

Colquitt, J. A., Conlon, D. E., Wesson, M. J., Porter, C. O. L. H., \& Ng, K. Y. (2001). Justice at the millennium: A meta-analytic review of 25 years of organizational justice research. Journal of Applied Psychology, 86, 425-445. Retrieved from http://ezproxy.fiu.edu/login?url=http://search.proquest.com.ezproxy.fiu.edu/docvi $\underline{\text { ew/619608476? accountid=10901 }}$

Cohen, J. (1988). Statistical power analysis for the behavioral sciences. San Diego, CA: Academic Press.

Cohen-Charash, Y., \& Spector, P. E. (2001). The role of justice in organizations: A metaanalysis. Organizational Behavior and Human Decision Processes, 86(2), 278321. doi:http://dx.doi.org.ezproxy.fiu.edu/10.1006/obhd.2001.2958 
Colquitt, A., Greenberg, J.(2005).In Handbook of organizational justice, by Greenberg, Jerald (ed.) ; Colquitt, Jason A (ed.) . 3-56, Chapter xxvi, 647 Pages. Mahwah, NJ, US: Lawrence Erlbaum Associates Publishers

Couper, M. P. (2000). Web surveys: A review of issues and approaches. Public Opinion Quarterly, 56, 464-494.

Chan, F., Lee, G. K., Lee, E., Kubota, C., \& Allen, C. A. (2007). Structural equation modeling in rehabilitation counseling research. Rehabilitation Counseling Bulletin, 51(1), 44-57. Retrieved from http://ezproxy.fiu.edu/login?url=https://search-proquestcom.ezproxy.fiu.edu/docview/213918040?accountid=10901

Chen, Y., Friedman, R., Yu, E.,\& Sun, F. (2011). Examining the positive and negative effects of guanxi practices: A multi-level analysis of guanxi practices and procedural justice perceptions, Asia Pacific Journal of Management, 28, 715-735.

Cheung, G. W., \& Lau, R. S. (2007). Testing mediation and suppression effects of latent variables: Bootstrapping with structural equation modeling. Organizational Research Methods, 11, 296-325. doi:10.1177/1094428107300343.

Chen, Zhenjiao; Zhang, Xi; Leung, Kwok; Zhou, Fan.Journal of social psychology Vol. 150, Iss. 2, (Mar 2010): 181-197.

Chou, S. Y., Han, B., \& Zhang, X. (2014). Effect of guanxi on Chinese subordinates' work behaviors: A conceptual framework. Asia-Pacific Journal of Business Administration, 6, 18-35. Retrieved from http://ezproxy.fiu.edu/login?url=http://search.proquest.com.ezproxy.fiu.edu/docvi ew/1512637971? accountid=10901

Chow Lee, J. W., Mohamad, O., \& Ramayah, T. (2010). Outsourcing: Is the social exchange theory still relevant in developing countries? An international journal. Journal of Research in Interactive Marketing, 4(4), 316-345. doi:http://dx.doi.org.ezproxy.fiu.edu/10.1108/17505931011092826

Chung, R. (2001). Job satisfaction and organizational commitment among junior high school counselors in Taipei, Taiwan (Order No. 3004518). Available from ProQuest Dissertations \& Theses A\&I; ProQuest Dissertations \& Theses Global. (251759948). Retrieved from http://ezproxy.fiu.edu/login?url=http://search.proquest.com.ezproxy.fiu.edu/docvi ew/251759948? accountid=10901

Creswell, J. W. (2002). Research design: Qualitative, quantitative, and mixed methods approaches (2nd ed.). Thousand Oaks, CA: SAGE Publications, Inc. 
Creswell, J. W. (2014). Research design: Qualitative, quantitative, and mixed methods approaches (4th ed.). Thousand Oaks, California: SAGE Publications.

Crawford, S., McCabe, S., Couper, M., \& Boyd, C. (2002). From mail to web: Improving response rates and data collection efficiencies. International Conference on Improving Surveys. Copenhagen, DK.

Cropanzano, R., \& Greenberg, J. (1997). Progress in organizational justice: Tunneling through the maze. In C. L. Cooper., \& I. T. Robertson (Eds.), International Review of Industrial and Organizational Psychology, 12, 317-372. Chichester, ENG: John Wiley \& Sons.

Cunningham, J. A., Neighbors, C., Bertholet, N., Hendershot, C. S. (2013). Use of mobile devices to answer online surveys: Implications for research. BMC Research Notes, 6, 258.

Damen, L. (1987). Culture learning: The fifth dimension on the language classroom. Reading, MA: Addison-Wesley.

Daniels, J. D., \& Insch, G. S. (1998). Why are early departure rates from foreign assignments lower than historically reported? International Journal of Intercultural Relation, 6, 13-23.

De Bruijne, M., \& Wijnant, A. (2013). Comparing survey results obtained via mobile devices and computers: An experiment with a mobile web survey on a heterogeneous group of mobile devices versus a computer-assisted web survey. Social Science Computer Review, 31, 482-504. doi:http://dx.doi.org.ezproxy.fiu.edu/10.1177/0894439313483976

DeFeo, D. J. (2013). Toward a model of purposeful participant inclusion: Examining deselection as a participant risk. Qualitative Research Journal, 13, 253-264. Retrieved from http://ezproxy.fiu.edu/login?url=http://search.proquest.com.ezproxy.fiu.edu/docvi ew/1625384376? accountid=10901

Dillman, D. A., Sinclair, M. D., \& Clark, J. R. (1993). Effects of questionnaire length, respondent-friendly design, and a diffucult question on response rates for occupant-addressed census mail surveys. Oxford Journals, 57, 289-304.

Dillman, D. A., Smyth, J. D., \& Christian, L. M. (2016). Internet, phone, mail and mixedmode surveys: The tailored design method. Revista Española De Investigaciones Sociológicas, (154), 161. Retrieved from http://ezproxy.fiu.edu/login?url=http://search.proquest.com.ezproxy.fiu.edu/docvi ew/1793123396?accountid=10901 
Dillman, D. A., Smyth, J. D., \& Christian, L. M. (2009). Internet, mail, and mixed-mode surveys: The tailored design method ( $3^{\text {rd }}$.ed.) John Wiley \& Sons Inc, Hoboken, NJ. Retrieved from http://ezproxy.fiu.edu/login?url=http://search.proquest.com.ezproxy.fiu.edu/docvi ew/621615353? accountid=10901

Dong, K., \& Liu, Y. (2010). Cross-cultural management in China. Cross Cultural Management, 17, 223-243. doi:http://dx.doi.org.ezproxy.fiu.edu/10.1108/13527601011068333

Dubinsky, A. J., Yammarino, F. J., Jolson, M. A. \& Spangler, W. D., (1995). Transformational leadership: An initial investigation in sales management, Journal of Personal Selling and Sales Management, 15, 17-29.

Dunbar, E., \& Ehrlich, M. (1986). International practices, selection, training and managing the international staff: A survey report. Project on International Human Resource. New York: Columbia University, Teachers College.

Durant, L. E., Carey, M. P., \& Schroder, K. E. E. (2002). Effects of anonymity, gender, and erotophilia on the quality of data obtained from self-reports of socially sensitive behaviors. Journal of Behavioral Medicine, 25, 439-467. doi:http://dx.doi.org.ezproxy.fiu.edu/10.1023/A:1020419023766

Du, J., Liao, J.Q. and Wang, F.S. (2005), “The study of justice perception in performance management and the degree of satisfaction", Science \& Technology Progress and Policy, Vol. 7 No. 3, pp. 191-192.

Duffy, Jo Ann M; Miller, John M; Bexley, James B. International Journal of Bank Marketing Vol. 24, Iss. 2, (2006): 112-132.

Egan, T. M., Yang, B., \& Bartlett, K. R. (2004). The effects of organizational learning culture and job satisfaction on motivation to transfer learning and turnover intention. Human Resource Development Quarterly, 15, 279-301. http://dx.doi.org.ezproxy.fiu.edu/10.1002/hrdq.1104 Retrieved from http://ezproxy.fiu.edu/login?url=https://search-proquestcom.ezproxy.fiu.edu/docview/620655407?accountid=10901

Erkutlu, H. (2008). The impact of transformational leadership on organizational and leadership effectiveness. The Journal of Management Development, 27, 708-726. doi:http://dx.doi.org.ezproxy.fiu.edu/10.1108/02621710810883616

Elamin, A. M. (2012). Perceived organizational justice and work-related attitudes: A study of Saudi employees. World Journal of Entrepreneurship, Management and Sustainable Development, 8, 71-88.

doi:http://dx.doi.org.ezproxy.fiu.edu/10.1108/20425961211221633 
Evans, J. R., and Mathur, A. (2005). The value of online surveys. Internet Research, 15(2):195-219 Retrieved from https://www.researchgate.net/publication/220146842_The_Value_of_Online_Sur veys

FAU. (2014, March 18). Hospitality management. Retrieved from Florida Atlantic University College of Business: http://business.fau.edu/undergraduate/majors/hospitalitymanagement/index.aspx\#.UyhpFqhdV8E

Hotel expatriate managers in China: Selection criteria, important skills and knowledge, repatriation concerns, and causes of failure. International Journal of Hospitality Management, 18, 309-321.

Fodchuk, K. M. (2009). Organizational justice perceptions in china: Development of the Chinese organizational justice scale (Order No. 3374154). Available from ProQuest Dissertations \& Theses A\&I; ProQuest Dissertations \& Theses Global. (305071073). Retrieved from http://ezproxy.fiu.edu/login?url=http://search.proquest.com.ezproxy.fiu.edu/docvi ew/305071073?accountid=10901

Folger, R., \&. Konovsky. M. A. (1989). Effects of procedural and distributive justice on reactions to pay raise decisions. The Academy of Management Journal, 32, 115130. doi: $10.2307 / 256422$.

Fisher, C. D. (2000). Mood and emotions while working: Missing pieces of job satisfaction? Journal of Organizational Behavior, 21, 185-202. Retrieved from http://ezproxy.fiu.edu/login?url=http://search.proquest.com.ezproxy.fiu.edu/docvi ew/224868072?accountid=10901

Fisher, G. B., \& Hartel, L. Z. (2003). Cross-cultural effectiveness of western expatriateThai client interactions: Lessons learned for IHRM research and theory. Cross Cultural Management, ??, 4-28.

Fu, Y., \& Zhang, L. (2012). Organizational justice and perceived organizational support. Nankai Business Review International, 3, 145-166. doi:http://dx.doi.org.ezproxy.fiu.edu/10.1108/20408741211244398

Gasper, J. M. (1992). Transformational leadership: An integrative review of the literature (Order No. 9234203). Available from ProQuest Dissertations \& Theses A\&I; ProQuest Dissertations \& Theses Global. (304010939). Retrieved from http://ezproxy.fiu.edu/login?url=http://search.proquest.com.ezproxy.fiu.edu/docvi ew/304010939?accountid=10901 
Gaertner, S. (1999). Structural determinants of job satisfaction and organizational commitment in turnover model. Human Resource Management Review, 9, 479493.

Ge, C., Fu, J., Chang, Y., \& Wang, L. (2011). Factors associated with job satisfaction among Chinese community health workers: A cross-sectional study. BMC Public Health, 11, 884-896. doi:http://dx.doi.org.ezproxy.fiu.edu/10.1186/1471-2458-11884

Gerstner, C. R., \& Day, D. V. (1997). Meta-analytic review of leader-member exchange theory: Correlates and construct issues. Journal of Applied Psychology, 82, 827844. Retrieved from http://ezproxy.fiu.edu/login?url=http://search.proquest.com.ezproxy.fiu.edu/docvi ew/619194982? accountid=10901

Graves, L. M., Sarkis, J., \& Zhu, Q. (2013). How transformational leadership and employee motivation combine to predict employee proenvironmental behaviors in China. Journal of Environmental Psychology, 35, 81-91. doi:http://dx.doi.org.ezproxy.fiu.edu/10.1016/j.jenvp.2013.05.002

Groves, R. M., Fowler, F. J., Couper, M., Lepkowski, J., Singer, E., \& Tourangeau, R. (2009). Survey methodology. Hoboken, New Jersey: John Wiley \& Sons, Inc.

George, J.M. and Jones, G.R. (2012), Understanding and managing organizational behavior. Pearson Prentice Hall, New Jersey, NJ.

Guzzo, R. A., Noonan, K. A., \& Elron, E. (1994). Expatriate managers and the psychological contract. Journal of Applied Psychology, 79, 617-626.

Gundersen, G., Helles $\varnothing y$, B.T. and Raeder, S. (2012). Leading international project teams: The effectiveness of transformational leadership in dynamic work environments. Journal of Leadership \& Organizational Studies, 19, 46-57.

Gu, Z., \& Sen, R. C. (2009). Drivers of job satisfaction as related to work performance in macao casino hotels: An investigation based on employee survey. International Journal of Contemporary Hospitality Management, 21(5), 561-578. doi:http://dx.doi.org.ezproxy.fiu.edu/10.1108/09596110910967809

Greenberg, J. (1990). Organizational justice: Yesterday, today, and tomorrow. Journal of Management, 16, 399-432.

Gillet, B., \& Schwab, D. P. (1975). Convergent and discriminant validities of corresponding job descriptive index and Minnesota satisfaction questionnaire scales. Journal of Applied Psychology, 60, 313-317. Retrieved from 
http://ezproxy.fiu.edu/login?url=http://search.proquest.com.ezproxy.fiu.edu/docvi ew/616018350?accountid=10901

Gibb, S., \& Zhang, S. (2017). Guanxi influence and talent management in Chinese organisations; evidence from the real estate sector. Human Resource Development International, 20, 79-98. http://dx.doi.org.ezproxy.fiu.edu/10.1080/13678868.2016.1240394 Retrieved from http://ezproxy.fiu.edu/login?url=https://search-proquestcom.ezproxy.fiu.edu/docview/1869131867? accountid=10901

Guo, C. (2009). The meaning and effects of organizational justice in a layoff situation: An indigenous Chinese investigation (Order No. 3379961). Available from ProQuest Dissertations \& Theses A\&I; ProQuest Dissertations \& Theses Global. (304924039). Retrieved from http://ezproxy.fiu.edu/login?url=http://search.proquest.com.ezproxy.fiu.edu/docvi ew/304924039? accountid=10901

Guo, Q.H. and Wang, D.F. (2008), “The empirical study about pay fairness and employee satisfaction", Statistics and Decision, Vol. 13 No. 3, pp. 91-93.

Han, Y., Peng, Z., \& Zhu, Y. (2012). Supervisor-subordinate guanxi and trust in supervisor: A qualitative inquiry in the People's Republic of China, Journal of Business Ethics, 108, 313-324.

Hao, Y., Hao, J., \& Wang, X. (2016). The relationship between organizational justice and job satisfaction. Journal of Chinese Human Resources Management, 7(2), 115128. doi:http://dx.doi.org.ezproxy.fiu.edu/10.1108/JCHRM-07-2016-0012

Han, Y., \& Altman, Y. (2009). Supervisor and subordinate guanxi: A grounded investigation in the People's Republic of China. Journal of Business Ethics, 88, 91-104. doi:http://dx.doi.org.ezproxy.fiu.edu/10.1007/s10551-008-9827-8

Harrison, J. K. (1994). Developing successful expatriate managers: A framework for the structural design and strategic alignment of cross-cultural training programs. Human Resource Planning, 17, 17-35.

Hair, J.F., Black, W.C, Babin, B.j., \& Anderson, R.E.(2010).Multivariate date analysis:A Global Perspective.Upper Sadder River,NJ:Prentice-Hall.

Hebert, J. R., Clemow, L., Pbert, L., Ockene, I. S., \& Ockene, J. K. (1995). Social desirability bias in dietary self-report may compromise the validity of dietary intake measures. International Journal of Epidemiology, 24, 389-398. Retrieved from

http://ezproxy.fiu.edu/login?url=http://search.proquest.com.ezproxy.fiu.edu/docvi ew/77446774? accountid=10901 
Herzberg, F., Mausner, B. and Snyderman, B. (1959). The motivation to work. New York, NY: Wiley.

Heskett, J. L., \& Schlesinger, L. A. (1994). Putting the service-profit chain to work. Harvard Business Review, 72, 164-174. Retrieved from http://ezproxy.fiu.edu/login?url=http://search.proquest.com.ezproxy.fiu.edu/docvi ew/38669673? accountid=10901

Heiervang, E., \& Goodman, R. (2011). Advantages and limitations of web-based surveys: Evidence from a child mental health survey. Social Psychiatric Epidemiology, 46, 69-76.

Hines, M.A. (1984). Overseas investment in Chinese hotel joint ventures, Real Estate Issues, 9, 45-7.

HSBC. (2013). Expat explorer survey 2013. HSBC.

Hoffman, B. J., \& Frost, B. C. (2006). Multiple intelligences of transformational leaders: An empirical examination. International Journal of Manpower, 27, 37-51. doi:http://dx.doi.org.ezproxy.fiu.edu/10.1108/01437720610652826

Hooper, D., Coughlan, J., \& Mullen, M. (2008). Structural equation modeling: Guidelines for determining model fit.

Homans, G. C. (1958). Social behavior as exchange. American Journal of Sociology, 63, 597-606. doi: http://dx.doi.org/10.1086/222355

Hogg, M. A., Martin, R., Epitropaki, O., Mankad, A., \& E. (2005). Effective leadership in salient groups: Revisiting leader-member exchange theory from the perspective of the social identity theory of leadership. Personality and Social Psychology Bulletin, 31, 991-1004. Retrieved from http://ezproxy.fiu.edu/login?url=http://search.proquest.com.ezproxy.fiu.edu/docvi $\underline{\text { ew/213989327? accountid=10901 }}$

Horn, C., Snyder, B. P., Coverdale, Louie, A. K., \& Roberts, L. (2009). Educational research questions and study design. Academic Psychiatry, 33, 261-7. Retrieved from http://ezproxy.fiu.edu/login?url=https://search-proquestcom.ezproxy.fiu.edu/docview/196523430?accountid=10901

Hon, A. H., Lu, L., \& Chan, W. W. (2015). Does cultural value exacerbate or mitigate the effect of perceived compensation gap between locals and expatriates in hotel industry? International Journal of Hospitality Management, 48, 83-91. doi:10.1016/j.ijhm.2014.12.006 
Hoonakker, P., \& Carayon, P. (2009). Questionnaire survey nonresponse: A comparison of postal mail and internet surveys. International Journal of Human - Computer Interaction, 25, 348-359. Retrieved from http://ezproxy.fiu.edu/login?url=http://search.proquest.com.ezproxy.fiu.edu/docvi ew/228821819? accountid=10901

Hooper, D., Coughlan, J., \& Mullen, M. (2008). Structural equation modeling: Guidelines for determining model fit. Retrieved from online www.dit.ie.

Hwang, Y.-H., \& Fesenmaier, D. (2004). Coverage error embedded in self-selected internet-based samples: A case study of northern Indiana. Journal of Travel Research

Huong, L., Zheng, C., \& Fujimoto, Y. (2016). Inclusion, organizational justice and employee well-being. International Journal of Manpower, 37, 945-964. Retrieved from http://ezproxy.fiu.edu/login?url=https://search-proquestcom.ezproxy.fiu.edu/docview/1826443007?accountid=10901

Igwebuike, J. G. (1998). Networking strategies and degree of job satisfaction of greater columbus, ohio managers (Order No. 9900848). Available from ABI/INFORM Collection; ProQuest Dissertations \& Theses A\&I; ProQuest Dissertations \& Theses Global. (304451326). Retrieved from http://ezproxy.fiu.edu/login?url=http://search.proquest.com.ezproxy.fiu.edu/docvi ew/304451326? accountid=10901

InterContinental Hotels Group. (2013, September 30). IHG hotel and room world stats. Retrieved January 30, 2014, from http://www.ihgplc.com/files/pdf/factsheets/factsheet_worldstats.pdf

IHG announces global partnership with alipay; IHG(R) becomes the first global hotel company to commit to offering alipay via its online and mobile channels as well as across all hotels globally. (2016, Aug 24). M2 Presswire Retrieved from http://ezproxy.fiu.edu/login?url=http://search.proquest.com.ezproxy.fiu.edu/docvi ew/1813580409? accountid=10901

Imberman, M. D. (2009). Organizational change and organizational justice: Assessing the impact on organizational commitment, change -oriented organizational citizenship behavior, and attitude toward future change (Order No. 3368103). Available from ProQuest Dissertations \& Theses A\&I; ProQuest Dissertations \& Theses Global. (305171397). Retrieved from http://ezproxy.fiu.edu/login?url=http://search.proquest.com.ezproxy.fiu.edu/docvi ew/305171397? accountid=10901

Jick, T. D. (1979). Mixing qualitative and quantitative methods: Triangulation in action. Administrative Science Quarterly, 24, 602-611. 
Johnson, B. (2001). Toward a new classification of nonexperimental quantitative research. Educational Researcher, 30(2), 3-13. Retrieved from http://ezproxy.fiu.edu/login?url=http://search.proquest.com.ezproxy.fiu.edu/docvi ew/62356078?accountid=10901

Judge, T. A., \& Piccolo, R. F. (2004). Transformational and transactional leadership: A meta-analytic test of their relative validity. The Journal of Applied Psychology, 89, 755-768. Retrieved from http://ezproxy.fiu.edu/login?url=http://search.proquest.com.ezproxy.fiu.edu/docvi $\underline{\text { ew/67012235? accountid }=10901}$

Kara, D., Uysal, M., \& Magnini, V. P. (2012). Gender differences on job satisfaction of the five-star hotel employees. International Journal of Contemporary Hospitality Management, 24, 1047-1065. doi:http://dx.doi.org.ezproxy.fiu.edu/10.1108/09596111211258919

Kaye, M., \& Taylor, W. G. (1997). Expatriate culture shock in China: A study in the Beijing hotel industry. Journal of Managerial Psychology, 15, 496.

Kaneshiro, P. (2008). Analyzing the organizational justice, trust, and commitment relationship in a public organization (Order No. 3299220). Available from ProQuest Dissertations \& Theses A\&I; ProQuest Dissertations \& Theses Global. (304827950). Retrieved from http://ezproxy.fiu.edu/login?url=http://search.proquest.com.ezproxy.fiu.edu/docvi ew/304827950?accountid=10901

Kinicki, A. J., Mckee-Ryan, F. M., Schriesheim, C. A., \& Carson, K. P. (2002).

Assessing the construct validity of the job descriptive index: A review and metaanalysis. Journal of Applied Psychology, 87, $14-32$.

http://dx.doi.org/10.1037/0021-9010.87.1.14

Kaur, S., \& Pandian, A. (2007). Higher education in Malaysia: Issues and challenges. In Z. Moris (Ed.), 50 Years of Higher Education Development in Malaysia (19572007), Penerbit USM, pp. 121-147.

Kline, R. B. (2009). Principals and practice of structural equation modeling. New York: Guilford.

Keith, T. Z. (1993). Latent variable structural equation models: LISREL in special education research. RASE: Remedial \& Special Education, 14(6), 36-46. doi:http://dx.doi.org.ezproxy.fiu.edu/10.1177/074193259301400609

Khalilzadeh, J., Giacomo, D. C., Jafari, J., \& Hamid, Z. B. (2013). Methodological approaches to job satisfaction measurement in hospitality firms. International 
Journal of Contemporary Hospitality Management, 25, 865-882. Retrieved from http://ezproxy.fiu.edu/login?url=http://search.proquest.com.ezproxy.fiu.edu/docvi ew/1425378663? accountid $=10901$

King, C. (2010). "One size doesn't fit all": Tourism and hospitality employees' response to internal brand management. International Journal of Contemporary Hospitality Management, 22, 517-534. Retrieved from http://ezproxy.fiu.edu/login?url=http://search.proquest.com.ezproxy.fiu.edu/docvi ew/1282237629?accountid $=10901$

Kim, S., Magnusen, M., Andrew, D., \& Stoll, J. (2012). Are transformational leaders a double-edged sword? Impact of transformational leadership on sport employee commitment and job satisfaction. International Journal of Sports Science \& Coaching, 7, 661-676. doi:http://dx.doi.org.ezproxy.fiu.edu/10.1260/17479541.7.4.661

Kobrin, S. (1988). Expatriate reduction and strategic control in American multinational corporations. Human Resource Management, 5, 63-75.

Kong, H., \& Cheung, C. (2009). Hotel development in china: A review of the English language literature. International Journal of Contemporary Hospitality Management, 21, 341-355. doi:http://dx.doi.org.ezproxy.fiu.edu/10.1108/09596110910948332

Kraimer, M. L., Wayne, S. J., \& Jaworski, R. A. (2001). Sources of support and expatriate performance: The mediating role of expatriate adjustment. Personal Psychology, 54, 71-99.

Kirkman, B.L., Chen, G., Farh, J.-L, \& Lowe, K.B. (2009). Individual power distance orientation and follower reactions to transformational leaders: A cross-level, cross-cultural examination. Academy of Management Journal, 52, 744-764.

Lambe, C. Jay; Wittmann, C. Michael; Spekman, Robert E. (2001). "Social Exchange Theory and Research on Business-to-Business Relational Exchange". Journal of Business-to-Business Marketing. 8 (3): 1-36. doi:10.1300/J033v08n03_01

Lee, H. (2000). An empirical study of organizational justice as a mediator of the relationships among leader -member exchange and job satisfaction, organizational commitment, and turnover intentions in the lodging industry (Order No. 9974193). Available from ABI/INFORM Collection; ProQuest Dissertations \& Theses A\&I; ProQuest Dissertations \& Theses Global. (304652754). Retrieved fromhttp://ezproxy.fiu.edu/login?url=http://search.proquest.com.ezproxy.fiu.edu/d ocview/304652754?accountid=10901 
Lee, K. (2002). China's hotel boom. The China Business Review, 29(6), 4-8. Retrieved from

http://ezproxy.fiu.edu/login?url=http://search.proquest.com.ezproxy.fiu.edu/docvi ew/202675814? accountid=10901

Leventhal, G. S. (1980). What should be done with equity theory? New approaches to the study of fairness in social relationship. In K. Gergen, M. Greenberg, \& R. Willis (Eds.), Social exchange: Advances in theory and research (pp. 27-55). New York: Plenum Press.

Lester, S. (1999). An introduction to phenomenological research. Taunton UK: Stan Lester Developments.

Leung, K., Wang, Z., \& Smith, P. (2010). Job attitudes and organizational justice in joint venture hotels in China: The role of expatriate managers. The International Journal of Human Resource Management, 4, 926-945.

Leung, K., Wang, Z., \& Hon, A. H. Y. (2011). Moderating effects on the compensation gap between locals and expatriates in china: A multi-level analysis. Journal of International Management, 17, 54-67. doi:http://dx.doi.org.ezproxy.fiu.edu/10.1016/j.intman.2010.12.002

Leung, K., Zhu, Y., \& Ge, C. (2009), Compensation disparity between locals and expatriates: moderating the effects of perceived injustice in foreign multinationals in China. Journal of World Business, 44, 85-93.

Lewis, B. (2006). Send the right people to the right places. People Management, 5, 85101.

Li, C., Wu, K., Johnson, D. E., \& Wu, M. (2012). Moral leadership and psychological empowerment in china. Journal of Managerial Psychology, 27, 90-108. doi:http://dx.doi.org.ezproxy.fiu.edu/10.1108/02683941211193875

Li-Yueh, L., Veasna, S., \& Wu, W. (2013). The effects of social support and transformational leadership on expatriate adjustment and performance. Career Development International, 18, 377-415. doi: http://dx.doi.org/10.1108/CDI-062012-0062

Lin, S. (2003). Relationship among conflict management styles, employees' job satisfaction and team effectiveness: A comparison between public and private hospitals in Taiwan (China) Available from PsycINFO. (620253037; 200395021-036). Retrieved from http://ezproxy.fiu.edu/login?url=http://search.proquest.com.ezproxy.fiu.edu/docvi ew/620253037?accountid=10901 
Lin, L., \& Chang, C. (2003). A Chinese translation of the EdFED-Q and assessment of equivalence. Alzheimer Disease and Associated Disorders, 17, 230-235. doi:http://dx.doi.org.ezproxy.fiu.edu/10.1097/00002093-200310000-00006

Liu, P. (2018). Transformational Leadership Research in China (2005-2015). Chinese Education \& Society. 51. 372-409. 10.1080/10611932.2018.1510690.

Loi, C. H. (2006). The roles of perceived organizational support, social exchange, and economic exchange in employment relationships in China (Order No. 3254527). Available from ProQuest Dissertations \& Theses A\&I; ProQuest Dissertations \& Theses Global. (304908922). Retrieved from http://ezproxy.fiu.edu/login?url=https://search-proquestcom.ezproxy.fiu.edu/docview/304908922?accountid=10901

Lu"dtke, O., Robitzsch, A., Trautwein, U., \& Kunter, M. (2009). Assessing the impact of learning environments: How to use student ratings of classroom or school characteristics in multilevel modeling.

López-Cabarcos, M. Á., Machado-Lopes-Sampaio-de Pinho, A. I., \& VázquezRodríguez, P. (2015). The influence of organizational justice and job satisfaction on organizational commitment in Portugal's hotel industry. Cornell Hospitality Quarterly, 56, 258-272. Retrieved from http://ezproxy.fiu.edu/login?url=http://search.proquest.com.ezproxy.fiu.edu/docvi ew/1701494683? accountid=10901

Lopes, S., Chambel, M. J., Castanheira, F., \& Oliveira-Cruz, F. (2015). Measuring job satisfaction in Portuguese military sergeants and officers: Validation of the job descriptive index and the job in general scale. Military Psychology, 27, 52-63. Retrieved from http://ezproxy.fiu.edu/login?url=http://search.proquest.com.ezproxy.fiu.edu/docvi ew/1645215459?accountid=10901

Lyon, M. L. (2006). The relation of managers' perceptions of their leadership styles to parenting styles in their families of origin (Order No. 3209590). Available from ABI/INFORM Collection; ProQuest Dissertations \& Theses A\&I; ProQuest Dissertations \& Theses Global. (304948790). Retrieved from http://ezproxy.fiu.edu/login?url=http://search.proquest.com.ezproxy.fiu.edu/docvi ew/304948790?accountid=10901

MacKinnon, D. P., Lockwood, C. M., Hoffman, J. M., West, S. G., \& Sheets, V. (2002). A comparison of methods to test mediation and other intervening variable effects. Psychological Methods, 7, 83-104. doi:http://dx.doi.org.ezproxy.fiu.edu/10.1037/1082-989X.7.1.83 
Magnini, V. P., \& Honeycutt Jr., E. D. (2003). Learning orientation and the hotel expatriate manager experience. International Journal of Hospitality Management, $22,267-280$.

Miao, R., Sun, J., Hou, X., \& Li, T. (2012). Job satisfaction: Linking perceived organizational support, organizational justice with work outcomes in china.Frontiers of Business Research in China, 6(2), 169-200. Retrieved from http://ezproxy.fiu.edu/login?url=https://search-proquestcom.ezproxy.fiu.edu/docview/1720467823?accountid=10901

Mardanov, I., Sterrett, J., \& Baker, J. (2007). Satisfaction with supervision and member job satisfaction in leader-member exchange: An empirical study in the restaurant industry. Journal of Applied Management and Entrepreneurship, 12, 37-56. Retrieved from http://ezproxy.fiu.edu/login?url=http://search.proquest.com.ezproxy.fiu.edu/docvi ew/203913526? accountid=10901

Marsh, H. W., Hau, K.-T., \& Wen, Z. (2004). In search of golden rules: Comment on hypothesis-testing approaches to setting cutoff values for fit indices and dangers in overgeneralizing $\mathrm{Hu}$ and Bentler's 1999 findings. Structural Equation Modeling, 11, 320-341. doi:10.1207/s15328007sem1103_2.

Masterson, S., Lewis, K., Goldman, B., \& Taylor, M. (2000). Integrating justice and social exchange: The differing effects of fair procedures and treatment on work relationships. Academy of Management Journal, 43, 738-748.

McAuliffe, Eilish; Manafa, Ogenna; Maseko, Fresier; Bowie, Cameron; White, Emma; et al.Reproductive health matters Vol. 17, Iss. 33, (May 2009): 80-90.

McCabe, S. E. (2004). Comparison of web and mail surveys in collecting illicit drug use data: A randomized experiment. Journal of Drug Education, 34, 61-72. doi:http://dx.doi.org.ezproxy.fiu.edu/10.2190/4hey-vwxl-dvr3-hakv

McNulty, Y. (2015). The added value of expatriation: Assessing the return on investment of international assignments. Human resource management practices: Assessing added value. (pp. 89-106). City: Springer International Publishing, Cham. doi:http://dx.doi.org.ezproxy.fiu.edu/10.1007/978-3-319-08186-1_6

McPhail, R., Patiar, A., Herington, C., Creed, P., \& Davidson, M. (2015). Development and initial validation of a hospitality employees' job satisfaction index.

International Journal of Contemporary Hospitality Management, 27, 1814-1838. Retrieved from http://ezproxy.fiu.edu/login?url=http://search.proquest.com.ezproxy.fiu.edu/docvi ew/1735347965?accountid=10901 
Mendenhall, M., \& Oddou, G. (1985). The dimensions of expatriate acculturation: A review. Academy of Management Review, 10, 39-47.

Merriam-Webster. (2014). Retrieved March 17, 2014, from http://www.merriamwebster.com/dictionary/adaptation

Miles, M. B., \& Huberman, A. M. (1994). Qualitative data analysis: An expanded sourcebook (2nd ed.). Thousand Oaks, CA: Sage.

Miao, L., Adler, H., \& Xu, X. (2011). A stakeholder approach to expatriate management: Perceptions of hotel expatriate managers in china. International Journal of Hospitality Management, 30, 530-541. http://dx.doi.org.ezproxy.fiu.edu/10.1016/j.ijhm.2010.08.007

Miller, B. K., Konopaske, R., \& Byrne, Z. S. (2012). Dominance analysis of two measures of organizational justice. Journal of Managerial Psychology, 27, 264282. doi:http://dx.doi.org.ezproxy.fiu.edu/10.1108/02683941211205817

Moorman, R. H. (1991). Relationship between organizational justice and organizational citizenship behaviors: Do fairness perceptions influence employee citizenship? Journal of Applied Psychology, 76, 845-855. Retrieved from http://ezproxy.fiu.edu/login?url=http://search.proquest.com.ezproxy.fiu.edu/docvi ew/618093939? accountid=10901

Munyanyiwa, T. (2009). Impact of cultural context on the transfer of best leadership practices by international hotel firms (Order No. 3401040). Available from ABI/INFORM Collection; ProQuest Dissertations \& Theses A\&I; ProQuest Dissertations \& Theses Global. (305125032). Retrieved from http://ezproxy.fiu.edu/login?url=https://search-proquestcom.ezproxy.fiu.edu/docview/305125032?accountid=10901

Naumann, E. (1992). A conceptual model of expatriate turnover. Journal of International Business Studies, 8, 499-531.

Naftchi-Ardebili, S. (1988). Maternal employment and family socioeconomic status effects on daughter's self-concept and attitude towards women and work: LISREL models (Order No. 8815396). Available from ProQuest Dissertations \& Theses A\&I; ProQuest Dissertations \& Theses Global. (303569584). Retrieved from http://ezproxy.fiu.edu/login?url=https://search-proquestcom.ezproxy.fiu.edu/docview/303569584?accountid=10901

Nederhof, A. J. (1985). Methods of coping with social desirability bias: A review. European Journal of Social Psychology, 15, 263-280. doi:http://dx.doi.org.ezproxy.fiu.edu/10.1002/ejsp.2420150303 
Nedeljkovic, M., Hadzic, O., \& Cerovic, S. (2012). Organizational changes and job satisfaction in the hospitality industry in Serbia. UTMS Journal of Economics, 3, 105-117. Retrieved from http://ezproxy.fiu.edu/login?url=http://search.proquest.com/docview/1289019074 ?accountid=10901

Niehoff, B. P., \& Moorman, R. H. (1993). Justice as a mediator of the relationship between methods of monitoring and organizational citizenship behavior. Academy of Management Journal, 36, 527-546. Retrieved from http://ezproxy.fiu.edu/login?url=http://search.proquest.com.ezproxy.fiu.edu/docvi $\underline{\text { ew/199836120?accountid=10901 }}$

Ning-Kuang Chuang, Yin, D., \& Dellmann-Jenkins, M. (2009). Intrinsic and extrinsic factors impacting casino hotel chefs' job satisfaction. International Journal of Contemporary Hospitality Management, 21, 323-340. doi:http://dx.doi.org.ezproxy.fiu.edu/10.1108/09596110910948323

Northouse, P.G. (2004). Leadership: Theory and practice. Sage, Thousand Oaks, CA.

Osman-Gani, A. M., \& Rockstuhl, T. (2009). Cross-cultural training, expatriate selfefficacy, and adjustments to overseas assignments: An empirical investigation of managers in Asia. International Journal of Intercultural Relations, 19, 277-290.

Osman-Gani, A., \& Tan, W. (2005). Expatriate development for Asia-Pacific: A study of training contents and methods. International Journal of Human Resources Development and Management, 8, 41-56.

Onorato, M. (2013). Transformational leadership style in the educational sector: An empirical study of corporate managers and educational leaders. Academy of Educational Leadership Journal, 17, 33-47. Retrieved from http://ezproxy.fiu.edu/login?url=http://search.proquest.com/docview/1368593704 ?accountid=10901

Parks, K., Pardi, A., \& Bradizza, C. (2006). Collecting data on alcohol use and alcoholrelated victimization: A comparison of telephone and Web-based survey methods. Journal of Studies on Alcohol, 4, 318-323.

Pan, B., Shen, X., Liu, L., Yang, Y., \& Wang, L. (2015). Factors associated with job satisfaction among university teachers in northeastern region of china: A crosssectional study. International Journal of Environmental Research and Public Health, 12, 12761-12775. Retrieved from http://ezproxy.fiu.edu/login?url=http://search.proquest.com.ezproxy.fiu.edu/docvi ew/1733897180?accountid=10901 
Park, C. K. (2016). Predicting employee engagement: An exploration of the roles of transformational leadership, power distance orientation, psychological collectivism, and psychological empowerment in Korean organizations (Order No. 10005122). Available from ProQuest Dissertations \& Theses A\&I; ProQuest Dissertations \& Theses Global. (1762244324). Retrieved from http://ezproxy.fiu.edu/login?url=http://search.proquest.com.ezproxy.fiu.edu/docvi ew/1762244324?accountid=10901

Perez, D. F., Nie, J. X., Ardern, C. I., Radhu, N., \& Ritvo, P. (2013). Impact of participant incentives and direct and snowball sampling on survey response rate in an ethnically diverse community: Results from a pilot study of physical activity and the built environment. Journal of Immigrant and Minority Health, 15, $207-$ 214. doi:http://dx.doi.org.ezproxy.fiu.edu/10.1007/s10903-011-9525-y

Patiar, A., \& Mia, L. (2009). Transformational leadership style, market competition and departmental performance: Evidence from luxury hotels in Australia. International Journal of Hospitality Management, 28, 254-262.

Pine, R. (2000). Definition of 'expatriate'. In J. Jafari (Ed.), Encyclopedia of tourism (pp. 214-215). London: Routledge.

Pires, G., Stanton, J. and Ostenfeld, S. (2006), Improving expatriate adjustment and effectiveness in ethnically diverse countries: marketing insights. Cross Cultural Management: An International Journal, 13, 156-170.

Pizam, A., Shapoval, V., \& Ellis, T. (2016). Customer satisfaction and its measurement in hospitality enterprises: A revisit and update. International Journal of Contemporary Hospitality Management, 28(1), 2-35. Retrieved from http://ezproxy.fiu.edu/login?url=https://search-proquestcom.ezproxy.fiu.edu/docview/1752974497?accountid=10901

Pine, R., Zhang, Q.H. and Qi, P. (2000). The challenges and opportunities of franchising in China's hotel industry. International Journal of Contemporary Hospitality Management, 12, 35-57.

Podsakoff, P., \& MacKenzie, S. (2000). Transformational leader behaviors and their effects on followers' trust in leader, satisfaction, and organizational citizenship behaviors. Leadership Quarterly, 6, 92-105.

Podsakoff, P. M., MacKenzie, S. B., Lee, J., \& Podsakoff, N. P. (2003). Common method biases in behavioral research: A critical review of the literature and recommended remedies. Journal of Applied Psychology, 88, 879-903.

Podsakoff, P. M., MacKenzie, S. B., Moorman, R. H., \& Fetter, R. (1990).

Transformational leader behaviors and their effects on followers' trust in leader, 
satisfaction, and organizational citizenship behaviors. The Leadership Quarterly, 1(2), 107-142. Retrieved from

http://ezproxy.fiu.edu/login?url=http://search.proquest.com.ezproxy.fiu.edu/docvi ew/618248971? accountid=10901

Podsakoff, P. M., MacKenzie, S. B., \& Bommer, W. H. (1996). Transformational leader behaviors and substitutes for leadership as determinants of employee satisfaction, commitment, trust, and organizational citizenship behaviors. Journal of Management, 22, 259-278. Retrieved from http://ezproxy.fiu.edu/login?url=http://search.proquest.com.ezproxy.fiu.edu/docvi ew/197135401 ?accountid $=10901$

Porter, L.W., \& Lawler, E.E. (1968). What job attitudes tell about motivation? Harvard Business Review, 46, 118-126.

Qualtrics brings out 2012 business results. (2013). Entertainment Close - Up, Retrieved from http://ezproxy.fiu.edu/login?url=http://search.proquest.com.ezproxy.fiu.edu/docvi ew/1283870880?accountid=10901

Quelch, J. A., \& Bloom, H. (1999). Ten steps to global human resource strategy. Strategy and Business (First Quarter), 1-6.

Quinn, R.P., \& Mangione, T.W. (1973), Evaluating weighted models of measuring job satisfaction: A Cinderella story, Organizational Behavior and Human Performance, 10, 1-23.

Qin, C., \& Baruch, Y. (2010). The impact of cross-cultural training for expatriates in a Chinese firm. Career Development International, 15, 296-318

Qin, Q., Wen, B., Ling, Q., Zhou, S., \& Tong, M. (2014). How and when the effect of ethical leadership occurs? A multilevel analysis in the Chinese hospitality industry. International Journal of Contemporary Hospitality Management, 26, 974-1001. Retrieved from http://ezproxy.fiu.edu/login?url=http://search.proquest.com.ezproxy.fiu.edu/docvi ew/1660174376? accountid=10901

Raja, G., \& Krishnan, V. R. (2014). Relationship between organizational justice and commitment: Role of leader-member exchange. International Journal on Leadership, 2, 10-22. Retrieved from http://ezproxy.fiu.edu/login?url=https://search-proquestcom.ezproxy.fiu.edu/docview/1845259938?accountid=10901

Reio, T. G., Jr. (2010). The threat of common method variance bias to theory building. Human Resource Development Review, 9, 405-411. Retrieved from 
http://ezproxy.fiu.edu/login?url=http://search.proquest.com.ezproxy.fiu.edu/docvi ew/822506974? accountid=10901

Reio, T. G., Ghosh, R. (2009). Antecedents and outcomes of workplace incivility: Implications for human resource development research and practice. Human Resource Development Quarterly, 20, 237-264.

Reynolds, A. J., \& Walberg, H. J. (1991). A structural model of science achievement. Journal of Educational Psychology, 83, 97-107. doi:10.1037/0022-0663.83.1.97.

Robbins, S., \& Judge, T. A. (2013). Organizational behavior (Fifteenth ed.). Pearson.

Robbins, S.P. (1996). Organizational behavior: Concepts, controversies, \& applications. Prentice Hall, Englewood Cliffs, NJ.

Roch, S. G., \& Shanock, L. R. (2006). Organizational justice in an exchange framework: Clarifying organizational justice distinctions. Journal of Management, 32, 299322. Retrieved from http://ezproxy.fiu.edu/login?url=http://search.proquest.com.ezproxy.fiu.edu/docvi ew/621141707? accountid=10901

Rothfelder, K., Ottenbacher, M. C., \& Harrington, R. J. (2012). The impact of transformational, transactional and non-leadership styles on employee job satisfaction in the German hospitality industry. Tourism and Hospitality Research, 12, 201-214. doi:http://dx.doi.org.ezproxy.fiu.edu/10.1177/1467358413493636

Salem, I. E. (2015). Transformational leadership: Relationship to job stress and job burnout in five-star hotels. Tourism and Hospitality Research, 15, 240-253. doi:http://dx.doi.org.ezproxy.fiu.edu/10.1177/1467358415581445

Scullion, H. (1991). Why companies prefer to use expatriates. Personnel Management, $38,32-35$.

Schermerhorn, J. R., Hunt, J. G., Osborn, R. N., \& Uhl-Blen, M. (2010). Organizational behavior. John Wiley \& Sons, Hoboken, NJ.

Schielzeth, H., \& Forstmeier, W. (2009). Conclusions beyond support: Overconfident estimates in mixed models. Behavioral Ecology, 20, 416-420. doi:http://dx.doi.org.ezproxy.fiu.edu/10.1093/beheco/arn145

Schreiber, J. B., Nora, A., Stage, F. K., Barlow, E. A., \& King, J. (2006). Reporting Structural Equation Modeling and Confirmatory Factor Analysis results: A review. The Journal of Educational Research, 99, 323-338. doi:10.3200/JOER.99.6.323-338. 
Schneider, B., \& Dachler, H.P. (1978). A note on the stability of the job descriptive index, Journal of Applied Psychology, 63, 650-653.

Schonlau, M., Fricker, R.D. Jr and Elliott, M.N. (2001), Conducting Research Surveys via E-Mail and the Web, Rand Corporation, Santa Monica, CA.

Schriesheim, C. A., Neider, L. L., Scandura, T. A., \& Tepper, B. J. (1992). Development and preliminary validation of a new scale (LMX-6) to measure leader-member exchange in organizations. Educational and Psychological Measurement, 52, 135-147. Retrieved from http://ezproxy.fiu.edu/login?url=http://search.proquest.com.ezproxy.fiu.edu/docvi ew/618128461?accountid=10901

Schwarz, N. (1999). Self-reports: How the questions shape the answers. The American Psychologist, 54, 93-105. Retrieved from http://ezproxy.fiu.edu/login?url=http://search.proquest.com.ezproxy.fiu.edu/docvi ew/212130164?accountid=10901

Schyns, B., \& Croon, M. A. (2006). A model of task demands, social structure, and leader-member exchange and their relationship to job satisfaction. The International Journal of Human Resource Management, 17, 602-615. Retrieved from http://ezproxy.fiu.edu/login?url=http://search.proquest.com.ezproxy.fiu.edu/docvi ew/621353459?accountid=10901

Selmer, J. (2004). Psychological barriers to adjustment of Western business expatriates in China: newcomers vs long stayers. International Journal of Human Resource Management, 15, 794-813.

Selmer, J. (2000). A quantitative needs assessment technique for cross-cultural work adjustment training. Human Resource Development Quarterly, 11, 269-281. Retrieved from http://ezproxy.fiu.edu/login?url=http://search.proquest.com.ezproxy.fiu.edu/docvi ew/234903835?accountid=10901

Settoon, R., Bennett, N., \& Liden, R. C. 1996. Social exchange in organizations: Perceived organizational support, leader-member exchange, and employee reciprocity. Journal of Applied Psychology, 81, 219-227.

Sharma, A., \& Nambudiri, R. (2015). Job-leisure conflict, turnover intention and the role of job satisfaction as a mediator: An empirical study of Indian IT professionals dagger. South Asian Journal of Management, 22, 7-27. Retrieved from http://ezproxy.fiu.edu/login?url=http://search.proquest.com.ezproxy.fiu.edu/docvi ew/1690205079? accountid=10901 
Shiang-Lih, C. M., Tsai, H., \& Bellino, N. (2010). Organizational justice, employees' ethical behavior, and job satisfaction in the casino industry. International Journal of Contemporary Hospitality Management, 22, 992-1009.

doi:http://dx.doi.org.ezproxy.fiu.edu/10.1108/09596111011066644

Solomon, C.M. (1996). Danger below! Spot failing global assignments. Personnel Journal, 75, 78-85.

Shay, J., \& Tracey, J. (1997). Expatriate managers. Cornell Hotel and Restaurant Administration Quarterly, 42, 30-35.

Shieh, Hueih-Lirng,PhD., R.N., Mills, Mary Etta, ScD,R.N., C.N.A.A., \& Waltz, Carolyn F, PhD,R.N., F.A.A.N. (2001). Academic leadership style predictors for nursing faculty job satisfaction in taiwan. Journal of Nursing Education, 40, 203-9. Retrieved from http://ezproxy.fiu.edu/login?url=http://search.proquest.com.ezproxy.fiu.edu/docvi ew/203956548? accountid=10901

Shim, I., \& Paprock, K. (2002). A study focusing on American expatriates' learning in host countries. International Journal of Training and Development, 6, 13-24.

Skogstad, A., Einarsen, S., Torsheim, T., Aasland, M. S., \& Hetland, H. (2007). The destructiveness of laissez-faire leadership behavior. Journal of Occupational Health Psychology, 12, 80-92. http://dx.doi.org.ezproxy.fiu.edu/10.1037/10768998.12.1.80

Smith, P. C., Kendall, L., \& Hulin, C. L. (1969). The measurement of satisfaction in work and retirement: A strategy for the study of attitudes. Chicago, IL: Rand McNally.

Sik Cho, Y., \& Jung, J. Y. (2014). The verification of effective leadership style for TQM. The International Journal of Quality \& Reliability Management, 31, 822-840. Retrieved from http://ezproxy.fiu.edu/login?url=http://search.proquest.com.ezproxy.fiu.edu/docvi ew/1651699448? accountid=10901

Silva, M. R., \& Caetano, A. (2016). Organizational justice across cultures: A systematic review of four decades of research and some directions for the future. Social Justice Research, 29, 257-287. http://dx.doi.org.ezproxy.fiu.edu/10.1007/s11211016-0263-0 Retrieved from http://ezproxy.fiu.edu/login?url=https://searchproquest-com.ezproxy.fiu.edu/docview/1812614242? accountid=10901

Snodgrass, J., \& Shachar, M. (2008). Faculty perceptions of occupational therapy program directors' leadership styles and outcomes of leadership. Journal of Allied Health, 37, 225-235. 
Story, L., Butts C., Janie B, Bishop T., Sandra F., Green L., Lisa Y., \& Mattison, R.N. (2010). Innovative strategies for nursing education program evaluation. Journal of Nursing Education, 49(6), 351-4.

doi:http://dx.doi.org.ezproxy.fiu.edu/10.3928/01484834-20100217-07

Streiner, D. L., \& Norman, G. R. (1995). Health measurement scales: A practical guide to their development and use (2nd ed.). New York: Oxford University Press.

Sweeney, P., \& McFarlin, D. (2005). Using relative deprivation theory to explain satisfaction with income and pay level: A multi study examination. Academy of Management Journal, 34, 351-368.

Sobel, M. E. (1982). "Asymptotic confidence intervals for indirect effects in structural equation models". Sociological Methodology. doi:10.2307/270723.

Sparrowe, R. T. (1994). Empowerment in the hospitality industry: An exploration of antecedents and outcomes. Hospitality Research Journal, 17, 51-73. $10.1177 / 109634809401700306$

Taylor, C. M., Cornelius, C. J., \& Colvin, K. (2014). Visionary leadership and its relationship to organizational effectiveness. Leadership \& Organization Development Journal, 35, 566-583. doi:http://dx.doi.org.ezproxy.fiu.edu/10.1108/LODJ-10-2012-0130

The influence of transformational leadership and Organizational commitment on job satisfaction and Employee performance. International Journal of Innovation, Management and Technology, 3(5), 566.

doi:http://dx.doi.org/10.7763/IJIMT.2012.V3.299

Tracey, J. B., \& Hinkin, T. R. (1996). How transformational leaders lead in the hospitality industry. International Journal of Hospitality Management, 15, 165176. Retrieved from http://ezproxy.fiu.edu/login?url=http://search.proquest.com.ezproxy.fiu.edu/docvi ew/621026119?accountid=10901

Tracey, B., \& Hinkin, T. (1994). Transformational leaders in the hospitality industry. Cornell Hotel and Restaurant Administration Quarterly, 18, 265-279.

Trask, K. M., Rice, R. W., Anchors, S., \& Lilieholm, R. J. (2009). Management styles of lumber mill managers in the northern United States. Forest Products Journal, 59, 29-34. Retrieved from http://ezproxy.fiu.edu/login?url=http://search.proquest.com.ezproxy.fiu.edu/docvi ew/214623922? accountid=10901 
Tsang, E. W. (2001). Adjustment of mainland Chinese academics and students to Singapore. International Journal of Intercultural Relations, 25, 347-372.

Tsai, M., Cheng, C., \& Chang, Y. (2010). Drivers of hospitality industry employees' job satisfaction, organizational commitment and job performance. African Journal of Business Management, 4, 4118-4134. Retrieved from http://ezproxy.fiu.edu/login?url=http://search.proquest.com.ezproxy.fiu.edu/docvi ew/1663920942?accountid=10901

Thomas, K.W., \&Tymon, W.G. Jr (1994). Does empowerment always work: Understanding the role of intrinsic motivation and personal interpretation. Journal of Management Systems, 6, 1-13.

Tsang, N. K. F., Lee, L. Y., \& Qu, H. (2015). Service quality research on china's hospitality and tourism industry. International Journal of Contemporary Hospitality Management, 27, 473-497. Retrieved from http://ezproxy.fiu.edu/login?url=http://search.proquest.com.ezproxy.fiu.edu/docvi ew/1673703588?accountid=10901

Tu, M. C. (2006). Culture and job satisfaction: A comparative analysis between Taiwanese and Filipino caregivers working in Taiwan's long-term care industry (Order No. 3231213). Available from ABI/INFORM Collection; ProQuest Dissertations \& Theses A\&I; ProQuest Dissertations \& Theses Global. (304910825). Retrieved from http://ezproxy.fiu.edu/login?url=https://searchproquest-com.ezproxy.fiu.edu/docview/304910825 accountid=10901

Tung, R. (1987). Expatriate assignments: Enhancing success and minimizing failure. Academy of Management Executive, 1, 117-125.

United Nations Conference on Trade and Development. (2012). Development and Globalization: Facts and Figures 2012. New York City: United Nations.

United Nations Conference on Trade and Development. (2013). Inward and outward foreign direct investment flows, annual, 1970 to 2012. United Nations.

Usmani, S., \& Jamal, S. (2013). Impact of distributive justice, procedural justice, interactional justice, temporal justice, spatial justice on job satisfaction of banking employees. Review of Integrative Business and Economics Research, 2, 351-383. Retrieved from http://ezproxy.fiu.edu/login?url=http://search.proquest.com.ezproxy.fiu.edu/docvi ew/1514370924? accountid=10901

Varner, I. I., \& Palmer, T. M. (2003). Role of cultural self-knowledge in successful expatriation. Singapore Management Review, 1, 1-26. 
Van Saane, N., Sluiter, J. K., Verbeek, J. H. A. M., \& Frings-Dresen, M. (2003). Reliability and validity of instruments measuring job satisfaction--a systematic review. Occupational Medicine, 53, 191-200. Retrieved from http://ezproxy.fiu.edu/login?url=http://search.proquest.com.ezproxy.fiu.edu/docvi ew/195264362? accountid=10901

Van Heerden, A. C., Norris, S. A., Tollman, S. M., Stein, A. D., \& Richter, L. M. (2014). Field lessons from the delivery of questionnaires to young adults using mobile phones. Social Science Computer Review, 32, 105-112. doi:http://dx.doi.org.ezproxy.fiu.edu/10.1177/0894439313504537

Walumbwa, F. O., Orwa, B., Wang, P., \& Lawler, J. J. (2005). Transformational leadership, organizational commitment, and job satisfaction: A comparative study of Kenyan and U.S. financial firms. Human Resource Development Quarterly, 16, 235-256, http://dx.doi.org/10.1002/hrdq.1135.

Wang, X., Liao, J., Xia, D., \& Chang, T. (2010). The impact of organizational justice on work performance. International Journal of Manpower, 31, 660-677. doi:http://dx.doi.org.ezproxy.fiu.edu/10.1108/01437721011073364

Wang, Y., Yang, C., \& Wang, K. (2012). Comparing public and private employees' job satisfaction and turnover. Public Personnel Management, 41, 557-573. Retrieved from http://ezproxy.fiu.edu/login?url=http://search.proquest.com.ezproxy.fiu.edu/docvi ew/1664817570?accountid=10901

Wang, M., \& Russell, S. S. (2005). Measurement equivalence of the job descriptive index across chinese and american workers: Results from confirmatory factor analysis and item response theory. Educational and Psychological Measurement, 65, 709732. http://dx.doi.org.ezproxy.fiu.edu/10.1177/0013164404272494

Washington, R. R. (2007). Empirical relationships among servant, transformational, and transactional leadership: Similarities, differences, and correlations with job satisfaction and organizational commitment Retrieved from http://ezproxy.fiu.edu/login?url=http://search.proquest.com.ezproxy.fiu.edu/docvi ew/849435445?accountid=10901

Wernimont, P. F. (1966). Intrinsic and extrinsic factors in job satisfaction. Journal of Applied Psychology, 50, 41-50. doi:http://dx.doi.org.ezproxy.fiu.edu/10.1037/h0022938

Wesley, K. R. (2012). A motivated workforce: A mixed methods study of worker motivation at a Nebraska manufacturing company (Order No. 3546642). Available from ProQuest Dissertations \& Theses A\&I; ProQuest Dissertations \& Theses Global. (1266844546). Retrieved from 
http://ezproxy.fiu.edu/login?url=http://search.proquest.com.ezproxy.fiu.edu/docvi ew/1266844546? accountid=10901

Weiss, D.J., Dawis, R.V., England, G. W. \& Lofguist, L.H. (1967). Manual for the Minnesota satisfaction questionnaire work adjustment project. Industrial Relations Center, University of Minnesota. Retrieved from http://ezproxy.fiu.edu/login?url=http://search.proquest.com.ezproxy.fiu.edu/docvi ew/59373252? accountid=10901

Weiss, H. M. (2002). Deconstructing job satisfaction: Separating evaluations, beliefs and affective experiences. Human Resource Management Review, 12, 173-194. Retrieved from http://ezproxy.fiu.edu/login?url=http://search.proquest.com.ezproxy.fiu.edu/docvi ew/619845991? accountid=10901

Wong, C. Y. A. (2008). Leadership perceptions of staff in the context of the hotel industry in china (Order No. 3313063). Available from Accounting \& Tax Database; ProQuest Dissertations \& Theses A\&I; ProQuest Dissertations \& Theses Global. (304809230). Retrieved from http://ezproxy.fiu.edu/login?url=http://search.proquest.com.ezproxy.fiu.edu/docvi ew/304809230?accountid=10901

Wong, S. C., \& Li, J. S. (2015). Will hotel employees' perception of unethical managerial behavior affect their job satisfaction? International Journal of Contemporary Hospitality Management, 27, 853-877. Retrieved from http://ezproxy.fiu.edu/login?url=http://search.proquest.com.ezproxy.fiu.edu/docvi ew/1694512569?accountid=10901

Wong, V. C., \& Steiner, P. M. (2015). Methodological foundations for the empirical evaluation of non-experimental methods in field settings. 6, 145-186.Society for Research on Educational Effectiveness, Evanston, IL 60208. Retrieved from http://ezproxy.fiu.edu/login?url=http://search.proquest.com.ezproxy.fiu.edu/docvi ew/1871580321? accountid=10901

World Travel \& Tourism Council. (2014). Travel \& tourism economic impact 2014: China. World Travel \& Tourism Council.

Wooten, K. C., \& Cobb, A. T. (1999). Career development and organizational justice: Practice and research implications. Human Resource Development Quarterly, 10, 173-179. Retrieved from http://ezproxy.fiu.edu/login?url=https://search-proquestcom.ezproxy.fiu.edu/docview/234904687? accountid=10901

Xiaoyi, W., \& Chunben, W. (2008). The impact of organizational justice on employees' pay satisfaction, Work attitudes and performance in Chinese hotels. Journal of Human Resources In Hospitality \& Tourism, 7, 181-195. doi:10.1080/15332840802156923 
$\mathrm{Xu}, \mathrm{L}$. (2010). The exploration and further development of the structure and measurement of transformational leadership in china (Order No. 10439486). Available from ProQuest Dissertations \& Theses A\&I; ProQuest Dissertations \& Theses Global. (1869232287). Retrieved from http://ezproxy.fiu.edu/login?url=https://search-proquestcom.ezproxy.fiu.edu/docview/1869232287?accountid=10901

Yahaya, R., \& Ebrahim, F. (2016). Leadership styles and organizational commitment: Literature review. The Journal of Management Development, 35, 190-216. Retrieved from http://ezproxy.fiu.edu/login?url=http://search.proquest.com.ezproxy.fiu.edu/docvi ew/1767544209?accountid=10901

Yaghi, A., Goodman, D., Holton, E. F., \& Bates, R. A. (2008). Validation of the Learning Transformation System Inventory. A study in the public sector in Jordan. Journal of Occupational Health Psychology, 19, 93-104.

Yeager, S. J. (1981). Dimensionality of the JDI. American Management Journal, 24, 205-212.

Yin, N. (2018). The influencing outcomes of job engagement: An interpretation from the social exchange theory. International Journal of Productivity and Performance Management, 67(5), 873-889.

doi:http://dx.doi.org.ezproxy.fiu.edu/10.1108/IJPPM-03-2017-0054

Yu, L., \& Huat, G. (1995). Perceptions of management difficulty factors by expatriate hotel professionals in China. International Journal of Hospitality Management, $13,375-388$.

Yu, L., (1992). Hotel development and structures in China. International Journal of Hospitality Management, 11, 99-110.

Yu, R. (2010, October 26). Starwood, Hilton, Marriott, other hotels flock to China. USA Today.

Yuan, G., Jia, L., \& Zhao, J. (2016). Organizational identification moderates the impact of organizational justice on job satisfaction. Work, 54(1), 189.

doi:http://dx.doi.org.ezproxy.fiu.edu/10.3233/WOR-162271

You-De, D., You-Yu, D., Kuan-Yang, C., \& Hui-Chun, W. (2013). Transformational vs transactional leadership: Which is better? International Journal of Contemporary Hospitality Management, 25, 760-778. Retrieved from http://ezproxy.fiu.edu/login?url=http://search.proquest.com.ezproxy.fiu.edu/docvi ew/1398041966? accountid=10901 
Zehir, C., Akyuz, B., Eren, M. S., \& Turhan, G. (2013). The indirect effects of servant leadership behavior on organizational citizenship behavior and job performance: Organizational justice as a mediator. International Journal of Research in Business and Social Science, 2, 1-13. Retrieved from http://ezproxy.fiu.edu/login?url=http://search.proquest.com.ezproxy.fiu.edu/docvi ew/1503663718? accountid=10901

Zhan, L., Sun, Y., Wang, N., \& Zhang, X. (2016). Understanding the influence of social media on people's life satisfaction through two competing explanatory mechanisms. Aslib Journal of Information Management, 68, 347-361. Retrieved from http://ezproxy.fiu.edu/login?url=https://search-proquestcom.ezproxy.fiu.edu/docview/1790903598?accountid=10901

Zhang, H., \& Wu, E. (2004). Human resources issues facing the hotel and travel industry in China. International Journal of Contemporary Hospitality Management, 16, 424-428. 
Appendix

Survey Item English Version

Items for organizational justice scales (Niehoff \& Moorman, 1993)

1. Distributive Justice

1.1.My work schedule is fair.

1.2.I think that my level of pay is fair.

1.3.I consider my work load to be quite fair.

1.4.Overall, the rewards I receive here are quite fair.

1.5.I feel that my job responsibilities are fair.

2. Procedures justice

2.1.Job decisions are made by the expatriate manager in an unbiased manner.

2.2.My expatriate manager makes sure that all employee concerns are heard before job decisions are made.

2.3.To make job decisions, my general manager collects accurate and complete information.

2.4.My expatriate manager clarifies decisions and provides additional information when requested by employees.

2.5. All job decisions are applied consistently across all affected employees.

2.6. Employees are allowed to challenge decisions made by the expatriate manager.

3. Interactional justice

3.1. When decisions are made about my job, the expatriate manager treats me with kindness and consideration. 
3.2.When decisions are made about my job, the expatriate manager treats me with respect and dignity.

3.3. When decisions are made about my job, the expatriate manager is sensitive to my personal needs.

3.4. When decisions are made about my job, the expatriate manager deals with me in a truthful manner.

3.5.When decisions are made about my job, the expatriate manager shows concern for my rights as an employee.

3.6.Concerning decisions made about my job, the expatriate manager discusses the implications of the decisions with me.

3.7.The expatriate manager offers adequate justification for decisions made about my job.

3.8. When making decisions about my job, the expatriate manager offers explanations that make sense to me.

3.9. My expatriate manager explains very clearly any decision made about my job.

Items for Minnesota Satisfaction Questionnaire Short Form (Weiss et al., 1967)

1. Intrinsic Satisfaction

1.1. The chance to make use of my abilities

1.2. The feeling of accomplishment I get from the job

1.3. Being able to keep busy all the time

1.4. The chances for advancement on this job

1.5. My pay and the amount of work I do 
1.6. The way my co-workers get along with each other

1.7. The opportunity to try my own methods of doing the job

1.8. The chance to work alone on the job

1.9. The chance to do things for other people

1.10. The chance to be "somebody" in the community

2. Extrinsic Satisfaction

2.1.The opportunity to tell other people what to do

2.2.The way company policies are put into practice

2.3. Being able to do things that do not go against my conscience

2.4. The praise I get for doing a good job

2.5. The freedom to use my own judgment

2.6. The way a job provides for steady employment

2.7. The relationship between supervisors and employees

2.8. The competence of my supervisor in making decisions

2.9. The opportunity to do different things from time to time

2.10. The working conditions

Items for Multifactor Leadership Questionnaire Dimension (Rothfelder et al., 2012).

1. Idealized influence

1.1. My expatriate manager articulates a clear vision.

1.2. My expatriate manager sets a personal example and acts as a role model for me to follow. 
1.3. My expatriate manager talks to us about his or her most important values and beliefs.

1.4. My expatriate manager behaves in ways that are consistent with his or her expressed values.

1.5. My expatriate manager makes me proud to be associated with him or her.

1.6. I have complete faith in my supervisor.

2. Inspirational motivation

2.1. My expatriate manager talks and acts optimistically and enthusiastic.

2.2. My expatriate manager sets high standards for my work and insists on only the best performance.

2.3. My expatriate manager expresses his or her confidence that I will achieve my goals.

2.4. I feel motivated and inspired by my expatriate manager.

2.5. My expatriate manager provides meaning to my work.

2.6. I feel committed to organizational goals.

3. Intellectual stimulation

3.1. My expatriate manager challenges me to think about old problems in new ways.

3.2. My expatriate manager provides me with challenging roles.

3.3. My expatriate manager stimulates me to achieve individual and organizational goals.

3.4. My expatriate manager wants me to participate intellectually. 
3.5. My expatriate manager requires that I back up my opinions with good reasoning.

3.6. I feel free to openly communicate my ideas.

4. Individualized consideration

4.1. My expatriate manager helps me to develop my strengths.

4.2. My expatriate manager treats each of us as individuals with different needs, abilities and aspirations.

4.3. My expatriate manager finds out what I want and helps me to get it.

4.4. My expatriate manager always listens attentively.

4.5. My expatriate manager rather acts as a coach or mentor than my boss.

\section{Survey Items Chinese Version}

组织公平

1. 分配公平

1.1. 我的工作时间安排是合理的。

1.2. 我认为我的薪酬水平是公平的

1.3. 我认为给我安排的工作量是合理的

1.4. 总的来说, 我在这里获得的奖励是公平的

1.5. 我觉得我工作职责的安排是合理的

2. 流程公平

2.1. 外籍经理做的工作决策无偏见。

2.2. 外籍经理确保在做出工作决定之前听取所有员工的意见 
2.3. 外籍经理在做决策前, 会收集准确完整的信息

2.4. 如果员工需要, 外籍经理会把工作决定解释清楚并且提供相关的辅助 信息

2.5. 外籍经理对所有员工都一视同仁

2.6. 员工有机会对外籍经理制定的工作决策提出质疑或者意见

3. 互动公平

3.1. 在做出与我的工作相关的决策时, 外籍经理会以善意对待我并站在我 的角度替我考虑

3.2. 在做出与我的工作相关的决策时, 外籍经理尊重我并顾及我的尊严

3.3. 在做出与我的工作相关的决策时, 外籍经理对我的个人需求很敏感

3.4. 在做出与我的工作相关的决策时, 外籍经理对待我的态度非常真诚

3.5. 在做出与我的工作相关的决策时, 外籍经理会关注我作为员工的权 利

3.6. 在做出与我的工作相关的决策时, 外籍经理会与我讨论讨论决策将会 带来的影响

3.7. 外籍经理在做决定时, 会给出充分的理由和解释

3.8. 在做出与我的工作相关的决策时, 经理会给出我认为合理的解释。

3.9. 在做出与我的工作相关的决策时, 经理会把此决策的具体事项解释清 楚

员工满意度 
1. 内在满意度

1.1. 我有机会发挥自己的能力

1.2. 我从工作中得到了成就感

1.3. 我在工作期间不会有闲着没事干的时候。

1.4. 我有机会在这份工作上取得进步

1.5. 我很满意我的薪水和工作量

1.6. 我喜欢和同事相处的方式

1.7. 我有机会尝试以自己的方式和风格来工作

1.8. 我有机会独自完成工作

1.9. 我有机会为别人服务

1.10. 我有机会成为团队中的“重要角色”

2. 外在满意度

2.1. 我有机会指导别人该怎么做

2.2. 我喜欢公司政策付诸实践的方式

2.3. 我能不违背我的良心做事情

2.4. 如果工作出色, 我能够得到相应的表扬

2.5. 我有自由使用自己的判断来做决策

2.6. 我的工作很稳定

2.7. 我喜欢外籍经理和员工之间的关系

2.8. 外籍经理可以胜任他所在的职位 
2.9. 我的工作给予我尝试做不同事情的机会

2.10. 我喜欢我的工作环境与条件

领导力

1. 理想化的影响力

1.1. 外籍经理阐述了一个清晰的酒店未来发展的蓝图

1.2. 外籍经理能够以个人表率, 为我树立一个好榜样

1.3. 外籍经理告诉我们他或她最重要的价值观和信仰。

1.4. 外籍经理表现得与他或她表达的价值观一致。

1.5. 外籍经理让我感觉能与他/她做同事很自豪。

1.6. 我相信并且看好我的外籍经理

2. 鼓舞人心的动力

2.1. 外籍经理在言行中都能够透漏出乐观与热情

2.2. 外籍经理为我的工作设定了高标准并坚持要求我做到最好

2.3. 外籍经理表达了他对我实现目标的信心

2.4. 我感受到了外籍经理的激励和鼓舞

2.5. 外籍经理让我觉得工作更有意义

2.6. 我觉得我们致力于共同的目标。

3. 智力激励

3.1. 外籍经理挑战我以新的方式思考处理旧问题

3.2. 外籍经理为我提供了挑战性的角色 
3.3.外籍经理激励我实现个人和组织的目标。

3.4. 外籍经理鼓励在工作中献计献策

3.5. 外籍经理要求我要有充分的理由支持我自己的观点。

3.6. 我可以随意公开传达我的想法。

4. 个性化的考虑

4.1. 外籍经理帮助我发展自己的优势

4.2. 外籍经理将我们每个人都视为具有不同需求, 能力和愿望的个人。

4.3. 外籍经理了解我的需求后, 会尽力帮助我

4.4. 外籍经理总是认真倾听。

4.5. 外籍经理对于我不像是老板倒更像是一名教练或导师。 
VITA

\section{WEI DING}

\section{EDUCATION}

Miami, FL

2016 to Present

Miami, FL

2014 to 2016

Miami, FL

2014 to Present

Miami, FL

Miami, FL

2015

Miami, FL

2014

Miami, FL

2013 to 2014
F.I.U., Graduate Assistant

Working with different faculties on co-teach courses, grading assignment, and research

F.I.U. Office of Community Engagement, Graduate Assistant Assisting College of Education faculty in searching for external funding opportunity that will support their research Assist Assistant Dean in analyzing data Assist Office Manager in budgeting reviewing, grants charts updating

Assist high school students for their visits in College of Education

Florida International University, 3.92 GPA

Doctoral of Education in Adult Education and Human Resource Development

A Quantitative Study of Expatriate Hotel Managers in Mainland China: An Exploration of How Organizational Justice Influences Local Employee Job Satisfaction and Their Evaluation of Expatriate Manager Leadership Performance

Dissertation

- Selected as 2017 International Council on Hotel, Restaurant, and Institutional Education conference paper

Millennials in the Workplace: Positioning Companies for Future Success

Class Paper

- Selected as South Florida Education Research Conference paper

T.U.C.-F.I.U. 10 Year Anniversary, Alumni Representative Speaker

F.I.U. Institute for Hospitality and Tourism Education and Research, Program Assistant Assist program manager in developing program's Standard Operating Procedures manual, trainer guides, course descriptions, curriculum, and syllabus

Monitor and journal daily program activity and training sessions 
Miami, FL 2013

Miami, FL 2013

Miami, FL 2012-2013

Miami, FL 2012

Miami, FL 2012

Miami, FL 2012

Miami, FL 2011-2012

Miami, FL 2011-2012

Miami Beach, FL 2011-2012

Miami, FL 2011 to 2013
Organize and maintain project reports, surveys and all database records related to registration for each training session Develop a "Critical Path" outlining daily/weekly operational deadlines

Relay for Life, Student Organizer, Fundraiser and Volunteer

An Examination of Students' Preferences on Campus Life Programs in Chinese and U.S. Universities Master's Thesis

- Selected as a poster presentation for the 2013 Annual International Council on Hotel, Restaurant, and Institutional Education Summer Conference under the Education/Curriculum category

F.I.U. Chinese Hospitality Management Student Association, President

The Prevailing Factors and Entry Mode into Foreign Lodging Market by Chinese and Indian Hotel Firms Group Term Paper

- Selected as a poster presentations for the 17th Annual Graduate Research Conference in Hospitality and Tourism

Confucius Celebration and the Moon Festival, Student Organizer Lead student organizer; interacted with city and university officials to ensure community presence, booked location, and assisted operationally with program development

U.S. Campus Life Presentation of Chinese Delegation, Volunteer Presenter

F.I.U. International Student \& Scholar Services, Peer Mentor

F.I.U. International Students Club, Vice-President

Food Network South Beach Food and Wine Festival, Team Leader

Florida International University, 3.88 GPA

Master of Science in Hospitality Management; Eta Sigma Delta Honor Society 